\title{
Review \\ Zn Metal Anodes for Zn-Ion Batteries in Mild Aqueous Electrolytes: Challenges and Strategies
}

\author{
Vo Pham Hoang Huy ${ }^{\dagger}$, Luong Trung Hieu ${ }^{\dagger}$ and Jaehyun Hur * (1) \\ Department of Chemical and Biological Engineering, Gachon University, Seongnam 13120, Gyeonggi, Korea; \\ vophamhoanghuy@yahoo.com.vn (V.P.H.H.); LuongTrungHieu290694@gmail.com (L.T.H.) \\ * Correspondence: jhhur@gachon.ac.kr; Tel.: +82-31-750-5593; Fax: +82-31-750-8839 \\ + These authors contributed equally to this study.
}

Citation: Hoang Huy, V.P.; Hieu, L.T.; Hur, J. Zn Metal Anodes for Zn-Ion Batteries in Mild Aqueous

Electrolytes: Challenges and Strategies. Nanomaterials 2021, 11, 2746. https://doi.org/10.3390/ nano11102746

Academic Editor: Christophe Detavernier

Received: 28 September 2021

Accepted: 14 October 2021

Published: 17 October 2021

Publisher's Note: MDPI stays neutral with regard to jurisdictional claims in published maps and institutional affiliations.

Copyright: (c) 2021 by the authors. Licensee MDPI, Basel, Switzerland. This article is an open access article distributed under the terms and conditions of the Creative Commons Attribution (CC BY) license (https:/ / creativecommons.org/licenses/by/ $4.0 /)$.

\begin{abstract}
Over the past few years, rechargeable aqueous Zn-ion batteries have garnered significant interest as potential alternatives for lithium-ion batteries because of their low cost, high theoretical capacity, low redox potential, and environmentally friendliness. However, several constraints associated with $\mathrm{Zn}$ metal anodes, such as the growth of $\mathrm{Zn}$ dendrites, occurrence of side reactions, and hydrogen evolution during repeated stripping/plating processes result in poor cycling life and low Coulombic efficiency, which severely impede further advancements in this technology. Despite recent efforts and impressive breakthroughs, the origin of these fundamental obstacles remains unclear and no successful strategy that can address these issues has been developed yet to realize the practical applications of rechargeable aqueous $\mathrm{Zn}$-ion batteries. In this review, we have discussed various issues associated with the use of $\mathrm{Zn}$ metal anodes in mildly acidic aqueous electrolytes. Various strategies, including the shielding of the $\mathrm{Zn}$ surface, regulating the $\mathrm{Zn}$ deposition behavior, creating a uniform electric field, and controlling the surface energy of Zn metal anodes to repress the growth of $\mathrm{Zn}$ dendrites and the occurrence of side reactions, proposed to overcome the limitations of $\mathrm{Zn}$ metal anodes have also been discussed. Finally, the future perspectives of Zn anodes and possible design strategies for developing highly stable $\mathrm{Zn}$ anodes in mildly acidic aqueous environments have been discussed.
\end{abstract}

Keywords: Zn metal anode; aqueous Zn ion batteries; mildly acidic electrolyte; dendrite-free; hydrogen evolution reaction suppression

\section{Introduction}

Renewable energy supplies have drawn worldwide attention because of the scarcity of fossil fuels and the increasing global warming [1-3]. Nevertheless, renewable energy resources, such as solar, wind, and geothermal are interrupted by various climatic and natural factors; thus, grid-scale energy is a vital underpinning for the continued development of large-scale energy storage techniques, and secondary batteries are an indispensable choice for achieving this [4-6]. Since their successful commercialization in the 1980s, lithium-ion batteries (LIBs) have dominated the energy market and have been employed in various applications, from portable electronics to grid-scale energy storage systems [7-22]. Nevertheless, the growth of the LIB technology has been limited owing to its safety issues, limited Li supplies, and high intrinsic prices [23-26]. Sodium-ion batteries (SIBs) and potassiumion batteries (PIBs) have been intensively studied as alternatives to LIBs. However, SIBs and PIBs utilize volatile, flammable, and toxic organic electrolytes, which lead to safety and environmental issues [27-33]. Therefore, various efforts have been made to develop potential alternatives to these batteries that are suitable for grid-scale applications [34-37]

Aqueous batteries are very promising alternatives for LIBs, SIBs, and PIBs because aqueous electrolytes are inexpensive and environmentally friendly, and hence can alleviate the risk of fire hazards and explosions [38-42]. In addition, fast charging and high energy density can be achieved with aqueous batteries because water has considerably higher (by 
two to three orders of magnitude) ionic conductance (i.e., $\sim 1 \mathrm{~S} \mathrm{~cm}^{-1}$ ) than most organic solvents [43-45].

Among the various aqueous batteries investigated to date, aqueous $\mathrm{Zn}$ ion batteries (AZIBs) have recently emerged as a promising technology capable of satisfying today's stringent battery requirements. The use of $\mathrm{Zn}$ metal as an anode in aqueous media is a unique feature of these batteries that contributes to their excellent performance. First, as compared to monovalent metals, such as $\mathrm{Li}$ or $\mathrm{Na}, \mathrm{Zn}$ is not only readily available and cheap but is also known for its non-toxicity and chemical durability in aqueous systems [46]. Second, in mildly acidic electrolytes $(\mathrm{pH}=4-6)$, $\mathrm{Zn}$ oxidizes to $\mathrm{Zn}^{2+}$ without producing intermediate products and possesses a high overpotential for the hydrogen evolution reaction (HER) [47]. Third, given the relatively narrow operating window in which gas $\left(\mathrm{H}_{2}\right.$ and $\left.\mathrm{O}_{2}\right)$ formation can be prevented in water, $\mathrm{Zn}$ has a redox potential of $-0.76 \mathrm{~V}$ (vs. the typical hydrogen electrode), which is suitable for battery applications. Finally, in its metallic state, $\mathrm{Zn}$ has a high theoretical capacity $\left(820 \mathrm{mAh} \mathrm{g}^{-1}, 5854 \mathrm{mAh} \mathrm{L}^{-1}\right)[45,48,49]$. However, the practical applications of AZIBs are significantly hindered by the formation of Zn dendrites and the occurrence of side reactions (HER and corrosion) on the $\mathrm{Zn}$ anode. $\mathrm{Zn}$ dendrites can transpierce the battery separator, causing a short circuit, while the corrosion of the $\mathrm{Zn}$ metal anode results in irreversible electrolyte consumption and the generation of insoluble byproducts, increasing the electrode polarity and degrading the battery performance. On the other hand, the $\mathrm{H}_{2}$ gas produced from the electrochemical reaction elevates the internal pressure of the battery, causing safety hazards, as illustrated in Figure 1. As a result, in recent years, various efforts have been made to develop appropriate strategies to overcome the limitations associated with $\mathrm{Zn}$ metal anodes. Figure 2a highlights some representative reviews on $\mathrm{Zn}$ metal anodes published over the last three years [45,50-64]. Currently, AZIBs can be largely categorized into two types: those with alkaline electrolytes, normally $\mathrm{Zn}-\mathrm{Ag}$, Zn-air, and Zn-Ni batteries [65-67]. and those with mildly acidic electrolytes, such as $\mathrm{Zn}-\mathrm{MnO}_{2}$ and $\mathrm{Zn}-\mathrm{V}_{2} \mathrm{O}_{5}$ batteries (as shown in Figure 2b) [68,69]. Although $\mathrm{Zn}$-based batteries with alkaline electrolytes generally have higher energy densities than those with non-alkaline electrolytes, mildly acidic aqueous electrolytes can effectively inhibit the growth of $\mathrm{Zn}$ dendrites, thus improving the cyclic performance of the battery through highly reversible electrochemical plating/stripping of $\mathrm{Zn}^{2+}$ on the $\mathrm{Zn}$ anode. As shown in Figure 2c, the number of publications on aqueous electrolytes with mildly low $\mathrm{pH}$ has increased significantly year by year. However, comprehensive and systematic reviews on the challenges and strategies for the development of next-generation Zn metal anodes suitable for application in mildly acidic electrolytes are scarce. Therefore, it will be beneficial to review the recent studies on $\mathrm{Zn}$ metal anodes in mildly acidic electrolytes to provide guidelines for the development of high-performance AZIBs.

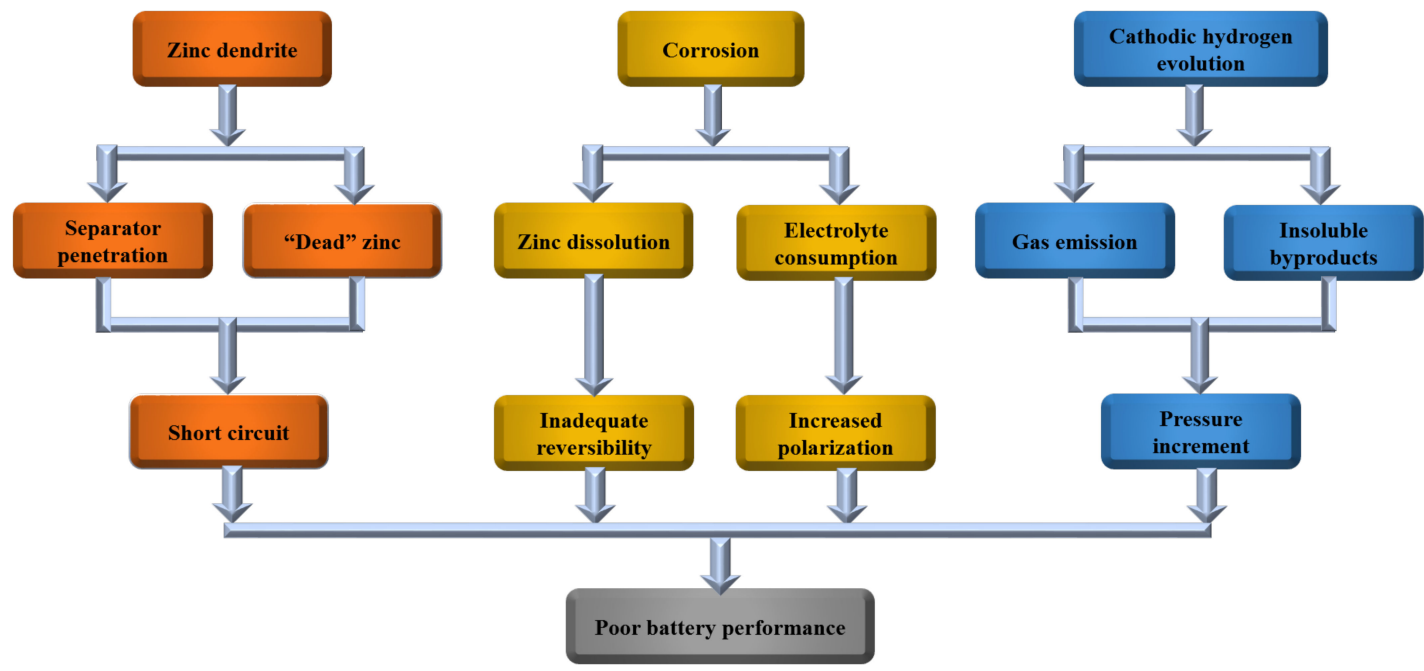

Figure 1. Major limitations of Zn metal anodes for battery applications. 
(a)

\section{9}

Challenges in $\mathrm{Zn}$ electrodes for alkaline zinc-air batteries commercialization ${ }^{63}$

Nanoscale design of $\mathrm{Zn}$ anodes for high-energy aqueous rechargeable batteries ${ }^{64}$

\section{0}

Aqueous $\mathrm{Zn}$ ion batteries: focus on zinc metal anodes $\mathbf{4 5}$

$>$ Issues and future perspective on $\mathrm{Zn}$ metal anode for rechargeable AZIBs ${ }^{\mathbf{5 0}}$

$>$ Recent advances in $\mathrm{Zn}$ anodes for high-performance aqueous $\mathrm{Zn}$-ion batteries $\mathbf{5 1}$

$>$ Principals and strategies for a highly reversible $\mathrm{Zn}$ metal anode in aqueous batteries $\mathbf{5 2}$

Issues and solution toward zinc anode in aqueous zinc-ion batteries: A mini review ${ }^{\mathbf{5 3}}$

$>$ Inhibition of zinc dendrite in Zn-based flow batteries ${ }^{\mathbf{5 4}}$

Challenges in the material and structural design of $\mathrm{Zn}$ anode towards AZIBs $\mathbf{5 5}$

Dendrite issues and advances in $\mathrm{Zn}$ anode for aqueous rechargeable $\mathrm{Zn}$-based batteries $5^{6}$

Understanding the $\mathrm{Zn}$ anode behavior and improvement strategies in different AZIBs ${ }^{\mathbf{5 7}}$

\section{1}

$\mathrm{Zn}$-ion batteries: strategies for the stabilization of $\mathrm{Zn}$ metal anodes $\mathbf{5 8}$

The strategies of boosting the performance of highly reversible zinc anode in ZIBs ${ }^{\mathbf{5 9}}$

Strategies towards the challenges of $\mathrm{Zn}$ metal anode in rechargeable AZIBs ${ }^{60}$

$>$ Controlling electrochemical growth of metallic $\mathrm{Zn}$ electrodes ${ }^{\mathbf{6 1}}$

$>$ The rising $\mathrm{Zn}$ anode for high-energy aqueous batteries ${ }^{\mathbf{6 2}}$

$>$ This work: Challenges and strategies towards $\mathrm{Zn}$ metal anode in mildly acidic aqueous electrolytes for $\mathrm{Zn}$-ion batteries

(b)

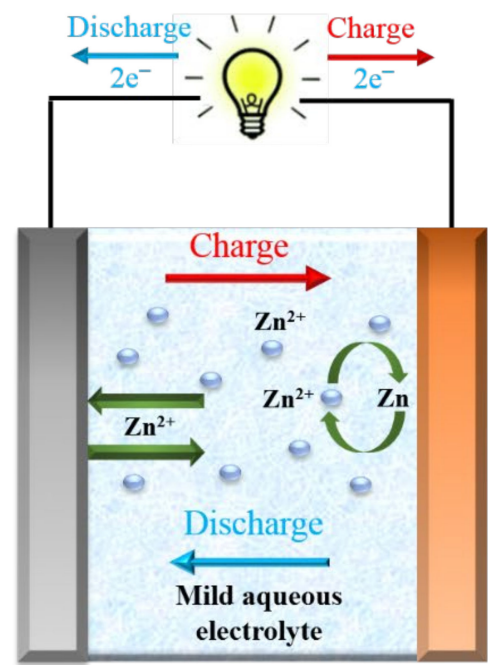

Cathode

Zn metal anode

(c)

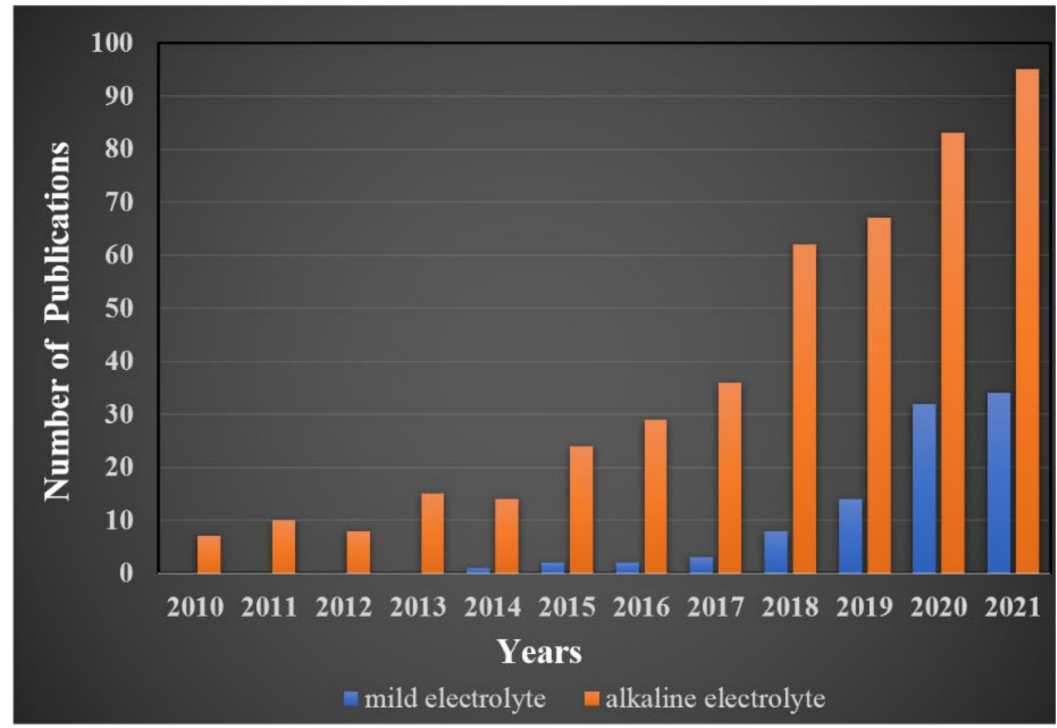

Figure 2. (a) Brief summary of recent reviews on Zn metal anodes for AZIBs [45,50-64], (b) a typical full cell battery configuration of AZIBs in a mildly acidic aqueous electrolyte. (c) The number of publications on AZIBs from 2010 to 2021 (search from Google Scholar; search time: 7 September 2021).

This review summarizes the strategies for the development of high-performance AZIB anode materials. First, the major limitations of zinc metal anodes are discussed followed by the approaches developed to overcome them. Finally, the future perspectives for next- 
generation AZIB research are discussed. This review will be beneficial for the rational design of $\mathrm{Zn}$ metal anodes in mildly acidic aqueous systems.

\section{Challenges in the Commercialization of Zn Metal Anodes \\ $\mathrm{Zn}$ Anode Reactions}

To date, various types of metal-ion aqueous rechargeable batteries $(\mathrm{M}=\mathrm{Li}, \mathrm{K}, \mathrm{Na}, \mathrm{Ca}$, $\mathrm{Zn}, \mathrm{Mg}, \mathrm{Al}$ ) operable in the $\mathrm{pH}$ range of 3-11 have been extensively investigated [70-72]. While most metals do not function properly in aqueous media because of their limited redox voltages, beyond which water becomes unstable, $\mathrm{Zn}$ exhibits advantages, such as a low redox potential ( $-0.76 \mathrm{~V}$ vs. the standard $\mathrm{H}_{2}$ evolution), high overpotential for the HER, and high theoretical capacity $\left(820 \mathrm{mAh} \mathrm{g}^{-1}, 5855 \mathrm{mAh} \mathrm{cm}^{3}\right)$, which make it suitable for application as a metal anode in aqueous systems $[57,73,74]$ (Figure 3a-c).

(a)

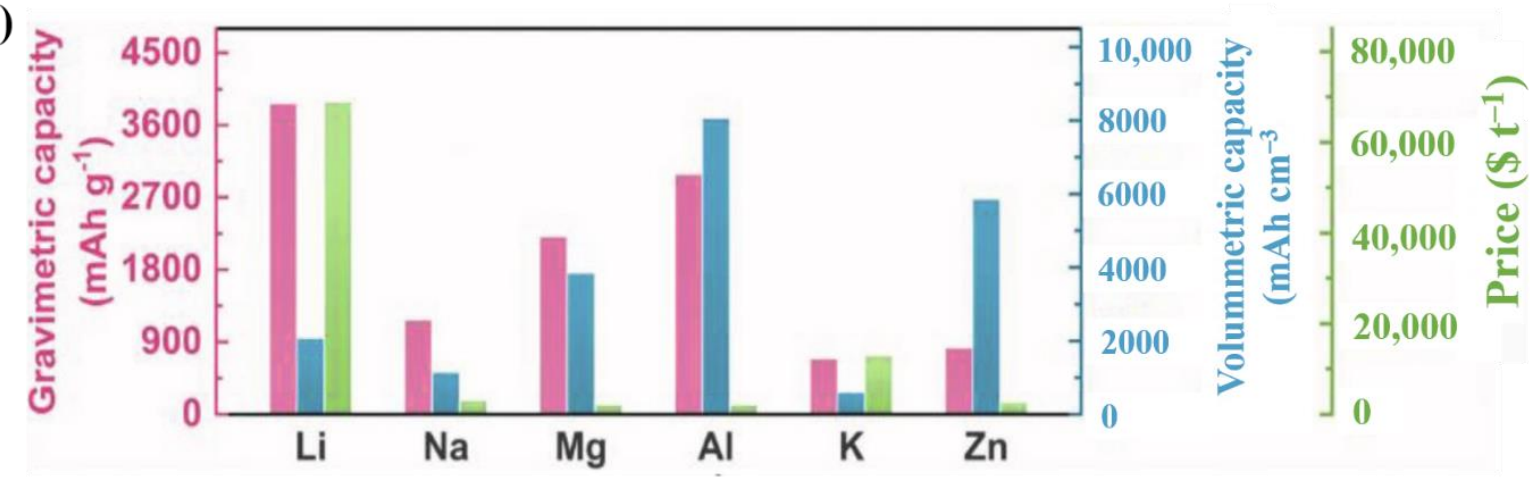

(b)

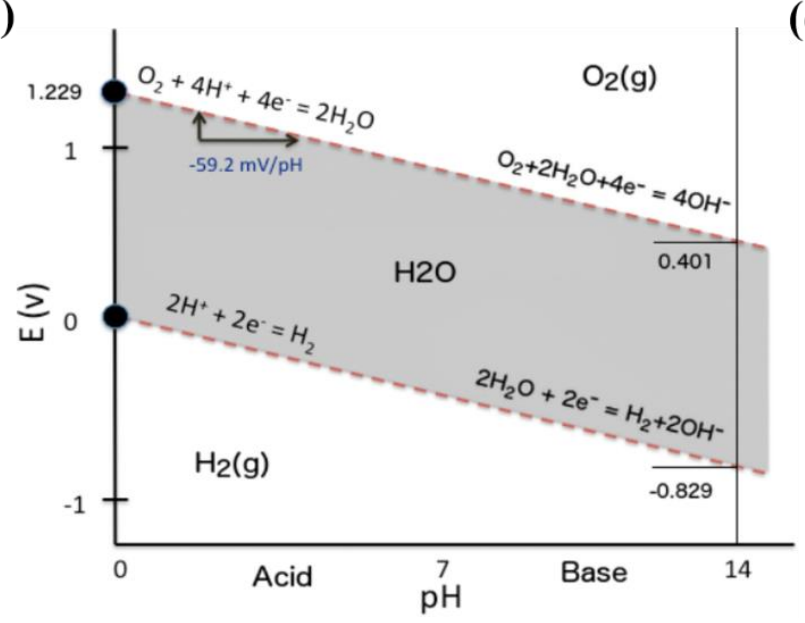

(c)

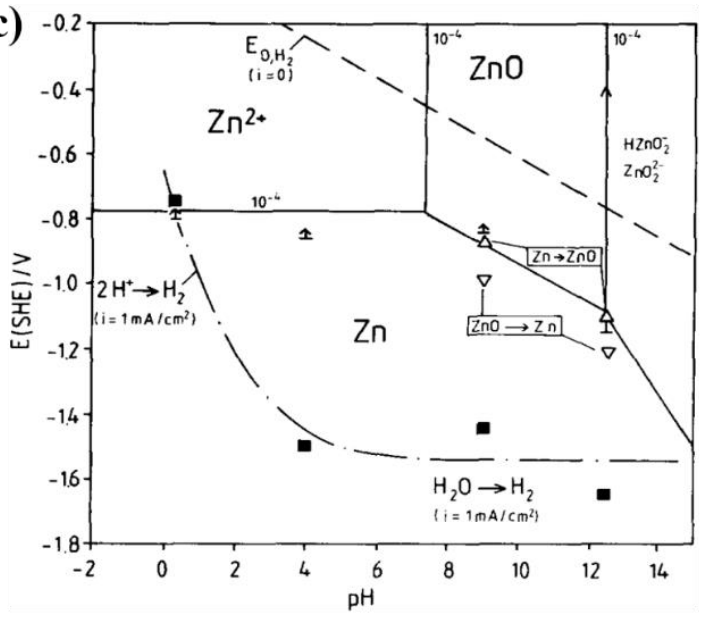

Figure 3. (a) Gravimetric capacity, volumetric capacity, and price of typical metal anodes. Reprinted with permission from Liang et al. [58]. Copyright 2021 Wiley-VCH GmbH. (b) Pourbaix diagram of water. Reprinted with permission from Zeng et al. [75]. Copyright 2019 Elsevier B.V. (c) Pourbaix diagram of the $\mathrm{Zn} / \mathrm{H}_{2} \mathrm{O}$ system with HER overpotential considerations. Reprinted with permission from Wippermann et al. [76]. Copyright 1990 Elsevier Ltd.

In AZIBs, the cathode reactions depend on the cathode material, whereas the $\mathrm{Zn}$ anode reactions are highly influenced by various electrolyte conditions. In alkaline media, $\mathrm{Zn}$ metal anodes oxidize to the zincate ion complex $\left(\mathrm{Zn}(\mathrm{OH})_{4}{ }^{2-}\right)$ because of the presence of numerous $\mathrm{OH}^{-}$ions in the surroundings [77]. When the concentration gradient changes, these zincate ions disperse away from the electrode surface, causing the loss of the active material. In addition, when the solubility of the zincate ions decreases locally, a passive $\mathrm{ZnO}$ layer is formed on the electrode surface [78]. This precipitate results in dendritic growth and/or passivation, which reduces the rechargeable capacity of the alkaline aqueous electrolyte battery. 
In mildly acidic aqueous media (virtually neutral media), the charge carrier is mainly $\mathrm{Zn}^{2+}$ owing to the lack of $\mathrm{OH}^{-}$. Unlike the case in alkaline systems, only $\mathrm{Zn}^{2+}$ ions are reversibly stripped/plated on the $\mathrm{Zn}$ metal anode surface during the battery operation in mildly acidic aqueous media, which is similar to the Li metal anode mechanism in LIBs. Despite this, Zn electrodes are highly reactive and induce many side reactions with the electrolyte, which results in low Coulombic efficiency (CE) and poor cycle life. Typically, highly reversible $\mathrm{Zn}$ plating/stripping is possible in mildly acidic aqueous electrolytes, such as $\mathrm{ZnSO}_{4}$ or $\mathrm{Zn}\left(\mathrm{CF}_{3} \mathrm{SO}_{3}\right)_{2}$. In these media, the reactions of the $\mathrm{Zn}$ metal anode occur as follows:

Discharge process:

$$
\mathrm{Zn} \rightarrow \mathrm{Zn}^{2+}+2 \mathrm{e}^{-} \text {(Zn stripping) }
$$

Charge process:

$$
\mathrm{Zn}^{2+}+2 \mathrm{e}^{-} \rightarrow \mathrm{Zn} \text { (Zn plating) }
$$

Figure 4 summarizes the common problems encountered in alkaline (Figure 4a) and mild-pH media (Figure 4b). Although some typical problems (e.g., shape change and $\mathrm{ZnO}$ passivation) encountered in alkaline electrolytes are not serious in mildly acidic electrolytes because of their different $\mathrm{Zn}$ electrode reaction mechanisms, the most common problems, such as dendrite growth and $\mathrm{H}_{2}$ evolution are the main reasons for the occurrence of irreversible reactions in $\mathrm{ZIBs}$, which reduces the $\mathrm{CE}$ of $\mathrm{Zn}$ electrodes and deteriorates their performance. In the following section, we will focus on these issues of $\mathrm{Zn}$ metal anodes in mildly acidic electrolyte systems.

\begin{tabular}{cc}
\hline $\mathbf{p H}>1$ & $3<\mathrm{pH}<7$ \\
$\mathrm{H}_{2} \mathrm{SO}_{4}$ & $\mathrm{ZnCl}_{2}, \mathrm{Zn}\left(\mathrm{NO}_{3}\right)_{2}, \mathrm{ZnSO}_{4}$ \\
& $\mathrm{Zn}\left(\mathrm{CF}_{3} \mathrm{SO}_{3}\right)_{2}, \mathrm{Zn}(\mathrm{TFSI})_{2}$
\end{tabular}

$$
\text { pH }<14
$$

LiOH, NaOH, KOH (a)

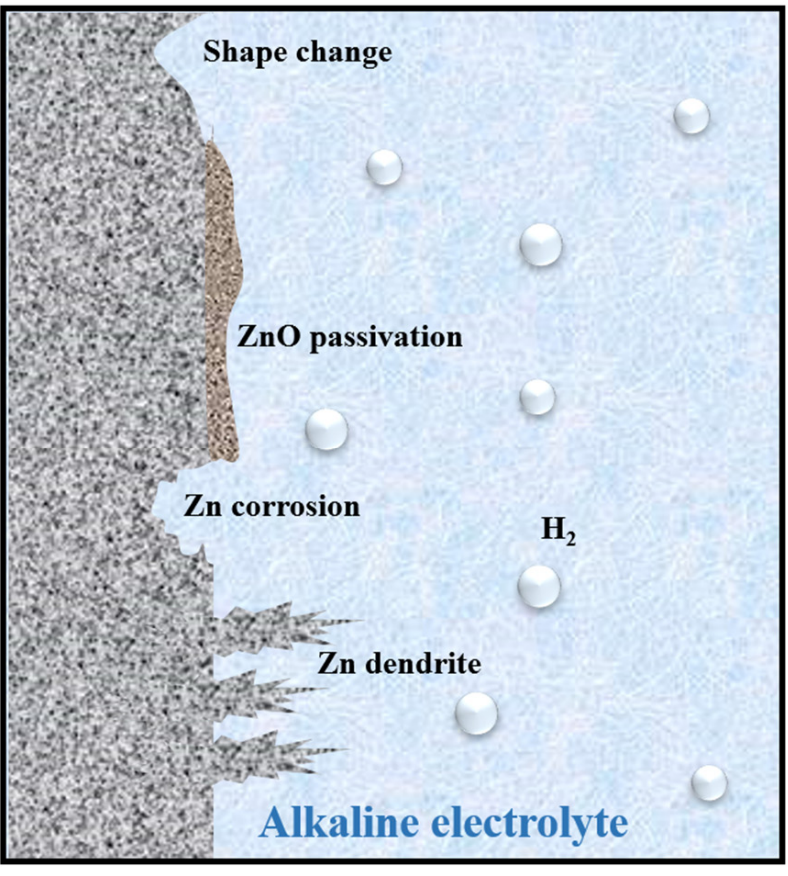

(b)

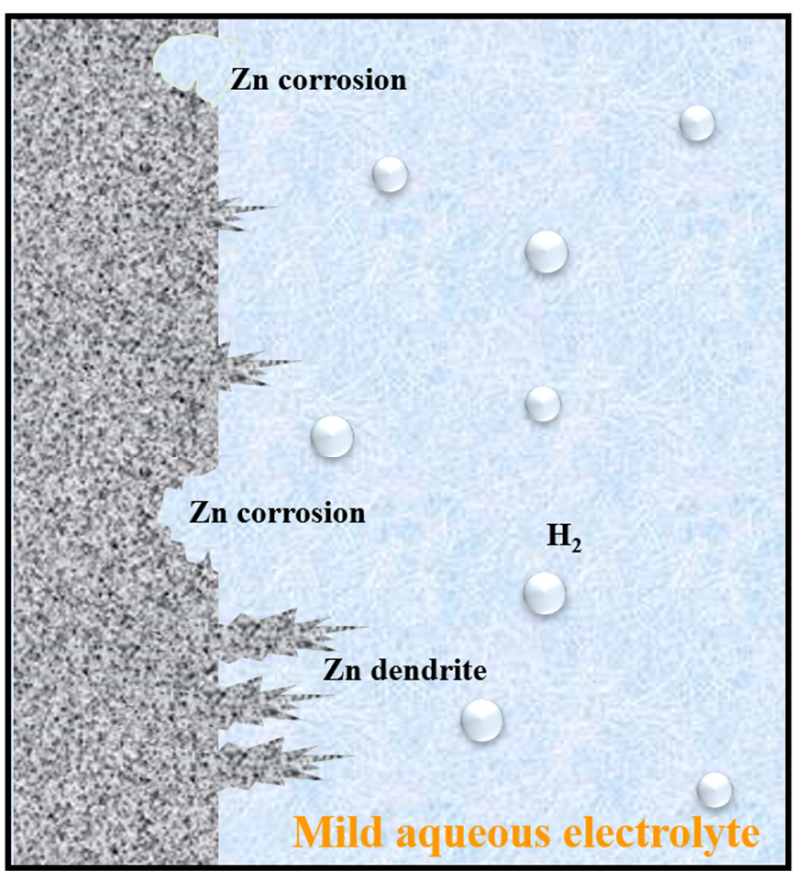

Figure 4. Schematic illustration of the phenomena observed on Zn electrodes in (a) alkaline and (b) mild aqueous electrolytes. 


\section{Assembly and Test Technology of Zn-Ion Batteries with Zn Metal Anodes 3.1. Cell Assembly}

A typical AZIB consists of the following components: Zn metal (anode), an aqueous electrolyte, a separator, and cathode material. Figure 5 and Table 1 show the list of components and typical materials used in the AZIB coin-cell. Because of its tunnel or layered structure which allows reversible insertion/extraction of $\mathrm{Zn}^{2+}$ ions, $\mathrm{MnO}_{2}$ has been extensively used as a cathode material in the early stages of mild aqueous ZIBs. Furthermore, manganese (Mn)-based oxides have been considered as promising energy storage materials due to their low cost, abundance, environmental friendliness, low toxicity, and numerous valence states $\left(\mathrm{Mn}^{0}, \mathrm{Mn}^{2+}, \mathrm{Mn}^{3+}, \mathrm{Mn}^{4+}\right.$, and $\left.\mathrm{Mn}^{7+}\right)[79,80]$. The cathode material is prepared as a slurry by mixing it with conductive carbon and polymer binder and dispersing it in the organic solvent. The slurry is cast on the current collector (typically, stainless steel) with a well-defined thickness using the doctor blade technique. The electrolyte, as a component in direct contact with the $\mathrm{Zn}$ anode and directing the plating/stripping process of $\mathrm{Zn}$, is critical to the electrochemical reversibility and stability of the $\mathrm{Zn}$ metal anode in AZIB systems. Currently, the $\mathrm{ZnSO}_{4}$ or $\mathrm{Zn}\left(\mathrm{CF}_{3} \mathrm{SO}_{3}\right)_{2}$ salt-based electrolytes are considered to be promising electrolytes in mild AZIBs [57]. Although a commercial Zn foil has been widely adopted as an anode and directly used as a current collector in most ZIBs, electrodeposited Zn electrodes on appropriate current collectors can also be the $\mathrm{Zn}$ metal anodes. The selection of the current collector is of great importance for the deposited Zn electrode; carbon-based, copper-based, and MOF-based current collectors have been widely used to support $\mathrm{Zn}$, owing to their great chemical and electrochemical stability in various electrolytes, robust mechanical strength to accommodate deposition, high electrical conductivity, and close affinity for Zn [81].

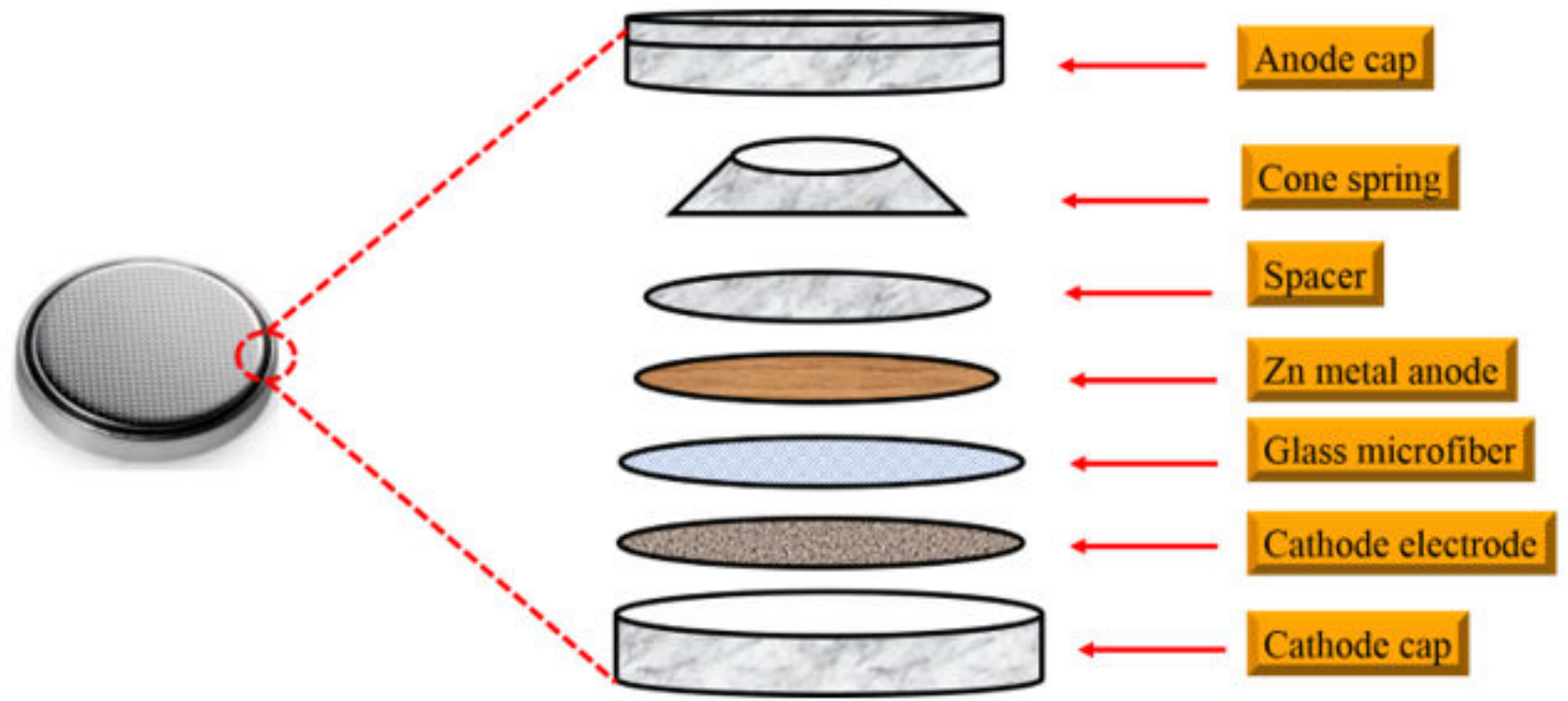

Figure 5. Components of the AZIB in coin cell assembly.

Table 1. List of components used in the typical coin-cell assembly of the ZIB with Zn metal anode [82].

\begin{tabular}{cc}
\hline Components & Representative Material \\
\hline Anode material & $\mathrm{Zn}$ foil $(80.0 \mathrm{~mm}$ in diameter, 0.25 mm in thickness $)$ \\
Cathode material & $\alpha-\mathrm{MnO}_{2}, \beta-\mathrm{MnO}_{2}, \mathrm{~V}$-based materials, Prussian blue analogues \\
Cathode current collector & Stainless steel spring (15.4 mm in diameter and 1.1 mm in thickness) \\
Separator & Whatman glass fiber filter \\
Electrolyte & $2 \mathrm{M} \mathrm{ZnSO}_{4}$ with $0.1 \mathrm{M} \mathrm{MnSO}_{4}$ \\
\hline
\end{tabular}




\subsection{Cell Test}

In AZIBs, the cell tests are typically performed with symmetric and full cell configuration. In evaluating the symmetrical cell performance, two identical electrodes ( $\mathrm{Zn} / \mathrm{Zn}$ ) are used to investigate the coulombic efficiency (CE) and degree of polarization as a function of cycle number. $\mathrm{CE}$ is one of the important parameters to quantify the reversibility of an electrochemical system. The tendency of $\mathrm{CE}$ can be a useful tool in accurately predicting cycle life and the reversibility of $\mathrm{Zn}$ deposition/stripping, which is calculated based on the capacity ratio of stripping to plating. In $\mathrm{Zn} / \mathrm{Zn}$ symmetric cells, there are three key parameters: cycle life, current density, and cycling capacity, which can provide a comprehensive picture of the electrochemical performance of symmetric batteries. Figure 6 is an example of evaluating a material's effectiveness through the symmetric cell test [83]. The stripping/plating stability and polarization of electrodes were evaluated at various current densities and cycling capacities with the symmetric cell test. For example, Yu et al. demonstrated the enhanced cycling stability of a $\mathrm{Zn}$ metal anode by using a Sn-coated separator. It was shown that a $\mathrm{Zn} / \mathrm{Zn}$ symmetric cell with Sn-coated separator exhibits a dramatically improved cycle life of $3800 \mathrm{~h}$ (current density: $2 \mathrm{~mA} \mathrm{~cm}^{-2}$, cycling capacity: $2 \mathrm{mAh} \mathrm{cm}{ }^{-2}$ ), $1000 \mathrm{~h}$ (current density: $5 \mathrm{~mA} \mathrm{~cm}^{-2}$, cycling capacity: $5 \mathrm{mAh} \mathrm{cm}^{-2}$ ) (Figure $6 \mathrm{a}, \mathrm{b}$ ). Furthermore, a highly reversible stripping/plating reversibility was achieved with a CE of $\sim 99 \%$ at $0.3 \mathrm{~A} \mathrm{~g}^{-1}$ after 600 cycles for the Sn-coated separator (Figure 6c).
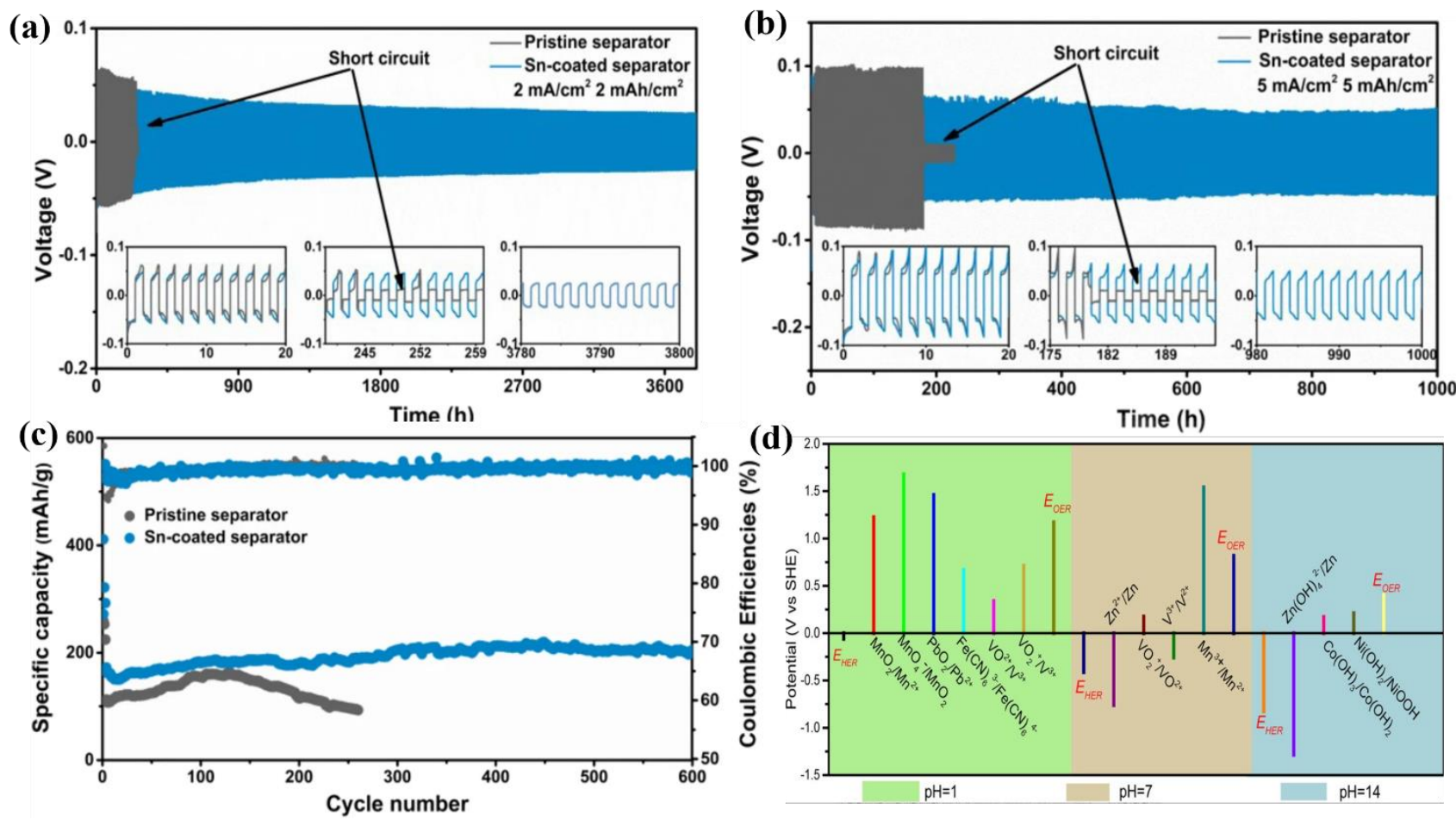

Figure 6. Cycling performance of $\mathrm{Zn} / \mathrm{Zn}$ symmetric cells tested at (a) $2 \mathrm{~mA} \mathrm{~cm}^{-2}$ and $2 \mathrm{mAh} \mathrm{cm}^{-2}$, (b) $5 \mathrm{~mA} \mathrm{~cm}^{-2}$ and $5 \mathrm{mAh} \mathrm{cm}^{-2}$, (c) cycling performance at $0.3 \mathrm{~A} \mathrm{~g}^{-1}$. Reprinted with permission from Zhen et al. [83]. (d) The standard potentials of redox couple in some reported cathode materials in ZIB systems. Reprinted with permission from [84]. Copyright 2021 Wiley-VCH GmbH.

In a full cell measurement, two different materials are used for cathode and anode which determines the voltage range that can be applied. In most cases, the practical output voltage of AZIBs cannot be fully in agreement with the theoretical voltage range. Theoretically, the maximum output voltage can be easily obtained by choosing a strong oxidizer for the cathode and a strong reducing agent for the anode, respectively. However, for AZIBs with $\mathrm{Zn}$ metal anode, the electrode potential is fixed $(-0.76 \mathrm{~V}$ vs. SHE in a neutral or acidic solution, $1.23 \mathrm{~V}$ vs. SHE in an alkaline solution). Thus, the key to 
constructing high-voltage AZBs is to choose a suitable cathode material that has a lower electrode potential than Zn metal [84]. Figure 6d shows the standard potentials of redox couples in some reported cathode materials. For instance, $\mathrm{Zn} / / \mathrm{MnO}_{2}$ batteries in a mild electrolyte deliver an output voltage that is below $1.5 \mathrm{~V}$ (vs. $\mathrm{Zn} / \mathrm{Zn}^{2+}$ ). The practical energy density, power density, and energy efficiency of the cell can be estimated from the full cell configuration.

\section{Drawbacks of Zn Metal Anodes in Mildly Acidic Electrolytes}

\subsection{Zn Dendrite Growth}

In AZIBs with mild aqueous electrolytes, the formation and growth of $\mathrm{Zn}$ dendrites within the battery is a major issue. The term " $\mathrm{Zn}$ dendrite" refers to a wide range of $\mathrm{Zn}$ morphologies with sharp ends or edges that pierce the separator and eventually lead to a short circuit and the breakdown of the cell. When $\mathrm{Zn}$ dendrites detach from an electrode, "dead" or "orphaned" Zn is easily generated, leading to a quick drop in the CE of the battery and an irreversible drop in its capacity. The $\mathrm{Zn}^{2+}$ concentration gradient in the proximity of the electrode surface influences the formation of $\mathrm{Zn}$ dendrites in a mildly acidic electrolyte. Zn ions diffuse on the electrode surface and accumulate easily on the nucleation sites, forming an initial protrusion. This further exacerbates the unequal electric field distribution, causing more $\mathrm{Zn}$ ions to be collected and the growth of dendrites over time via repeated plating/stripping at the anode. This inhomogeneous $\mathrm{Zn}^{2+}$ deposition directly affects the development of $\mathrm{Zn}$ dendrites $[53,85]$. Figure 7 a shows the free energy diagram of the $\mathrm{Zn}$ reduction process, where $\mathrm{Zn}$ ions must overcome a nucleation energy barrier to reach a new solid stage. After the nucleation, $\mathrm{Zn}$ tends to be plated and accumulated in the pre-deposited region owing to the combined actions of the electric field and concentration gradient $[86,87]$. Figure $7 \mathrm{~b}$ shows the voltage profile during the $\mathrm{Zn}$ deposition process. The difference between the potential minima and the subsequent stable potential, which indicates the thermodynamic cost of establishing a crucial atom cluster, is known as the nucleation overpotential, whereas the plateau overpotential is related to the $\mathrm{Zn}$ growth after the initial nucleation $[88,89]$. The lower the value of these two parameters, the better is the progress of the nucleation and growth processes (with low energy consumption). In addition, the electric field, ion concentration, and surface energy all influence the $\mathrm{Zn}$ nucleation. The "tip effect" causes $\mathrm{Zn}^{2+}$ to be concentrated in the protruded regions with high surface energy because the electric field at these points is substantially higher than those in the remaining areas. As a result, the $\mathrm{Zn}$ nucleation and growth are inclined to occur at such points. The "tip effect" leads to an uneven distribution of the electric field intensity at the surface of the electrode, a non-uniform ion concentration distribution, and the preferential deposition of $\mathrm{Zn}$ at locations with higher $\mathrm{Zn}^{2+}$ concentrations (Figure $7 \mathrm{c}, \mathrm{d}$ ). It is obvious that the $\mathrm{Zn}^{2+}$ concentration is high in a region with a high electric field where dendrites are easily formed [90]. While Zn dendrites are homogeneously formed at surfaces with high surface energies, which can minimize the nucleation barriers by generating a large number of nucleation sites, irregular $\mathrm{Zn}$ dendrites are formed at the surfaces with a large number of nucleation barriers because of the unequal distribution of the electric field or a small number of nucleation sites [53,58,91].

Kang et al. proposed an intriguing concept concerning the dimensions and distribution of pores in the coating material, which influences the evolution of $\mathrm{Zn}$ protrusions/dendrites, to understand the formation of $\mathrm{Zn}$ dendrites [92]. They proposed that the dimensions and dispensation of pores in a filter paper resemble those of the immense protuberances on cycled $\mathrm{Zn}$ foils (Figure 8a,b vs. Figure 8c,d). Therefore, a study with a filter paper can provide an understanding of the stripping/plating behavior of $\mathrm{Zn}^{2+}$ on $\mathrm{Zn}$ metal anodes. During cycling, the pores in a filter paper (an example of a porous coating material) behave similarly to the holes in water-permeable bricks (Figure 8e), forming a region highly active for $\mathrm{Zn}$ stripping/plating. As the number of cycles increases, additional Zn accumulates on the $\mathrm{Zn}$ metal surface, which makes contact with the porous regions in the coating material and generates a large number of protrusions, affecting the efficiency of the $\mathrm{Zn}^{2+}$ 
stripping/plating processes in diverse ways. First, the separator with uneven voids (such as filter paper) kinetically deteriorates the electrochemical performance of $\mathrm{Zn}$ anodes by limiting the local electrolyte transport. Second, the effect of the composition of the filter paper pores on the $\mathrm{Zn}$ dendrite evolution is pore dimension dependent; that is, a tiny pore promotes the development of small protrusions/dendrites. As a result, the dimensional characteristics of the pores in the covering material are important for regulating the $\mathrm{Zn}$ dendrite formation.

(a)

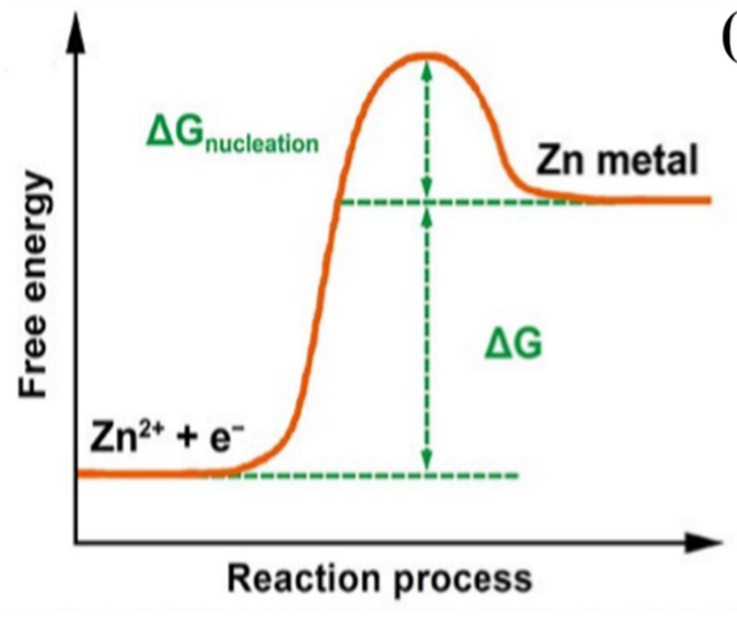

(b)

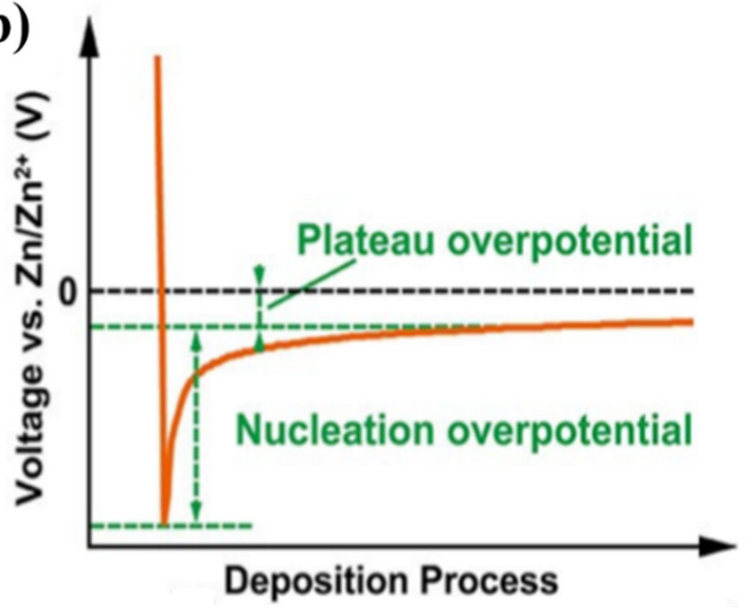

um

(c)
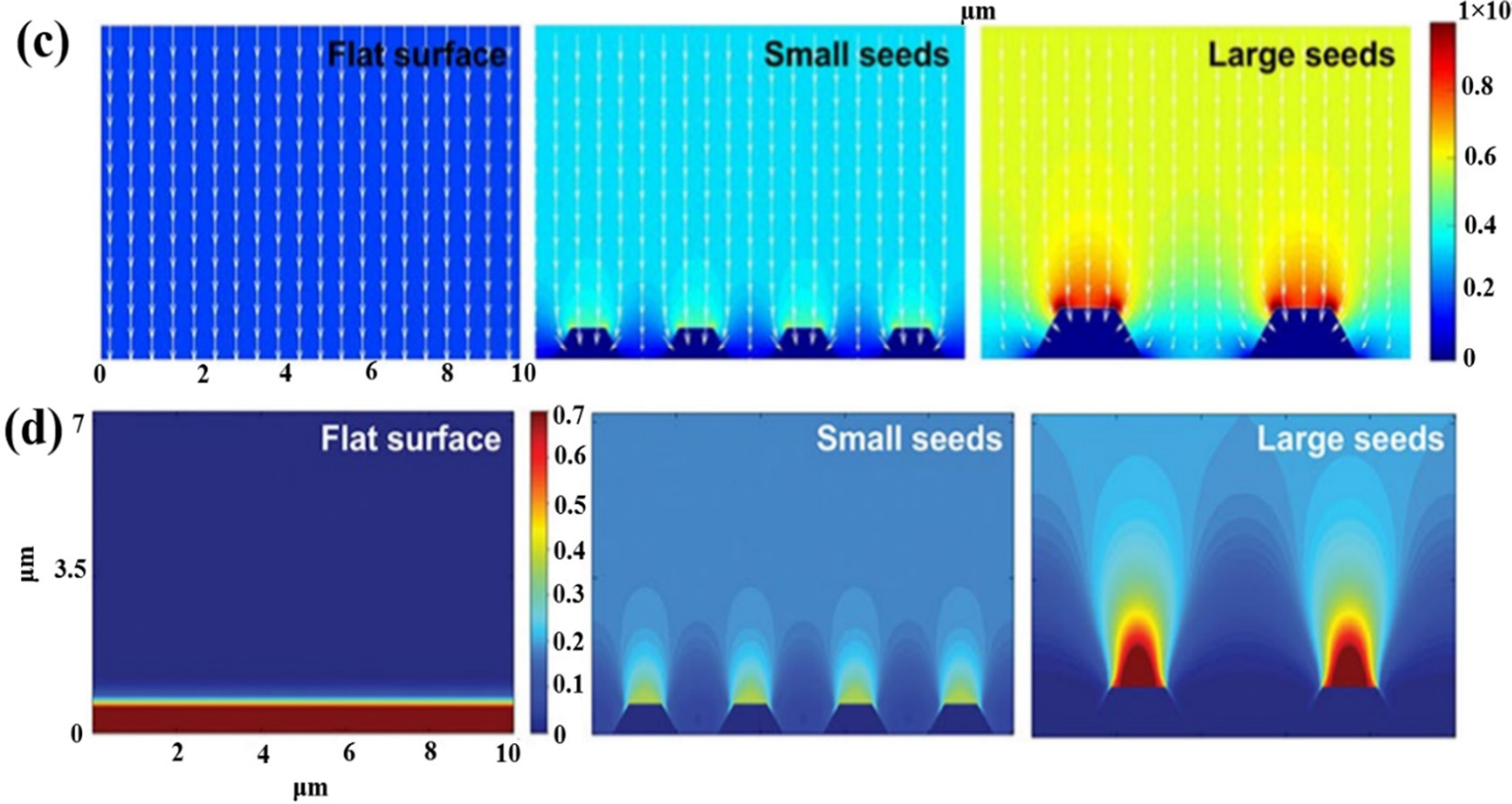

Figure 7. (a) Energy barrier for the Zn nucleation process, (b) voltage profile during Zn deposition. Reprinted with permission from Pei et al. [87]. Copyright 2017 American Chemical Society. Simulation of (c) electric field and (d) ion distribution on the $\mathrm{Zn}$ anode surface under different dendrite formation conditions: flat surface, small dendritic seeds, and large dendritic seeds. Reprinted with permission from [90]. Copyright 2019 WILEY-VCH Verlag GmbH\&Co. KgaA, Weinheim. 
(a)

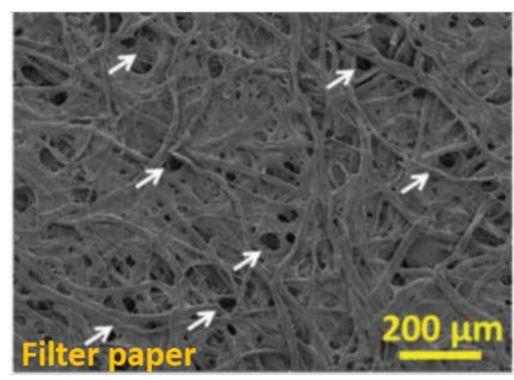

(c)

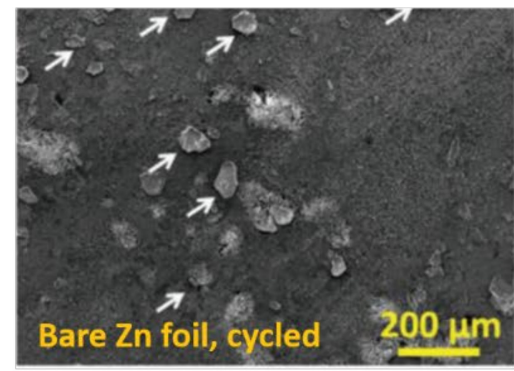

(b)

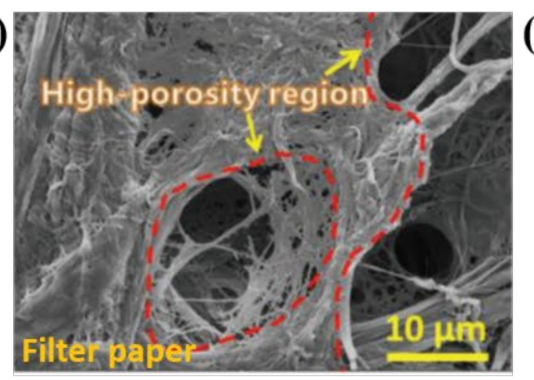

(d)

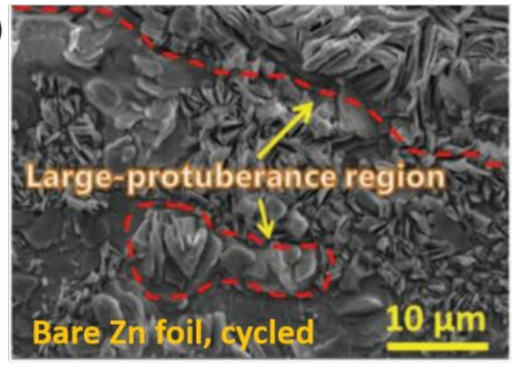

(e)

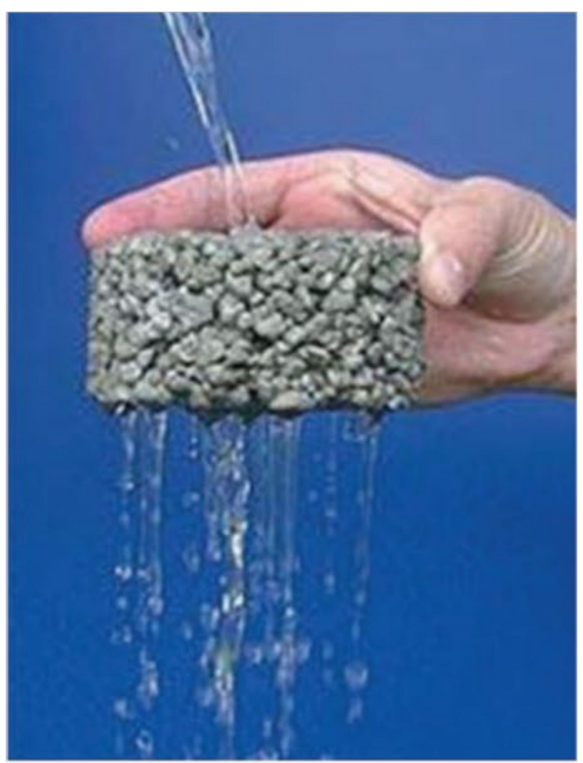

Figure 8. SEM images of $(\mathbf{a}, \mathbf{b})$ a fresh filter paper, and (c,d) a cycled bare Zn foil. The pores in filter papers act as "highways" for electrolyte transport, like the (e) pores in water-permeable bricks. Reprinted with permission from [92]. Copyright 2018 WILEY-VCH Verlag GmbH\&Co. KgaA, Weinheim.

\subsection{Zn Electrode Corrosion}

Owing to its amphoteric nature, $\mathrm{Zn}$ can react with $\mathrm{OH}^{-}$and $\mathrm{H}^{+}$ions. The presence of a considerable number of $\mathrm{OH}^{-}$species in alkaline electrolytes deteriorates the performance of $\mathrm{Zn}$ anodes by forming $\mathrm{Zn}(\mathrm{OH})_{4}{ }^{2-}$ or $\mathrm{ZnO}$ by-products. On the other hand, electrolytes with mildly low $\mathrm{pH}$ can limit the occurrence of such unfavorable reactions because of the presence of modest amounts of $\mathrm{H}^{+}$species [93]. According to the Pourbaix diagram, although $\mathrm{Zn}$ metal is thermodynamically stable over a wide $\mathrm{pH}$ range in mild aqueous media, the corrosion caused by free water should still be considered [94]. Unlike the case of Li metal batteries, in which the solid electrolyte interface (SEI) prevents the excessive consumption of Li metal, in AZIBs, $\mathrm{Zn}$ deposition is hampered by $\mathrm{H}_{2}$ evolution, leading to severe $\mathrm{Zn}$ metal corrosion. When the corrosion process continues, the $\mathrm{Zn}$ anode surface becomes more uneven and unsafe because of the increased pressure inside the cell. A recent study demonstrated that some $\mathrm{Zn}$ salts (e.g., $\mathrm{Zn}\left(\mathrm{NO}_{3}\right)_{2}$ and $\left.\mathrm{Zn}\left(\mathrm{ClO}_{4}\right)_{2}\right)$ may play a negative role in the $\mathrm{Zn}$ corrosion reaction [95]. For example, in the early stages of corrosion in a neutral electrolyte, a strong oxidizing agent with $\mathrm{NO}_{3}{ }^{-}$anions leads to the corrosion of the $\mathrm{Zn}$ foil and cathode materials. Although $\mathrm{Zn}\left(\mathrm{ClO}_{4}\right)_{2}$ with $\mathrm{ClO}_{4}{ }^{2-}$ having four $\mathrm{O}$ atoms and one $\mathrm{Cl}$ atom located at the corners and center of the tetrahedral structure, respectively, shows low reactivity, it requires an excessive operational voltage, which leads to slow reaction kinetics because of the formation of by-products [96]. Zinc halides (e.g., $\mathrm{ZnCl}_{2}$ and $\mathrm{ZnF}_{2}$ ) have been widely studied as Zn-based electrolytes owing to their poor oxidative properties [97]. However, there are certain disadvantages of these electrolytes: (i) the utilization of the $\mathrm{ZnF}_{2}$ electrolyte is limited by its low water solubility; (ii) although $\mathrm{ZnCl}_{2}$ is highly soluble in water, it has a narrow stable potential window for the occurrence of anodic electrochemical reactions without any side reactions, which limits its application in AZIBs. On the other hand, $\mathrm{ZnSO}_{4}$ has been extensively employed as an electrolyte for AZIBs because of its low cost, good solubility, wide potential window, and mild $\mathrm{pH}$ in water. Furthermore, in such mild $\mathrm{ZnSO}_{4}$ electrolytes, $\mathrm{Zn}$ anodes exhibit excellent dissolution/deposition reaction dynamics, little dendritic development, and moderate corrosion [98-100]. Nevertheless, the exact electrochemical reaction mechanism of $\mathrm{Zn}$ metal anodes in $\mathrm{ZnSO}_{4}$ electrolytes is not known yet, partly because of the formation of $\mathrm{Zn}_{4}(\mathrm{OH})_{6} \mathrm{SO}_{4} \mathrm{nH}_{2} \mathrm{O}$ (ZHS). It is believed 
that the $\mathrm{pH}$ fluctuations of the electrolytes throughout the discharge process are normally regulated by ZHS according to the following reaction.

$$
4 \mathrm{Zn}^{2+}+\mathrm{SO}_{4}{ }^{2-}+6 \mathrm{OH}^{-}+5 \mathrm{H}_{2} \mathrm{O} \rightarrow \mathrm{Zn}_{4}(\mathrm{OH})_{6}\left(\mathrm{SO}_{4}\right) \cdot 5 \mathrm{H}_{2} \mathrm{O}
$$

These by-products are formed by prolonged electrolysis and $\mathrm{Zn}$ ion consumption, which generally reduces the plating/stripping CE of the Zn anode to some extent [13]. As a result, extra $\mathrm{Zn}$ is required to ensure continuous cycling to prevent the $\mathrm{Zn}$ anode from reaching its maximum theoretical capability. Furthermore, the inert by-products deposited on the $\mathrm{Zn}$ surface obstruct the ion transfer and reduce the reversibility of the $\mathrm{Zn}$ anode.

Recently, Cai et al. studied the corrosion process of $\mathrm{Zn}$ metal anodes in $\mathrm{ZnSO}_{4}$ electrolysis [101]. They found that the corrosion of the $\mathrm{Zn}$ metal anode started from the surface layer, leading to the formation of $\mathrm{Zn}_{4}(\mathrm{OH})_{6} \mathrm{SO}_{4}$, followed by $\mathrm{H}_{2}$ evolution. Subsequently, $\mathrm{Zn}_{4}(\mathrm{OH})_{6} \mathrm{SO}_{4}$ is further hydrated and converted into $\mathrm{Zn}_{4}(\mathrm{OH})_{6} \mathrm{SO}_{4} \cdot 5 \mathrm{H}_{2} \mathrm{O}$, leading to the considerable corrosion of the $\mathrm{Zn}$ metal anode (Figure $9 \mathrm{a}-\mathrm{c}$ ). In this way, the $\mathrm{Zn}$ metal surface could not be passivated, and the corrosion proceeded until the liquid electrolyte or active $\mathrm{Zn}$ metal was completely consumed. Notably, the corrosion process continued until an uneven corrosion depth of $132.2 \mu \mathrm{m}$ was achieved (Figure 9d), which could be clearly detected by the $\mathrm{O}$ atom signal in the energy-dispersive $\mathrm{X}$-ray spectroscopy (EDS) elemental mapping image.

(a)

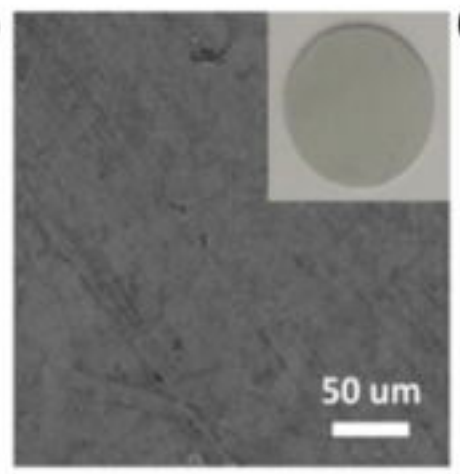

(c)

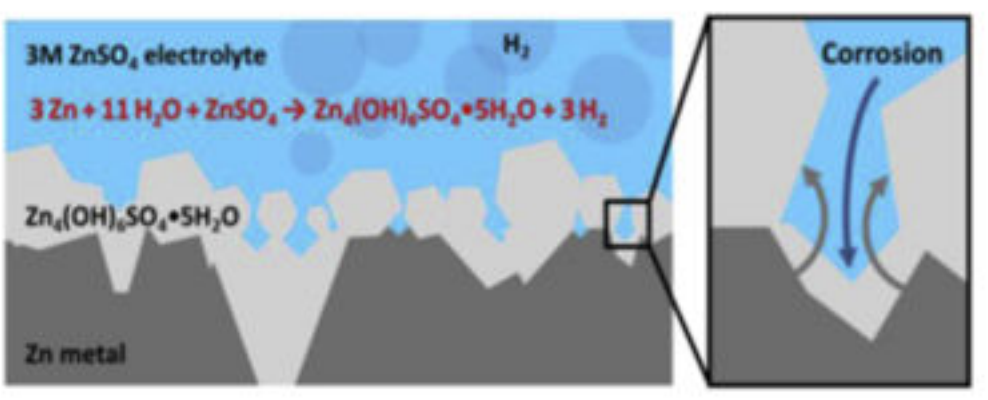

(b)

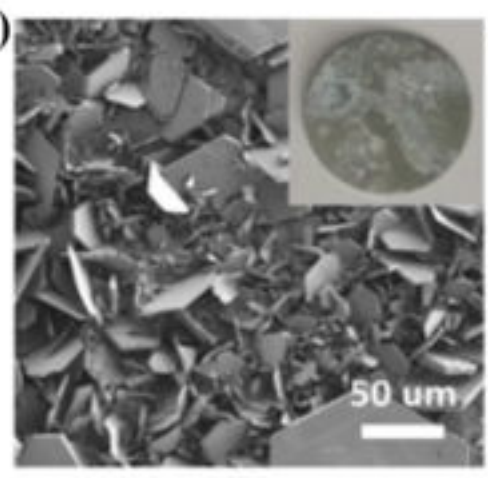

\section{(d)}

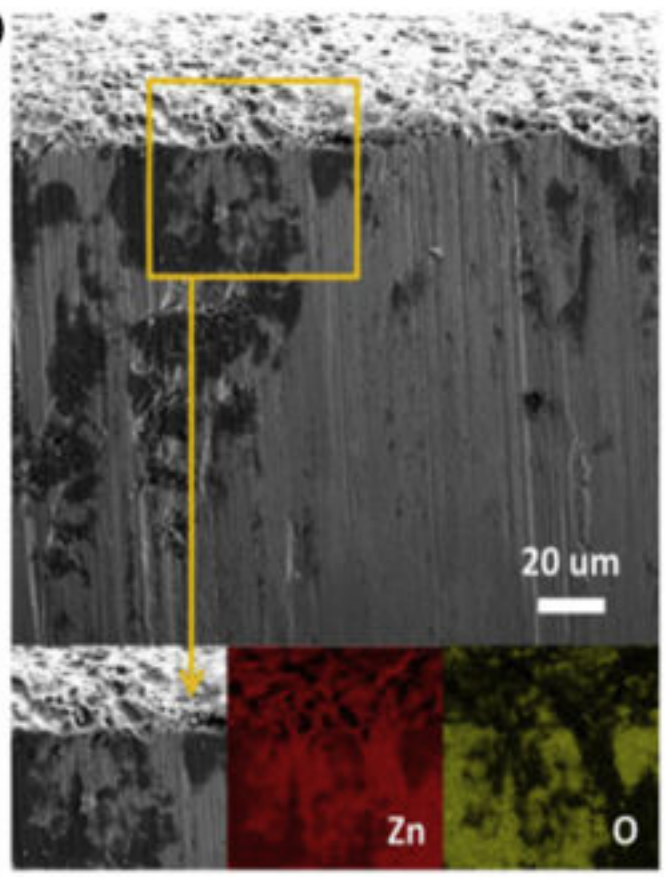

Figure 9. SEM images of a Zn electrode (a) before and (b) after 30 days of operation, (c) Chemical corrosion of the Zn metal electrode in a $\mathrm{ZnSO}_{4}$ electrolyte. (d) cross-section SEM and EDS elemental mapping results of the electrode operated for 30 days. Reprinted with permission from Cai et al. [101]. Copyright 2020 Elsevier B.V.

\subsection{Hydrogen Evolution}

Metal corrosion is a common side effect of the HER, which is another key issue limiting the applications of ZIBs. Owing to its lower electronegativity than that of $\mathrm{H}, \mathrm{Zn}$ prefers to react with water in neutral or slightly acidic electrolytes [102]. In addition, the $\mathrm{Zn}^{2+}$ deposited on the surface of highly reactive $\mathrm{Zn}$ metal anodes enhances the occurrence of side reactions. The hydrogen evolution that occurs over time not only dries out the electrolyte but also speeds up the hydration of the $\mathrm{Zn}$ cations in the aqueous electrolyte, resulting in suboptimal $\mathrm{Zn}$ usage as compared to the theoretical capacity. This generates $\mathrm{H}_{2}$ gas, which also corrodes the $\mathrm{Zn}$ metal surface, deteriorates the battery performance, and poses 
a safety risk. Furthermore, the consumption of $\mathrm{H}^{+}$in water leads to an increase in the $\mathrm{OH}^{-}$ ion concentration at the interface of the $\mathrm{Zn}$ anode/electrolyte, which produces insulating by-products and causes non-uniform Zn plating [103]. In mildly acidic electrolysis, the occurrence of the HER is inevitable because the standard reduction potential of $\mathrm{Zn} / \mathrm{Zn}^{2+}$ lags behind the $\mathrm{H}_{2}$ evolution potential (0 V vs. SHE) [104]. as follows [105]:

$$
\begin{gathered}
\mathrm{Zn}^{2+}+2 \mathrm{e}^{-} \leftrightarrow \mathrm{Zn}(-0.76 \mathrm{~V}) \\
2 \mathrm{H}^{+}+2 \mathrm{e}^{-} \leftrightarrow \mathrm{H}_{2}(0 \mathrm{~V})
\end{gathered}
$$

Because $\mathrm{Zn}$ has a large overpotential for $\mathrm{H}_{2}$ evolution in aqueous electrolytes, the HER is not as problematic as the values indicate [106], which could be described by the Tafel equation as follows [107].

$$
\eta=b \log i+a
$$

where $\eta$ is the $\mathrm{H}_{2}$ evolution overpotential, $\mathrm{i}$ is the current density, $\mathrm{b}$ is the Tafel slope constant, and a is the overpotential when the current density $i$ is equal to the unit current density. Because $b$ is roughly the same for all metals $(0.112 \mathrm{~V})$, the value of the overpotential for $\mathrm{H}_{2}$ evolution is mostly determined by the value of a [108]. $\mathrm{Zn}$ has a strong $\mathrm{H}_{2}$ overpotential as well as a high a value. According to the Pourbaix diagram of $\mathrm{Zn}$ in aqueous media, the high overpotential of $\mathrm{H}_{2}$ evolution on the $\mathrm{Zn}$ metal surface suppresses the evolution of $\mathrm{H}_{2}[46,109]$. Nevertheless, in reality, the $\mathrm{H}_{2}$ overpotential is also influenced by various other factors, including the roughness of the Zn surface [110], operating temperature [111], and $\mathrm{Zn}$ concentration [112]. As a result, under certain conditions, $\mathrm{H}_{2}$ evolution can be observed even in mildly acidic electrolytes. Because the HER is affected by the Zn surface conditions and the interaction of the $\mathrm{Zn}$ anode with the electrolyte, the HER is related to the formation of dendrites. On the one hand, the dendritic growth leads to a porous structure of the $\mathrm{Zn}$ anode with a larger specific surface area, which provides more reaction sites for the HER. On the other hand, it can be thought that an increase in the specific surface area lowers the current density, which suppresses the HER and corrosion on the $\mathrm{Zn}$ surface by increasing the overpotential and forming nonconductive by-products capable of obstructing the electron transfer and Zn deposition.

Overall, the three drawbacks of $\mathrm{Zn}$ dendrite growth, Zn electrode corrosion, and hydrogen evolution have been discussed in the $\mathrm{Zn}$ metal anode. These drawbacks are not simple independent problems but are closely correlated with one another. The formation of dendrite increases the surface area of the $\mathrm{Zn}$ metal anode, which contributes to the accelerated hydrogen evolution. Hydrogen evolution causes a change in the local $\mathrm{pH}$ due to an increase in the $\mathrm{OH}^{-}$concentration; however, it simultaneously accelerates the electrochemical corrosion reaction and changes the anode surface. In addition, the inert byproducts from the corrosion on the anodic surface can lead to the non-uniform surface and increased electrode polarization, which in turn facilitates the dendrite formation. Considering this complex phenomenon, it is necessary to tackle all these entangled problems with a comprehensive viewpoint rather than addressing each one of these problems separately.

\section{Common Strategies for Modifying the Surface of Zn Metal Anodes}

The electrochemical behavior of AZIBs is highly dependent on the structure of the $\mathrm{Zn}$ metal electrode surface. Therefore, various methods have been proposed to modify the surface of $\mathrm{Zn}$ metal electrodes. These methods can be categorized into several main approaches, including shielding the $\mathrm{Zn}$ metal to prevent side reactions, regulating the $\mathrm{Zn}$ deposition behavior, and creating a uniform electric field, as illustrated in Figure 10. 


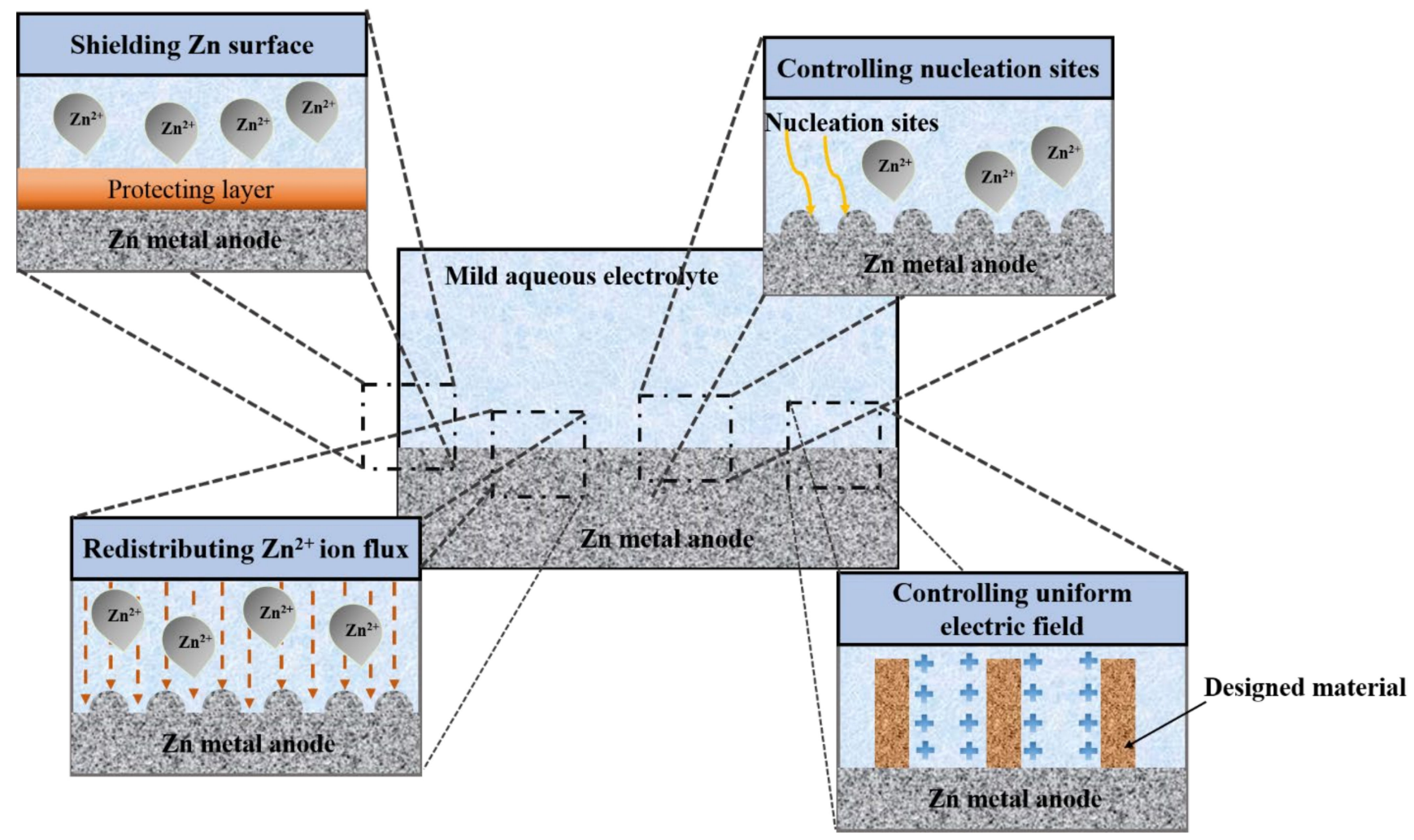

Figure 10. Modification strategies for enhancing the electrochemical performance of Zn metal anodes.

\subsection{Shielding the Zn Surface}

In LIBs and other battery systems with alkali metal anodes (e.g., Na and K), the SEI is automatically formed, which acts as a protective barrier to prevent undesired reactions [45]. However, in AZIBs, an SEI is indispensable. Because most of the electrolytes used in AZIBs are highly corrosive $\left(\mathrm{ZnSO}_{4}, \mathrm{ZnCl}_{2}\right.$, etc.) and $\mathrm{Zn}$ metal is quite steady in both aqueous and non-aqueous conditions, the natural formation of the SEI layer becomes insignificant. As a result, covering a $\mathrm{Zn}$ metal electrode with an artificial protective coating is one of the simplest yet efficient ways to enhance its stability. Preventing immediate contact between the electrode and electrolyte is the key to enhancing the electrochemical behavior of AZIBs. To overcome the harsh operational conditions of AZIBs, which are more complex than those of LIBs, the shielding material on the $\mathrm{Zn}$ metal anode must possess electrochemical and chemical stability. Atomic layer deposition (ALD) is an efficient technique for coating Zn metal electrodes as it offers advantages such as large coverage, conformal deposition, and precisely controllable film thickness at the nanoscale. The basic working principle of ALD relies on the chemical reactions between two or more precursors pumped alternately into a chamber containing a substrate at a specific temperature and pressure, allowing materials to be deposited in a layer-by-layer fashion on the substrate surface $[113,114]$. Unlike chemical vapor deposition (CVD) and other related deposition processes, ALD pumps the precursors progressively rather than simultaneously. Although ALD and CVD have certain similarities, they are different in terms of the self-limiting properties for precursor adsorption, as well as the alternate and sequential entry of the precursors and reactants [115]. A general ALD process is illustrated in Figure 11. 
(a)

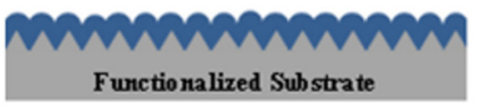

(d)

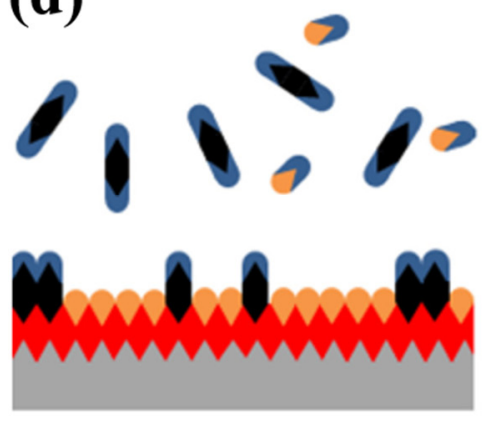

Precursor A (b)

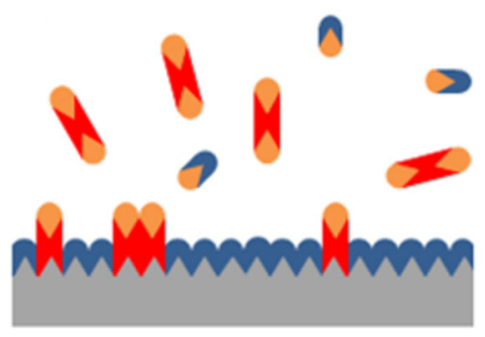

(e)

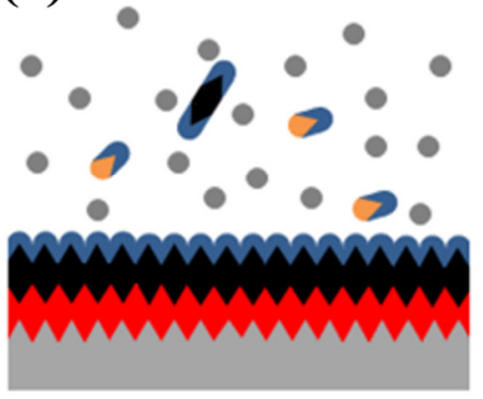

Legend: (c)

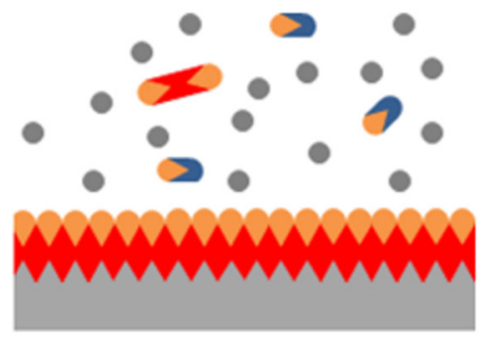

(f)
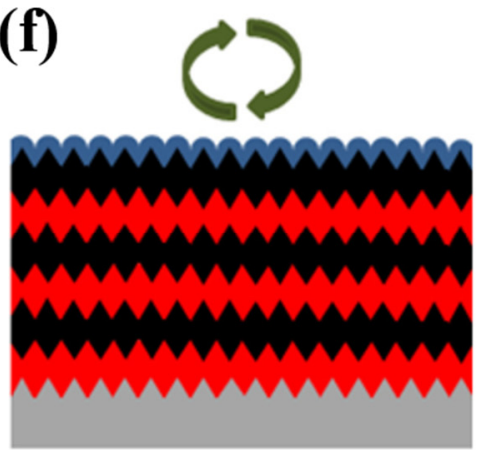

- Inert Carrier Gas

Figure 11. Schematic illustration of the ALD process; (a) the substrate surface is naturally functionalized or treated to be functionalized; (b) precursor A reacts with the surface after being pulsed; (c) an inert carrier gas is used to remove the excess precursor and by-products; (d) the surface reacts with the pulsed precursor B; (e) the inert carrier gas is used to remove excess precursor and byproducts; (f) repeat steps $2-5$ until the desired material thickness is achieved. Reprinted with permission from Johnson et al. [114]. Copyright 2014 Elsevier Ltd.

Inspired by these advantages of ALD, Zhao et al. fabricated an ultrathin $\mathrm{TiO}_{2}$ coating using the ALD method for the first time [116]. This passivation layer was chemically stable enough to resist the mildly acidic state and prevented the electrolyte and Zn plate electrode from coming into direct contact (as shown in Figure 12a,b). The undesirable HER was efficiently restricted under the protection of amorphous $\mathrm{TiO}_{2}(8 \mathrm{~nm}$ in thickness), resulting in decreased gas generation, thus reducing the risk of cell breakage by the increased internal pressure. As a result, the symmetric cell with the ALD TiO ${ }_{2} @ Z$ Zn electrodes had a low overpotential of $72.5 \mathrm{mV}$ at $1 \mathrm{~mA} \mathrm{~cm}{ }^{-2}$ and could hold it for $150 \mathrm{~h}$ without fluctuation, whereas the cell with the bare $\mathrm{Zn}$ electrodes only managed to cycle for $10 \mathrm{~h}$ (Figure 12c). The scanning electron microscopy (SEM) images of the electrodes cycled for $150 \mathrm{~h}$ revealed the presence of a large number of flakes on the surface of the $\mathrm{Zn}$ plate without the $\mathrm{TiO}_{2}$ coating (Figure 12e); however, in the case of the $\mathrm{Zn}$ plate coated with $\mathrm{ALD} \mathrm{TiO}_{2}$, only a few flakes were visible, and their dimensions were substantially smaller than those of the flakes observed on the uncoated plate (Figure 12d). After several cycles, the hydrolysis of $\mathrm{Zn}^{2+}$ caused the loss of the solvent (water), leading to the formation of $\mathrm{Zn}(\mathrm{OH})_{2}$. The presence of $\mathrm{Zn}(\mathrm{OH})_{2}$ rather than $\mathrm{Zn}$ dendrites on the electrode surface is another issue that needs to be resolved because it is thermodynamically unfavorable in slightly acidic solutions. In this study, the full cell performance was tested using an $\mathrm{ALD} \mathrm{TiO}_{2} @ \mathrm{Zn}$ anode and a $\mathrm{MnO}_{2}$ cathode $\left(\mathrm{ALD} \mathrm{TiO}_{2} @ \mathrm{Zn}-\mathrm{MnO}_{2}\right)$. With $\mathrm{TiO}_{2}$ protection, the ALD TiO $@ \mathrm{Zn}-\mathrm{MnO}_{2}$ full cell exhibited a discharge capacity of $235 \mathrm{mAh} \mathrm{g}{ }^{-1}$ after 60 cycles. In contrast, the $\mathrm{Zn}-\mathrm{MnO}_{2}$ cell showed a rapid capacity decay ( $155 \mathrm{mAh} \mathrm{g}^{-1}$ after 60 cycles) (Figure 12f). Additionally, the $\mathrm{ALD} \mathrm{TiO}_{2}$ coating also enhanced the $\mathrm{CE}$ of the $\mathrm{Zn}$ plate (Figure 12g). 
(a)

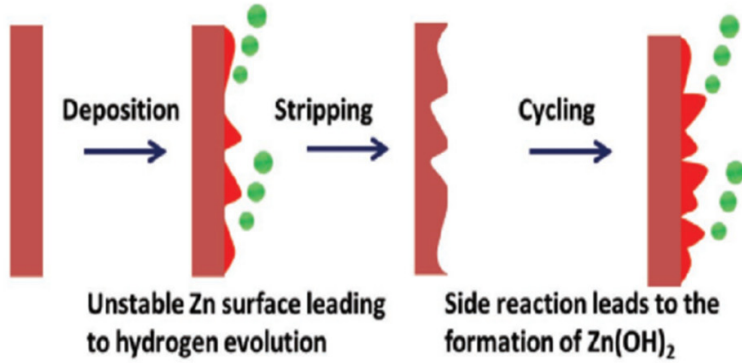

(b)

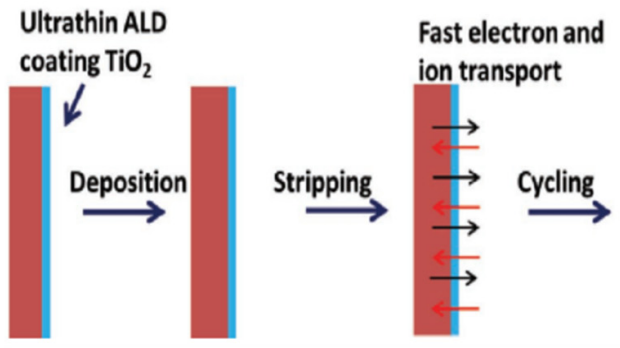

(f)

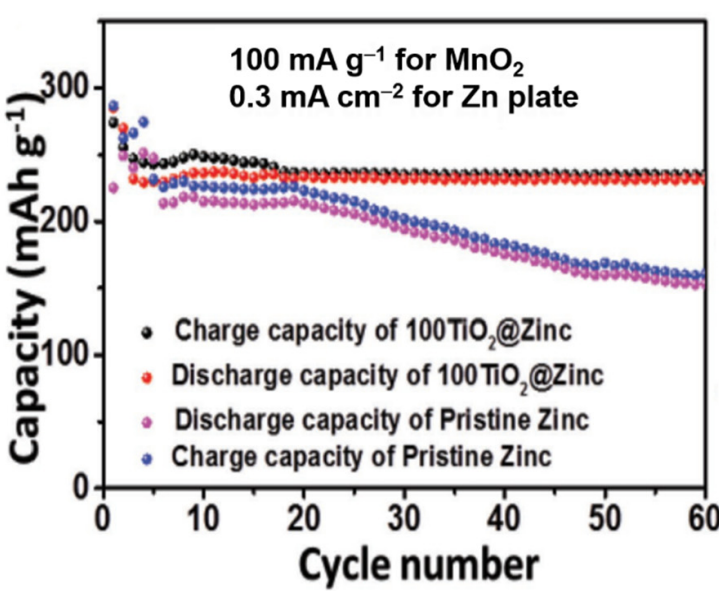

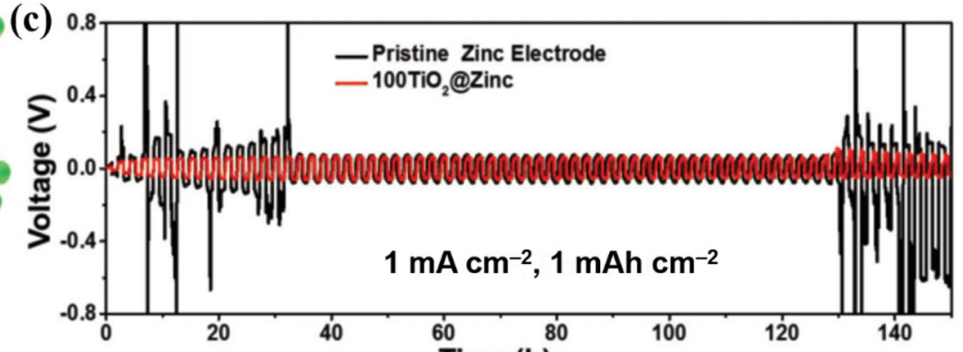

(d)

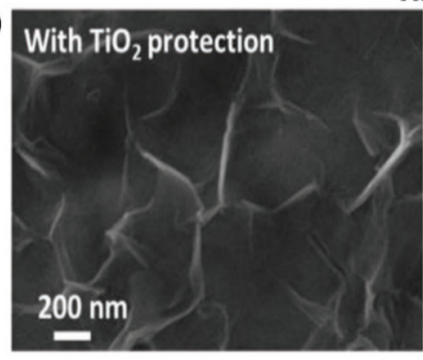

(e)

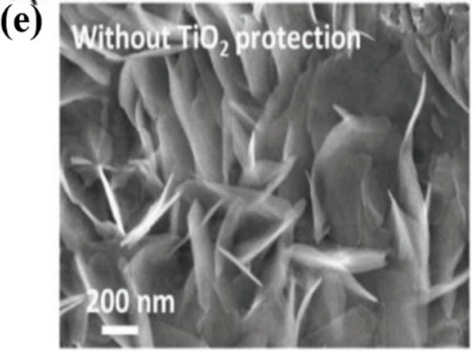

(g)

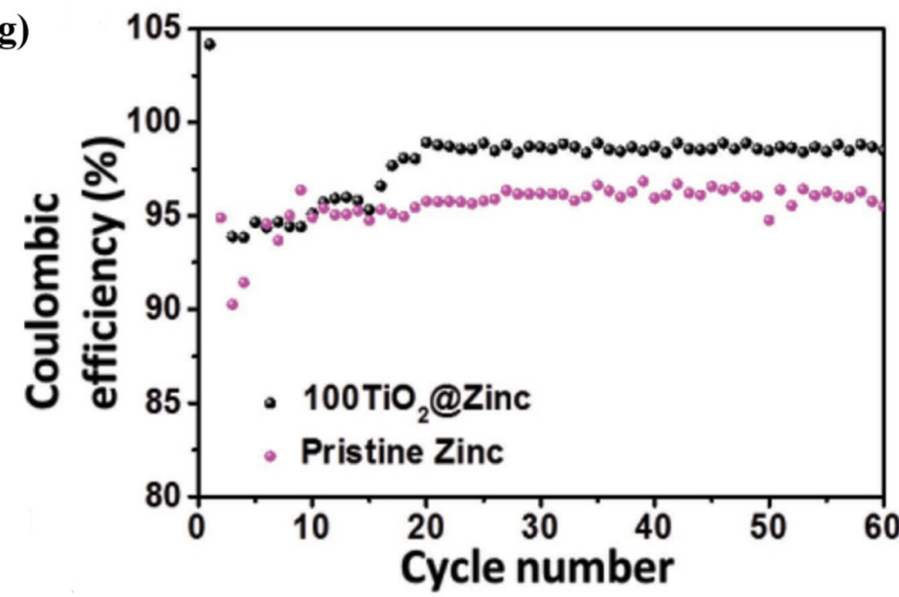

Figure 12. (a) Schematic illustration of $\mathrm{Zn}$ corrosion and $\mathrm{H}_{2}$ evolution under repeated plating/stripping cycles, (b) stable deposition/stripping process with a thin layer of $\mathrm{TiO}_{2}$ coated on the $\mathrm{Zn}$ anode, (c) symmetric cell performances of pristine $\mathrm{Zn}$ and $\mathrm{TiO}_{2} @ \mathrm{Zn}$, (d,e) ex-situ SEM images of the (d) $\mathrm{TiO}_{2} @ \mathrm{Zn}$ and (e) pristine $\mathrm{Zn}$ anodes, (f) full cell performances of ALD $\mathrm{TiO}_{2} @ \mathrm{Zn}-\mathrm{MnO}_{2}$ and $\mathrm{Zn}-\mathrm{MnO}_{2}$ at $100 \mathrm{~mA} \mathrm{~g}{ }^{-1},(\mathrm{~g}) \mathrm{CEs}$ of the $\mathrm{ALD} \mathrm{TiO}{ }_{2} @ \mathrm{Zn}-\mathrm{MnO}_{2}$ and $\mathrm{Zn}-\mathrm{MnO}_{2}$ full cells at $100 \mathrm{~mA} \mathrm{~g}{ }^{-1}$. Reprinted with permission from [116]. Copyright 2018 WILEY-VCH Verlag GmbH\&Co. KgaA, Weinheim.

Inspired by Zhao's work, He et al. [117]. coated an ultrathin $\mathrm{Al}_{2} \mathrm{O}_{3}$ film on a $\mathrm{Zn}$ metal foil via ALD. Unlike sol-gel $\mathrm{Al}_{2} \mathrm{O}_{3}$ coatings, the $\mathrm{ALD} \mathrm{Al}_{2} \mathrm{O}_{3}$ layer was homogeneous and thin enough $(10 \mathrm{~nm})$ to act as a corrosion inhibitor. Because the $\mathrm{ALD} \mathrm{Al}_{2} \mathrm{O}_{3}$ coating provided effective surface wetting, less electrolyte was used during the repeated $\mathrm{Zn}$ stripping/plating while maintaining high efficiency. The parasitic processes were successfully suppressed by shielding the $\mathrm{Zn}$ surface, resulting in a significant reduction of inactive by-products such as $\mathrm{Zn}(\mathrm{OH})_{2}$. Furthermore, the hydrophilic $\mathrm{Al}_{2} \mathrm{O}_{3}$ coating significantly improved the wettability of the $\mathrm{Zn}$ anode surface. It is believed that excess electrolyte plays a key role in improving the half-cell performance of $\mathrm{Zn}$ metal anodes. He et al. evaluated the charge-discharge profiles of symmetric cells with different electrolyte contents and found that the cells could show competitive results even at low electrolyte concentrations because of the presence of the $\mathrm{ALD} \mathrm{Al}_{2} \mathrm{O}_{3}$ thin coatings. The improved wettability of the $\mathrm{Zn}$ foil not only reduced the charge-transfer barrier but also facilitated additional $\mathrm{Zn}^{2+}$ ion flux through the surface. As a result, the $\mathrm{Al}_{2} \mathrm{O}_{3} @ \mathrm{Zn}$ symmetric cells could cycle for up to $500 \mathrm{~h}$ while maintaining a minimal overpotential $(36.5 \mathrm{mV})$ at $1 \mathrm{~mA} \mathrm{~cm}^{-2}$. The $\mathrm{Zn}$ nucleation overpotential was related not only to the dynamics of the Zn plating/stripping reaction but also to the transfer of $\mathrm{Zn}^{2+}$ and electrons. $\mathrm{Zn}^{2+}$ and electron transport are 
normally the intrinsic features of the electrolyte and electrode employed; however, the $\mathrm{Zn}$ stripping/plating kinetics are affected by a variety of variables, including the $\mathrm{Zn}$ nucleus dimension and surface tension, size distribution, and nucleation substrate shape. Furthermore, the $\mathrm{ALD} \mathrm{Al}_{2} \mathrm{O}_{3}$ showed a high surface wetting ability. As a result, the cells showed excellent electrochemical performance even at low electrolyte contents, which made them suitable for practical applications.

Meanwhile, Cai et al. [101]. further explored this strategy by decorating a Zn anode with an inert metal $(\mathrm{Cu})$ via a facile replacement reaction (Figure 13a). $\mathrm{Cu}$ shows excellent chemical stability and high conductivity in aqueous electrolytes; thus, the deposition of a $\mathrm{Cu}$-rich composite surface efficiently prevents the corrosion of $\mathrm{Zn}$ metal. The corrosion potential of the $\mathrm{Cu}-\mathrm{Zn}$ electrode $(-0.964 \mathrm{~V})$ was higher than that of the pristine $\mathrm{Zn}$ electrode $(-0.976 \mathrm{~V})$, which indicates that the deposition of $\mathrm{Cu}$ improved the chemical stability of the $\mathrm{Zn}$ electrode, as illustrated in Figure 13b. As compared to the pristine $\mathrm{Zn}$ anode, the $\mathrm{Cu}-\mathrm{Zn}$ anode showed significantly high resistance. The $\mathrm{Cu}-\mathrm{Zn}$ alloy (primarily $\mathrm{Cu}_{5} \mathrm{Zn}_{8}$ ) was produced in situ on the $\mathrm{Cu} / \mathrm{Zn}$ anode during the electrochemical cycling, leading to the formation of a dense and $\mathrm{Cu}$-rich surface layer. This alloy acted as a corrosion inhibitor and stabilizer for the electrode. Furthermore, its shape remained compact and smooth over time and prevented the deep penetration of bulk zinc metal by the electrolyte, which resulted in the formation of a significant amount of "dead $\mathrm{Zn}$ " and accelerated the corrosion. Another interesting approach was reported by Xie et al., who reformed a $\mathrm{Zn}$ plate with three-dimensional (3D)-nanoporous $\mathrm{ZnO}$ (3D-ZnO@Zn) [118]. The activation of the thin surface layer in the electric double layers (EDLs) by alien molecules on the inner Helmholtz plane improved the stability and long-term cycling performance of the electrode. Because $\mathrm{ZnO}$ had a 3D architecture with uniformly dispersed $\mathrm{O}$ on the surface of $\mathrm{Zn}$, it not only reduced the current density by limiting the "tip effect," but also suppressed the side-reactions at the interface and the formation of $\mathrm{H}_{2}$ by creating a tight exterior solvate sheath. In contrast, in the case of the bare $\mathrm{Zn}$ anode, $\mathrm{Zn}^{2+}$ showed sluggish transport kinetics into the host, resulting in strong polarization, high nucleation potential, and low stripping/plating efficiency. Another objective of this research was to gain a better understanding of the dynamic tuning of the $\mathrm{Zn}^{2+}$ transport toward the anode. In contrast to $\mathrm{TiO}_{2}$ or $\mathrm{Al}_{2} \mathrm{O}_{3}$, which completely shielded the $\mathrm{Zn}$ surface from the corrosive electrolyte, the porous $\mathrm{ZnO}$ layer showed strong electrostatic attraction for $\mathrm{Zn}^{2+}$ ions (preferably the solvated ones) in the EDL. $\mathrm{H}_{2}$ evolution was suppressed because of this propensity. Furthermore, because of its conductive and well-connected framework, the 3D architecture permitted quick $\mathrm{Zn}^{2+}$ transport, resulting in dramatically enhanced deposition kinetics. For a more precise assessment of the deposition dynamics, the exchange current density in the $\mathrm{Zn}$ electrodeposition process was calculated using the following equation:

$$
i \sim i_{0} \frac{F}{R T} \frac{\eta}{2}
$$

where $\mathrm{i}$ is the exchange current density, $\mathrm{i}_{0}$ is the reference exchange current density, $\mathrm{F}$ is the Faraday constant, $R$ is the gas constant, $T$ is the absolute temperature, and $\eta$ is the total overpotential. The exchange current density represents the redox reaction rate of the electrode at the equilibrium potential. The value was determined from the temperature and $\mathrm{H}_{2}$ concentration as well as the surface modification and cycling parameters. In addition to improving the deposition kinetics, the Arrhenius equation was used to examine the activation energy $\left(E_{a}\right)$, which can provide information on the transfer and desolvation of $\mathrm{Zn}^{2+}$.

$$
\frac{1}{R_{c t}}=A \exp \left(-\frac{E_{a}}{R T}\right)
$$

where $R_{c t}$ is the charge transfer resistance, $A$ is the pre-exponential factor, $E_{a}$ is the activation energy, $\mathrm{R}$ is the gas constant, and $\mathrm{T}$ is the absolute temperature. Meanwhile, $\mathrm{Zn}$ deposition unavoidably competed with $\mathrm{H}_{2}$ evolution. The HER performance of the electrode was evaluated using linear sweep voltammetry (LSV). This novel structure and artificial 
surface improved the $\mathrm{Zn}^{2+}$ deposition kinetics (nucleation potential of only $42.4 \mathrm{mV}$ for 3D$\mathrm{ZnO} @ \mathrm{Zn}$ vs. $66.9 \mathrm{mV}$ for bare $\mathrm{Zn}$; charge transfer resistance of $292.7 \Omega$ for 3D-ZnO@Zn vs. $1240 \Omega$ for bare $\mathrm{Zn})$, reduced the de-solvation energy consumption $\left(51.0 \mathrm{~kJ} \mathrm{~mol}^{-1}\right.$ for 3DZnO@Zn vs. $77.2 \mathrm{~kJ} \mathrm{~mol}^{-1}$ for bare $\mathrm{Zn}$ ) in the EDLs, and suppressed the HER. Besides this, 3D-ZnO@Zn showed a low current density of $7.938 \mathrm{~mA} \mathrm{~cm}^{-2}$, whereas pristine $\mathrm{Zn}$ exhibited a value of $19.68 \mathrm{~mA} \mathrm{~cm}{ }^{2}$, indicating the paradoxically sluggish deposition dynamics of 3D-ZnO@Zn.

(a)

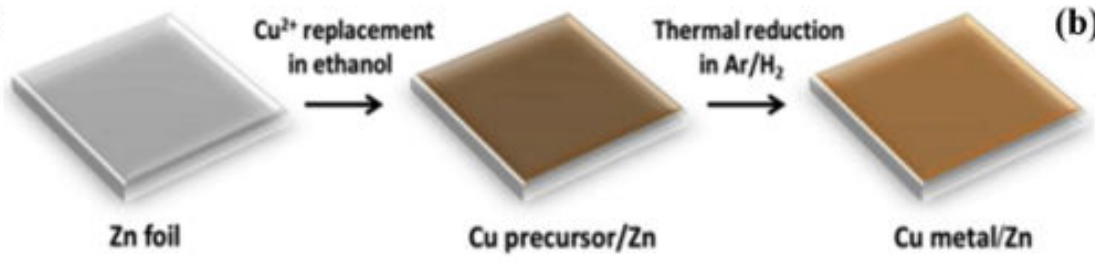

(c)

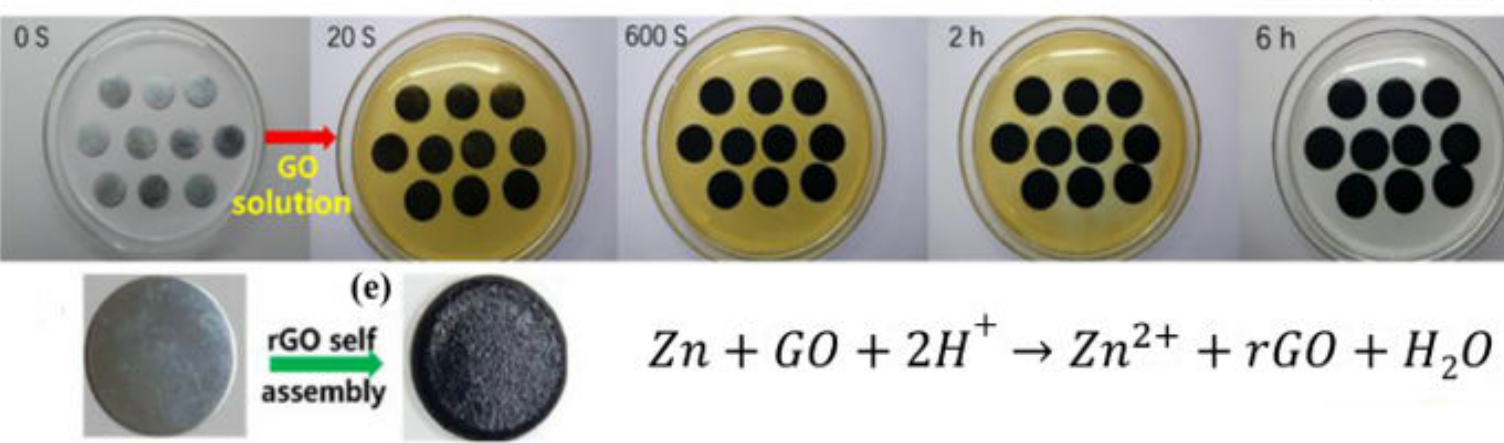

Figure 13. (a) Schematic illustration of the fabrication of the $\mathrm{Cu}-\mathrm{Zn}$ electrode. (b) linear polarization curve of the $\mathrm{Cu} / \mathrm{Zn}$ electrode in a $3 \mathrm{M} \mathrm{ZnSO}_{4}$ electrolyte. Reprinted with permission from Cai et al. [101]. Copyright 2020 Elsevier B.V. (c) Photographs depicting the preparation of the Zn/rGO. Zn plate (d) before and (e) after coating the rGO film. Reprinted with permission from Xia et al. [119]. Copyright 2019 Elsevier B.V.

The idea of shielding the $\mathrm{Zn}$ surface to prevent the formation of undesired by-products is not limited to coating with an inert metal or oxide passivation layer. Xia et al. employed a casting method to modify a $\mathrm{Zn}$ mesh anode with reduced graphene oxide (rGO) for application in ZIBs [119]. As shown in Figure 13c, when the pretreated Zn foil was dipped into a brown aqueous solution with a dispersion of GO, the $\mathrm{Zn}$ surface quickly became dark, and with an increase in the incubation time, the brown GO aqueous solution turned colorless and transparent, indicating that the GO was completely reduced to rGO. Finally, the color of the $\mathrm{Zn}$ plate turned black (Figure 13d), indicating that a uniform black rGO layer was coated onto the $\mathrm{Zn}$ foil (Figure 13e). The rGO coating deposited on Zn plates offered many advantages. First, the low density of rGO increased the energy density of the full cell. Second, the layered rGO provided a flexible framework, which significantly reduced the volume change during $\mathrm{Zn}$ stripping/plating while improving the cyclic stability of the cell. Finally, owing to its large specific surface area, rGO promoted uniform Zn deposition during cycling and inhibited the formation of $\mathrm{Zn}$ dendrites on the $\mathrm{Zn}$ plate. In this study, the porous rGO foam on the $\mathrm{Zn}$ anode scaffold successfully prevented the production of Zn dendrites.

\subsection{Regulating the Zn Deposition Behavior}

\subsubsection{Controlling the Nucleation Sites}

In traditional planar metal electrodes, uncontrollable dendrite formation has been an unresolved issue. Large protuberances on the $\mathrm{Zn}$ surface can pierce the separator, causing 
a short circuit and cell failure. The basic strategy of controlling the nucleation sites is to create additional $\mathrm{Zn}^{2+}$ nucleation sites, regulate the $\mathrm{Zn}$ plating/stripping behavior by $\mathrm{Zn}^{2+}$ nucleation and deposition homogeneity, restrict the dendrite growth, and prevent the $\mathrm{Zn}$ corrosion. As a result, several studies focusing on regulating this protrusionforming tendency aimed to mitigate the uncontrollable dendrite formation in Zn electrodes. For instance, Cui et al. proposed the novel concept of covering $\mathrm{Zn}$ electrodes with $\mathrm{Au}$ nanoparticles (Au NPs) [120]. They decorated a $\mathrm{Zn}$ anode with quasi-isolated nano-Au particles to manage its $\mathrm{Zn}$ striping behavior, promoting the nucleation/deposition on $\mathrm{Zn}$, reducing the "tip effect", and therefore eliminating the dendritic/protuberance growth. During the stripping stage, the exposed Zn metal between the Au-NPs tended to strip faster than the $\mathrm{Zn}$ metal covered by the Au-NPs, leading to the formation of artificial nano-Zn tips. Because of their high $\mathrm{Zn}^{2+}$ affinity, the exposed $\mathrm{Zn}$ areas could serve as nucleation sites for directing the homogenous $\mathrm{Zn}$ deposition process in consecutive cycles. Because of the presence of the Au-NPs, the protrusions could be managed well and replaced by an ordered $\mathrm{Zn}$ plating layer even in the first few cycles. As a result, the plating layer aided the homogenous nucleation of $\mathrm{Zn}^{2+}$ ions, resulting in the formation of well-organized $\mathrm{Zn}$ flake arrays. The cell performance improved significantly because of the nucleation control mechanism, which allowed the cell to function for up to 2000 cycles with a capacity of $67 \mathrm{mAh} \mathrm{g}^{-1}\left(500 \mathrm{~mA} \mathrm{~g}^{-1}\right)$.

Following this approach, Liang et al. exploited the Maxwell-Wagner-Sillars polarization phenomenon as the working principle for their $\mathrm{ZrO}_{2} @ \mathrm{Zn}$ anode, which was prepared using the sol-gel method (Figure 14a,b) [121]. The Maxwell-Wagner-Sillars polarization (or more commonly, Maxwell-Wagner (MW) polarization) occurs at the interface of two structures with different relative permittivities $(\varepsilon)$ and electrical conductivities ( $\delta)$. As a result, the charges are separated over a significant distance. This phenomenon was intentionally implemented in Liang's research by coating $\mathrm{ZrO}_{2}$ nanoparticles (a typical ceramic material with low electrical conductivity) onto a highly conductive $\mathrm{Zn}$ metal anode. Although the insulating nature of $\mathrm{ZrO}_{2}$ necessitated an activation step for the movement of $\mathrm{Zn}^{2+}$ ions through the coating layer, resulting in a high interface resistance in the first plating stage, the impedance then reduced in the subsequent cycles by the MW polarization phenomenon. The $\mathrm{CV}$ curves of the symmetric and complete cells with the $\mathrm{ZrO}_{2} @ \mathrm{Zn}$ anode revealed the unexpected effects of $\mathrm{ZrO}_{2}$ on the stripping/plating reactions of the $\mathrm{Zn}$ anode. At $0.125 \mathrm{mAh} \mathrm{cm}^{-2}$, the $\mathrm{ZrO}_{2} @ \mathrm{Zn}$ symmetric cell showed a substantially lower initial overpotential ( $38 \mathrm{mV}$ vs. $74 \mathrm{mV}$ for the bare $\mathrm{Zn}$ anode) and a much longer lifespan $(3800 \mathrm{~h})$ than the cell with the bare Zn electrode (Figure 14c). In addition, as shown in Figure $14 \mathrm{~d}$, the $\mathrm{ZrO}_{2}$-coated $\mathrm{Zn}$ anode showed a longer cycle lifespan (up to $2100 \mathrm{~h}$ ) and lower polarization $(32 \mathrm{mV})$ than the bare $\mathrm{Zn}$ anode at $5 \mathrm{~mA} \mathrm{~cm}^{-2}$. This can be attributed to the increase in the number of nucleation sites and the ion diffusion rate of the $\mathrm{ZrO}_{2}$-coated $\mathrm{Zn}$ anode due to the MW polarization effect. Furthermore, because $\mathrm{ZrO}_{2}$ is a chemically inert oxide, it can serve as a protective barrier, preventing $\mathrm{Zn}$ from contacting mildly acidic electrolytes. This dual-functional coating effectively reduced the uncontrollable dendrite growth and its potentially dangerous side effects. As a result, even after cycling at $5 \mathrm{~mA} \mathrm{~cm}{ }^{-2}$, the $\mathrm{ZrO}_{2}$-coated $\mathrm{Zn}$ anode retained its flat and dense surface. 
(a)

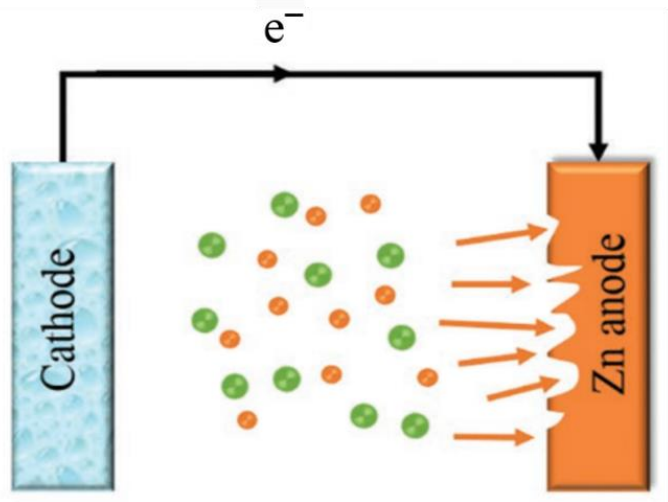

uncontrollable nucleation and

Zn corrosion caused by HER

$$
\mathrm{ZrO}_{2} \text { nanoparticles }
$$

(b)

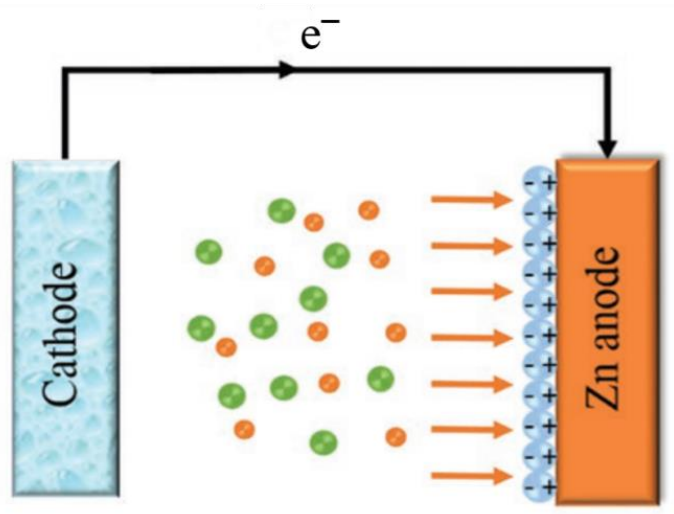

uniform Zn plating by Maxwell-Wagner polarization of $\mathrm{ZrO}_{2}$ coating layer
- $\mathrm{Zn}^{2+}$
(- $\mathrm{H}_{3} \mathrm{O}^{+}$

(c)

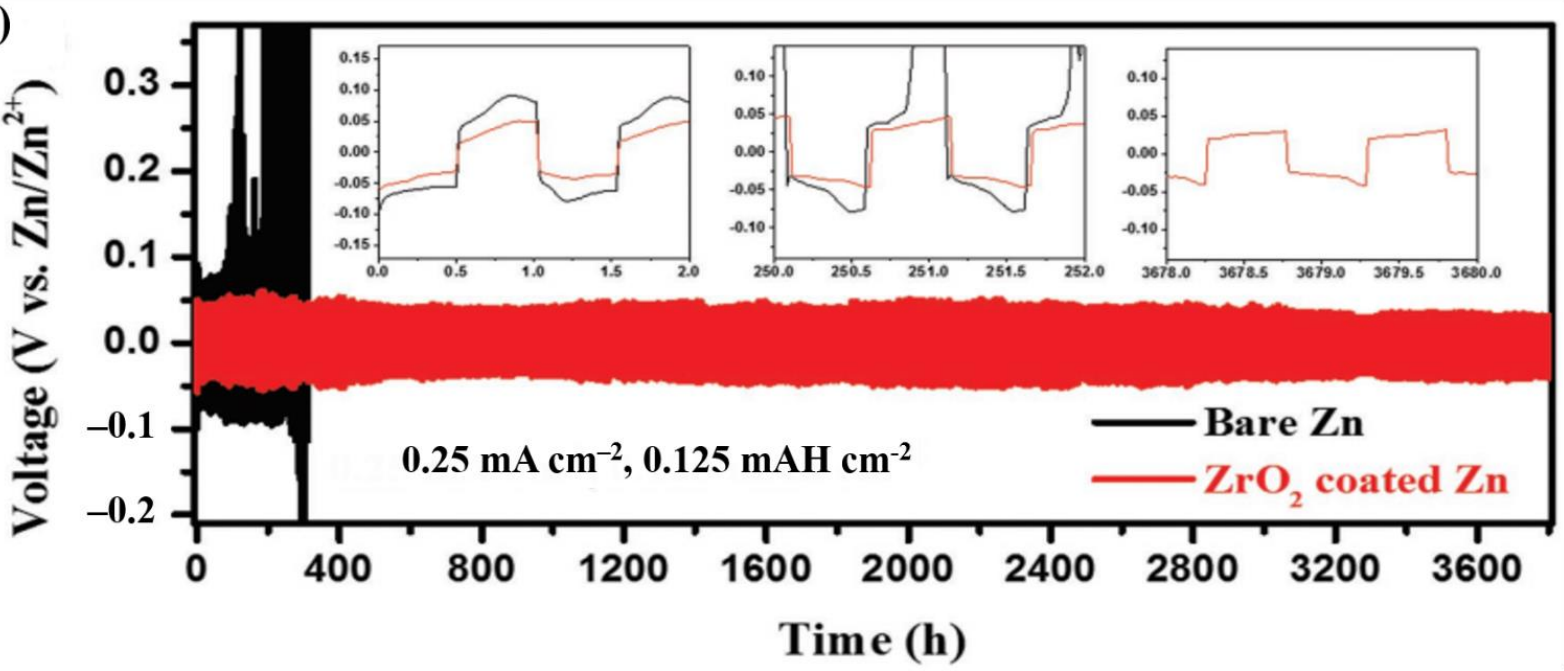

(d)

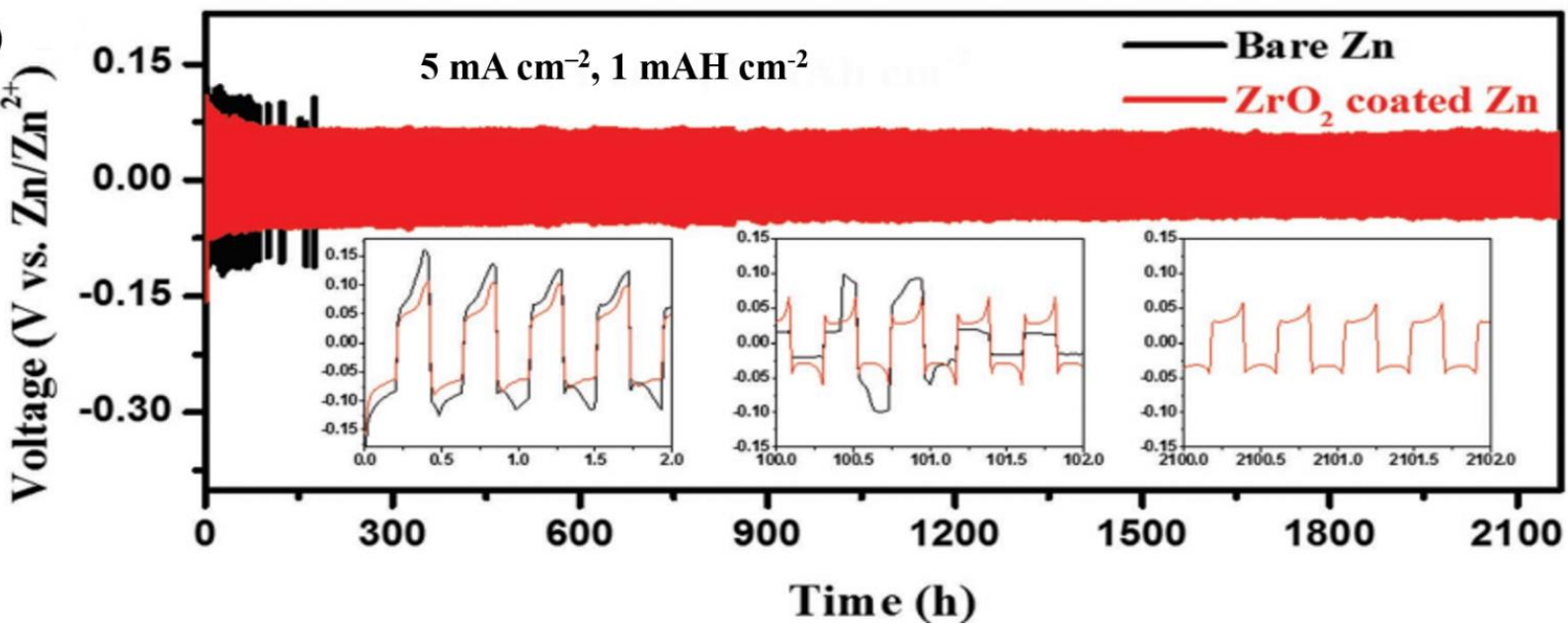

Figure 14. Schematics for the stripping/plating processes of (a) bare $\mathrm{Zn}$ and (b) $\mathrm{ZrO}_{2}$-coated $\mathrm{Zn}$. Voltage profiles of bare $\mathrm{Zn}$ and $\mathrm{ZrO}_{2}$-coated $\mathrm{Zn}$ in a symmetric cell at (c) $0.25 \mathrm{~mA} \mathrm{~cm}{ }^{-2}$ for $0.125 \mathrm{mAh} \mathrm{cm}^{-2}$ and (d) $5 \mathrm{~mA} \mathrm{~cm}{ }^{-2}$ for $1 \mathrm{mAh} \mathrm{cm}^{-2}$. Reprinted with permission from Liang et al. [121]. Copyright 2020 WILEY-VCH Verlag GmbH\&Co. KgaA, Weinheim. 
Along this line, Kang et al. used a nanoporous $\mathrm{CaCO}_{3}$ coating to control the $\mathrm{Zn}$ deposition (Figure 15a) [92]. The holes in the $\mathrm{CaCO}_{3}$ coating on the $\mathrm{Zn}$ metal anode were crucial for controlling the formation of $\mathrm{Zn}$ dendrites. The electrolyte quickly penetrated the nano $\mathrm{CaCO}_{3}$ coating owing to its high porosity, resulting in a consistent electrolysis flux and plating of $\mathrm{Zn}$ throughout the $\mathrm{Zn}$ metal surface. After continuous running, large protuberances and detached zinc flakes were formed as a large amount of $\mathrm{Zn}$ was deposited in these areas. The merits of nanoporous $\mathrm{CaCO}_{3}$ were utilized based on this assumption. Owing to its high porosity, the nanoporous $\mathrm{CaCO}_{3}$ buffer layer facilitated the electrolyte flux and prevented the "local bias" behavior. In addition, the fine pores and holes at the nanoscale enclosed the $\mathrm{Zn}$ nuclei, thus reducing the polarization. In addition, the potential variation induced by the electrically insulating characteristics of $\mathrm{CaCO}_{3}$ was favorable for countering the "tip effect" as $\mathrm{Zn}^{2+}$ ions could be converted into $\mathrm{Zn}$ only in the area with enough negative potential, namely the area near the anode surface. Consequently, the battery with the nano- $\mathrm{CaCO}_{3}$-coated $\mathrm{Zn}$ anode showed a capacity of $206 \mathrm{mAh} \mathrm{g}^{-1}$ at $1 \mathrm{~A} \mathrm{~g}^{-1}$ and a CE of $84.7 \%$. These values are higher than those of the pristine $\mathrm{Zn}$ anode (188 $\mathrm{mAh} \mathrm{g}^{-1}$ and $77.5 \%$, respectively) (Figure $15 \mathrm{~b}$ ). The battery with the nano- $\mathrm{CaCO}_{3}$ coated $\mathrm{Zn}$ anode exhibited substantially better cycling steadiness than that with the pristine $\mathrm{Zn}$ anode at $1 \mathrm{~A} \mathrm{~g}^{-1}$ (Figure 15c). Its capacity gradually increased from 206 to a maximum of $236 \mathrm{mAh} \mathrm{g}^{-1}$ in the first 500 cycles, and then reached $177 \mathrm{mAh} \mathrm{g}^{-1}$ after the 1000th cycle (capacity retention of $86 \%$ ). On the other hand, the battery with the pristine $\mathrm{Zn}$ anode had a lower initial capacity of $188 \mathrm{mAh} \mathrm{g}^{-1}$, which remained only $124 \mathrm{mAh} \mathrm{g}^{-1}$ after 1000 cycles. Later, Zeng et al. proposed a similar strategy using conductive CNT scaffolds [122]. The highly porous CNT skeleton helped to ensure uniform seeding sites across the electrode (similar to $\mathrm{CaCO}_{3}$ ). Moreover, this flexible sheet also served as a "supplemental host" because of the occurrence of Zn stripping/plating in it, thus providing additional space for $\mathrm{Zn}$ deposition and alleviating the aggressive dendrite growth. More impressively, no coating process was employed; instead, the CNT scaffolds only needed to be placed between the $\mathrm{Zn}$ foil anode and separator, which indeed set this work apart from others because of its simplicity and scalability. In addition to applying CNTs in AZIBs, Dong et al. further applied this Zn@CNT electrode for hybrid capacitors. The Zn ion capacitor delivered remarkable stability with an average capacity of $47 \mathrm{mAh} \mathrm{g}^{-1}$ at $2 \mathrm{~A} \mathrm{~g}^{-1}$ (CE $\sim 100 \%$ ) for 7000 cycles.

\subsubsection{Redistributing $\mathrm{Zn}^{2+}$ Ion Flux}

Another efficient strategy to improve the $\mathrm{Zn}$ deposition behavior of $\mathrm{Zn}$ metal anodes is to redistribute the $\mathrm{Zn}^{2+}$ ion flux. As a pioneer in this field, Zhao et al. proposed a solid-state interphase comprising of polyamide (PA) and zinc trifluoromethane sulfonate $\left(\mathrm{Zn}(\mathrm{TfO})_{2}\right)[94]$. They demonstrated that ions tended to move horizontally across the electrode surface and aggregated at already existing nucleation sites to optimize the surface energy. However, this inclination was intentionally restrained by introducing the PA chains. Because of their higher energy barrier to diffuse laterally, the $\mathrm{Zn}^{2+}$ ions were obligated to deposit at the premier position where they were initially adsorbed through the interface, resulting in an increase in the number of nucleation sites. In addition, the synergistic interaction between the $\mathrm{Zn}^{2+}$ ions and polar groups $(\mathrm{C}=\mathrm{O})$ in the PA backbones improved the nucleation overpotential, which favored the formation of smaller nuclei. These dual effects ultimately led to the formation of a dense and smooth $\mathrm{Zn}$ layer when the cells were continuously cycled. It is important to note that the PA coating did not allow electrons to cross over it, preventing the external reduction of $\mathrm{Zn}^{2+}$. Therefore, the electrolyte could not contact the newly formed $\mathrm{Zn}$ without shielding. The water-resistant characteristics of the coating also suppressed the adverse HERs. The carbonyl-rich networks offered plentiful hydrogen bonds to bind and impair the $\mathrm{Zn}^{2+}$ ion solvation-sheath, preventing $\mathrm{H}_{2} \mathrm{O}$ and $\mathrm{O}_{2}$ from participating in such reactions. As a result, the discharge capacity of the $\mathrm{Zn} / \mathrm{MnO}_{2}$ battery increased with an increase in the number of cycles from 450 (below $30 \mathrm{mAh} \mathrm{g}^{-1}$ ) to 1000 (155.4 $\mathrm{mAh} \mathrm{g}^{-1}, 88 \%$ capacity retention) at $2 \mathrm{C}$. 
(a)

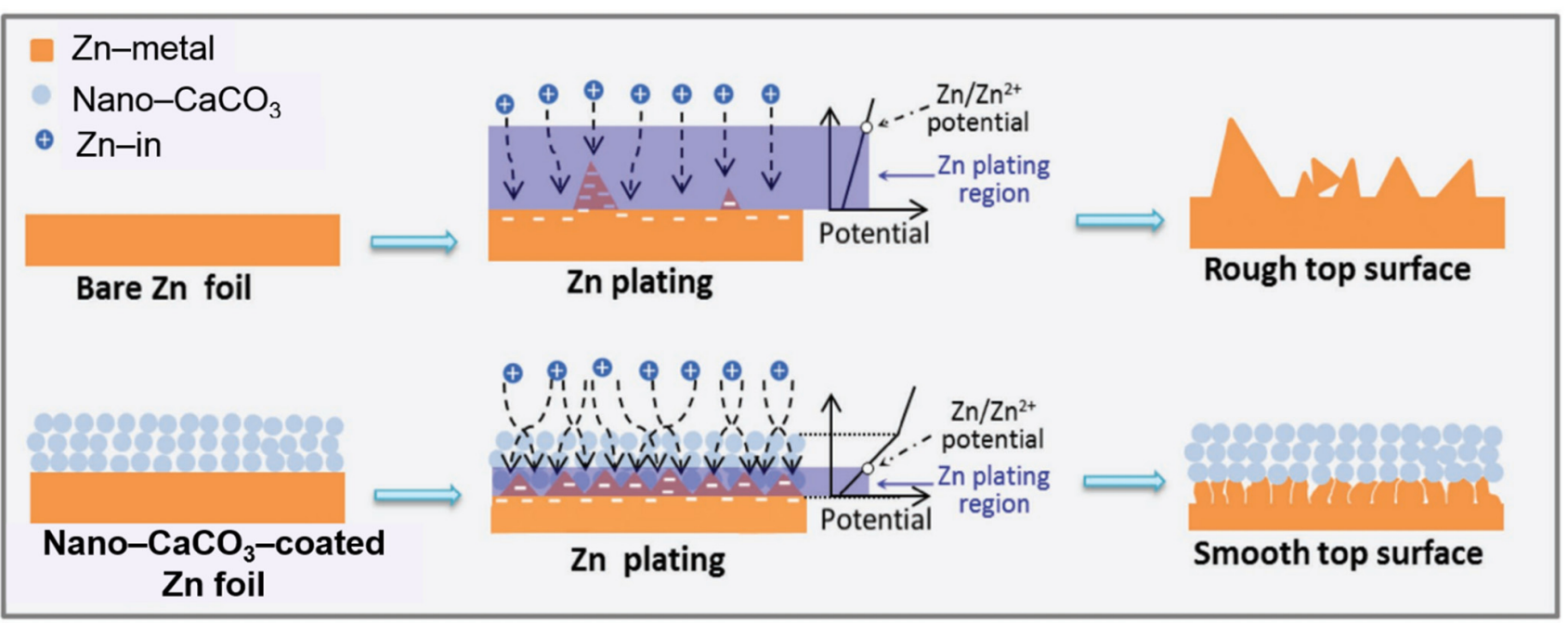

(b)
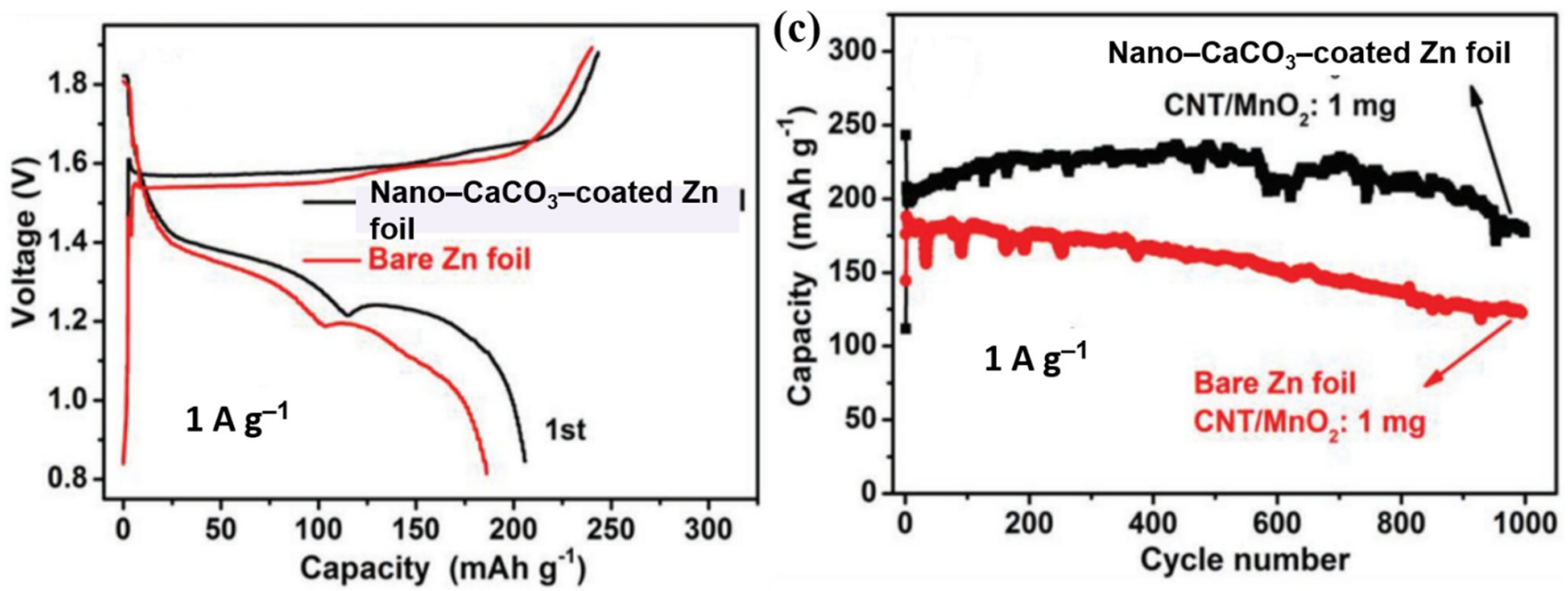

Figure 15. (a) Schematic illustration of morphology evolution for bare and nano- $\mathrm{CaCO}_{3}$-coated $\mathrm{Zn}$ foils during $\mathrm{Zn}$ stripping/plating cycling, (b) charge-discharge profiles and (c) full cell performance of nano- $\mathrm{CaCO}_{3}$-coated $\mathrm{Zn}$ foil and bare Zn foil. Reprinted with permission from [92]. Copyright 2018 WILEY-VCH Verlag GmbH\&Co. KgaA, Weinheim.

Although the coating of metal anodes with polymers has been widely practiced with positive results, an appropriate polymer should be chosen based on some fundamental principles. To withstand the volume changes during repeated cycling, a metal anode must be mechanically strong and flexible. Chemical stability, water insolubility, and hydrophilicity are also essential features of an ideal metal anode. Finally, the polymer network used for coating $\mathrm{Zn}$ anodes must possess abundant polar groups to interact with the metal ions. Considering these requirements, polyvinylidene fluoride (PVDF) has been used to modify the surface of Zn anodes via a facile spin-coating process (Figure 16a) [123]. Under slow evaporation conditions, the F atoms in the PVDF side chains rearrange to form an all-trans conformation known as the $\beta$-phase, in which all the dipoles align on the same side. Owing to its high polarity, $\beta$-PVDF shows excellent ferroelectric, piezoelectric, and pyroelectric properties. When symmetric $\beta$-PVDF@Zn $\left|\mathrm{ZnSO}_{4}\right| \beta-\mathrm{PVDF} @ \mathrm{Zn}$ was cycled at $0.25 \mathrm{~mA} \mathrm{~cm}^{-2}$ and an area capacity of $0.05 \mathrm{mAh} \mathrm{cm}^{-2}$, a small overpotential was achieved even after $2000 \mathrm{~h}$ of operation. This performance is far superior to that shown by $\mathrm{Zn}\left|\mathrm{ZnSO}_{4}\right| \mathrm{Zn}$, which withered after $200 \mathrm{~h}$ (Figure 16b). This superior performance of $\beta$-PVDF@Zn I ZnSO $\mid \beta-P V D F @ Z n$ can be attributed to the presence of the multifunctional $\beta$-PVDF membrane in it. On the one hand, the highly electronegative $C-F$ alignments acted as preferable diffusion paths for $\mathrm{Zn}^{2+}$ and distributed these ions uniformly onto the entire anode surface. This efficient channel network helped to abate the local current density and developed a homogeneous layer of $\mathrm{Zn}$ plating. On the other hand, owing to its resilience, the 
(a)

$\beta$-PVDF polymer could withstand dendrite growth and hindered the formation of inactive side-products $(\mathrm{ZnO})$ in acidic electrolytes. Protected by the versatile $\beta$-PVDF cover, the $\mathrm{Zn}$ anode retained its morphology without serious damage and, as a result, the full cell delivered an appealing cycling performance (discharge capacity of $60 \mathrm{mAh} \mathrm{g}^{-1}$ after 4000 cycles).

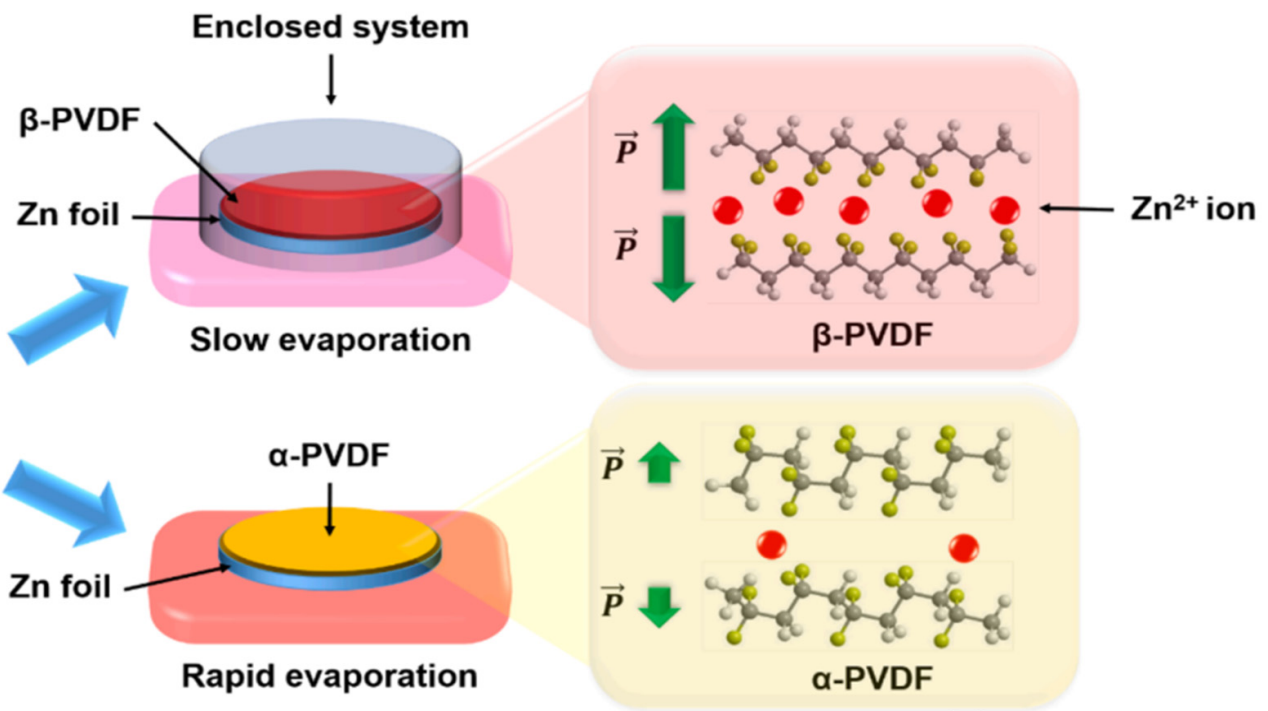

(b)

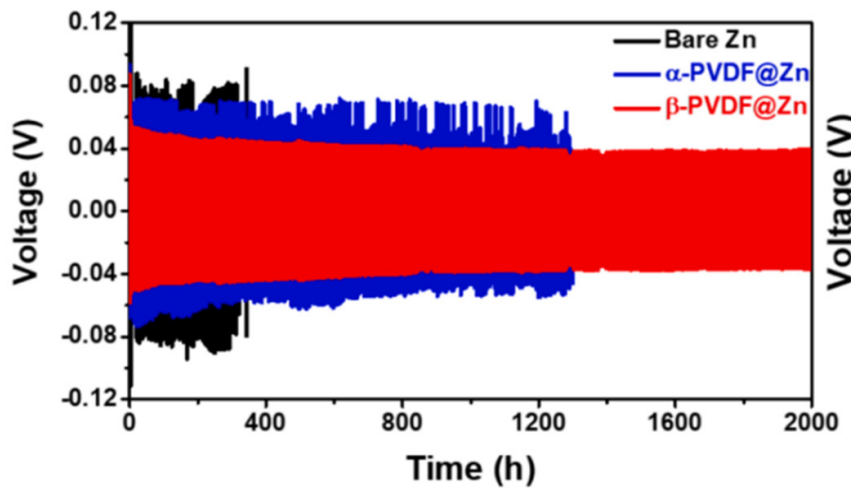

(c)

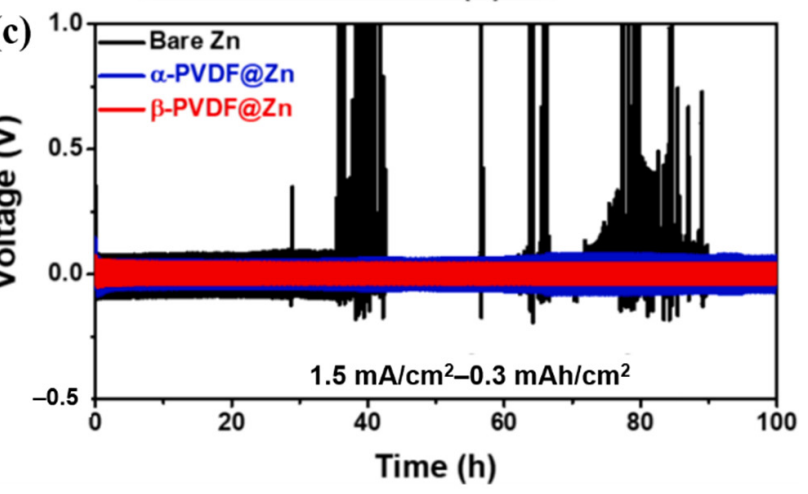

Figure 16. (a) Schematic illustration of the $\beta$ - and $\alpha$-PVDF coating processes, (b) long-term profiles of $\beta$-PVDF@Zn (red), $\alpha$-PVDF@Zn (blue), and bare Zn (black) with symmetrical cells at a current density of (b) $0.25-0.05 \mathrm{mAh} \mathrm{cm}^{-2}$, (c) $1.5-0.3 \mathrm{mAh} \mathrm{cm}^{-2}$. Reprinted with permission from Hieu et al. [123]. Copyright 2021 Elsevier B.V.

With regard to PVDF, Liu et al. synthesized a MOF-PVDF composite coating layer consisting of PVDF and hydrophilic microporous metal-organic framework (MOF) particles [124]. The metal ions could evenly access the anode surface because of their low wettability with common aqueous electrolytes, resulting in local ion deposition and troublesome protrusion growth. The microporous architecture of the MOF induced a wetting effect on the $\mathrm{Zn}$ electrode at the nanoscale, generating a hydrophilic surface. Each MOF nanoparticle made intimate contact with $\mathrm{Zn}$ and served as a nanoscale electrolyte reservoir. As a result, the ion flux cooperated well with the $\mathrm{Zn}$ plate to the greatest extent, promoting a uniform Zn stripping/plating process. Furthermore, the compact MOF particles enabled fast ion diffusion through the fully wetted surface, dramatically lowering the charge-transfer resistance.

\subsection{Creating Uniform Electric Field}

One of the most important issues affecting the stability of $\mathrm{Zn}$ anodes is the formation of $\mathrm{Zn}$ dendrites. Engineering a synthetic SEI on the surface of $\mathrm{Zn}$ is an effective method for limiting the $\mathrm{Zn}$ dendrite formation. The fundamental goal of this strategy is to develop materials that can direct the orderly migration of $\mathrm{Zn}$ ions while providing a homogenous electric field at the electrode-electrolyte interface, preventing the formation of $\mathrm{Zn}$ den- 
drites. Recently, it has been demonstrated that an artificial SEI based on $\mathrm{BaTiO}_{3}(\mathrm{BTO})$ can effectively restrain the Zn dendrite growth (Figure 17a,b) [125]. The polarized BTO layer played a significant role in controlling the orderly migration of $\mathrm{Zn}$ ions because of the uniform electric field through it. The polarization of BTO was induced by the Ti ions that deviated from the center of the symmetrical site in BTO under an external electric field. In this situation, the two-dimensional diffusion of $\mathrm{Zn}$ ions was highly restricted, and the vertical movement of $\mathrm{Zn}$ ions through the BTO layer was thermodynamically preferable. Moreover, according to the density functional theory calculation results, the formation energy of $\mathrm{Zn}$ deposition was much lower for BTO@Zn than that for bare $\mathrm{Zn}$ $(-2.28$ vs. $-0.35 \mathrm{eV})$, thus BTO promoted dense $\mathrm{Zn}$ plating without dendrites. In addition, the water molecules in the solvated $\mathrm{Zn}$ ions $\left(\mathrm{Zn}\left(\mathrm{H}_{2} \mathrm{O}\right)_{6}{ }^{2+}\right)$ were easily attracted by the $\mathrm{O}$ atom in BTO via hydrogen bonding, which facilitated the diffusion of $\mathrm{Zn}$ ions and restricted the $\mathrm{Zn}$ dendrite formation [91]. In contrast, in the absence of the BTO coating, the $\mathrm{Zn}$ dendrite formation could not be regulated because of the uneven deposition of $\mathrm{Zn}$ ions as well as the preferential deposition at the protruded surfaces. As a consequence, the BTO@Zn-symmetric cell showed cycling stability for more than $2000 \mathrm{~h}$ (1000 cycles) at $1 \mathrm{~mA} \mathrm{~cm}^{-2}, 1 \mathrm{mAh} \mathrm{cm}^{-2}$ (Figure 17c) and for 1500 cycles at $5 \mathrm{~mA} \mathrm{~cm}^{-2}, 2.5 \mathrm{mAh} \mathrm{cm}^{-2}$ (Figure 17d). After 300 cycles at $2 \mathrm{~A} \mathrm{~g}^{-1}$, the BTO@Zn-MnO 2 full cell battery showed high rate capability and approximately $100 \% \mathrm{CE}$ in a mild aqueous electrolyte.

Zhang et al. investigated $\mathrm{CuO}$ nanowires grown on a $\mathrm{Cu}$ mesh ( $\mathrm{CM} @ \mathrm{CuO})$ by anodic oxidation, followed by thermal annealing in air [126]. Because of the decreased energy barrier and increased number of active sites, $\mathrm{Zn}^{2+}$ was preferentially absorbed by $\mathrm{CuO}$ and dispersed evenly on the Zn surface, which was advantageous for Zn nucleation. Furthermore, as illustrated in Figure 18a, the $\mathrm{Cu}$ generated from $\mathrm{CuO}$ enhanced the electrical conductance, which in turn increased the electric field during the Zn nucleation, resulting in a more ordered $\mathrm{Zn}$ growth. Because of the increased zincophilicity and uniform $\mathrm{Zn}^{2+}$ distribution on the surface, small $\mathrm{Zn}$ nanosheets were consistently developed on the $\mathrm{CuO}$ nanowires, as shown in the SEM image (Figure $18 \mathrm{~b}$ ). Zn remained within the $\mathrm{CuO}$ nanowire structure even when the capacity was increased to $5 \mathrm{mAh} \mathrm{cm}^{-2}$ (Figure 18c). In contrast to the dendrite-free plating behavior of $\mathrm{CM} @ \mathrm{CuO} @ \mathrm{Zn}$, the early Zn growth on the pristine $C M$ was uneven, and micron-sized $\mathrm{Zn}$ dendrites $(5 \mu \mathrm{m})$ were observed in the CM@Zn anode (Figure 18d,e). This work demonstrated that CM@CuO@Zn shows excellent electrochemical performance owing to its uniform electric field and 3D structure. The as-prepared $\mathrm{Zn}$ anode showed excellent cycling stability $(340 \mathrm{~h})$ and low voltage hysteresis $(20 \mathrm{mV})$ in symmetric cells at $1 \mathrm{~mA} \mathrm{~cm}^{-2}$ and $1 \mathrm{mAh} \mathrm{cm}^{-2}$. Meanwhile, a 3D hierarchical $\mathrm{N}$ doped carbon cloth (NC) was produced using magnetron sputtering as a scaffold combining a 3D architecture and an interfacial control to efficiently promote the uniform nucleation of $\mathrm{Zn}$ metal and reduce the growth of $\mathrm{Zn}$ dendrites [127]. The dynamics of $\mathrm{Zn}^{2+}$ transfer and deposition could be accelerated by the desolvation process of $\mathrm{Zn}^{2+}$ with surface chemistry control. The 3D hierarchical conductive carbon scaffold uniformly distributed the electric fields and lowered the local current density. The $\mathrm{N}$-containing functional groups in NC served as nucleation sites to distribute the Zn nuclei uniformly across the electrode surface. As Zn was constantly deposited, an electric charge was generated in the uneven nucleation sites. The carbon scaffold doped with $\mathrm{N}$ atoms encouraged the homogenous nucleation and growth of $\mathrm{Zn}$, thus constraining the formation of $\mathrm{Zn}$ dendrites. The $\mathrm{N}$ atoms generated by the addition of pyrrole lowered the migration energy barrier and promoted the redistribution of $\mathrm{Zn}$ ions. Furthermore, the zincophilicity of the NC scaffold was enhanced by the strong electrostatic interaction between the negatively charged pyrrole $\mathrm{N}$ sites in the carbon lattice and the $\mathrm{Zn}$ atoms, resulting in the homogeneous nucleation and growth of $\mathrm{Zn}$. The negative state of the pyrrole $\mathrm{N}$ site can be explained by the formation of $\sigma$-bonds between the doped $\mathrm{N}$ atoms and the adjacent carbons from which electrons moved toward pyrrole $\mathrm{N}$ through the inductive effect. As a result, the assembled half-cell showed a high zinc stripping/plating CE of $98.8 \%$. The NC-Zn symmetrical cell showed 
stable operation at a high current density of $5 \mathrm{~mA} \mathrm{~cm}^{-2}$ with an overpotential as low as $11 \mathrm{mV}$ after 210 cycles.

(a)
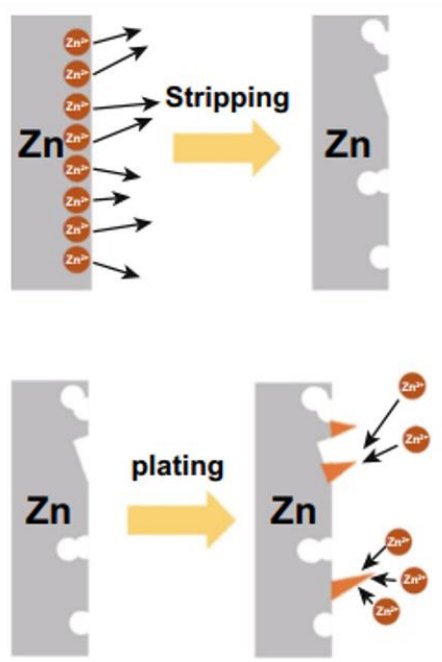

(b)

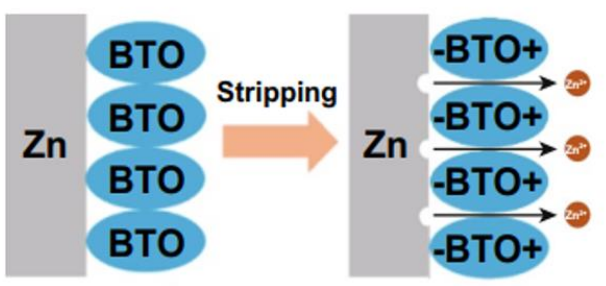

Deposited Zn layer

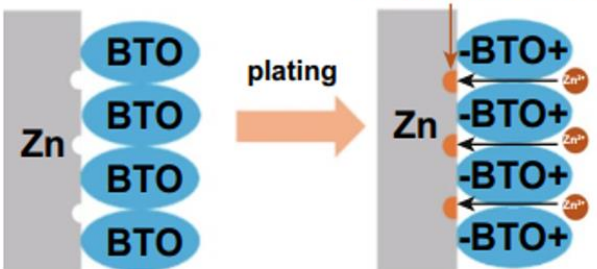

(c)

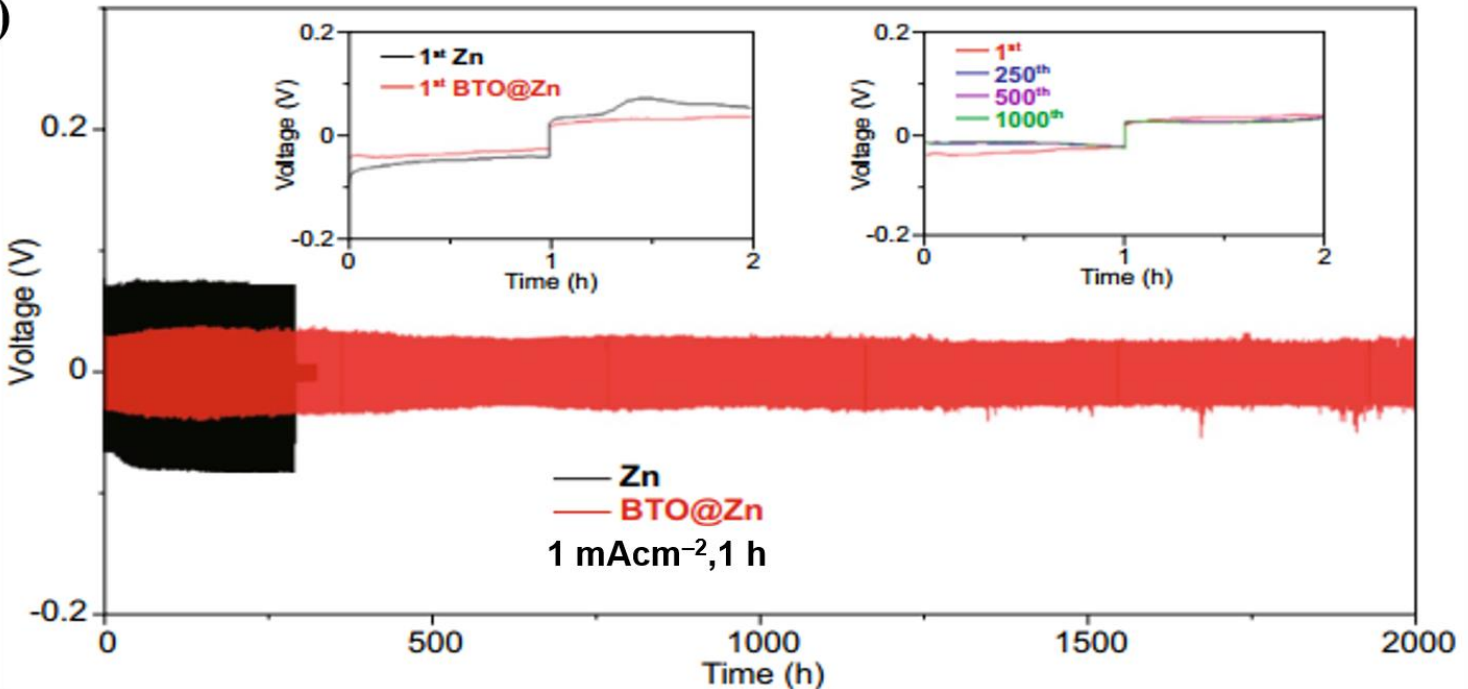

(d)

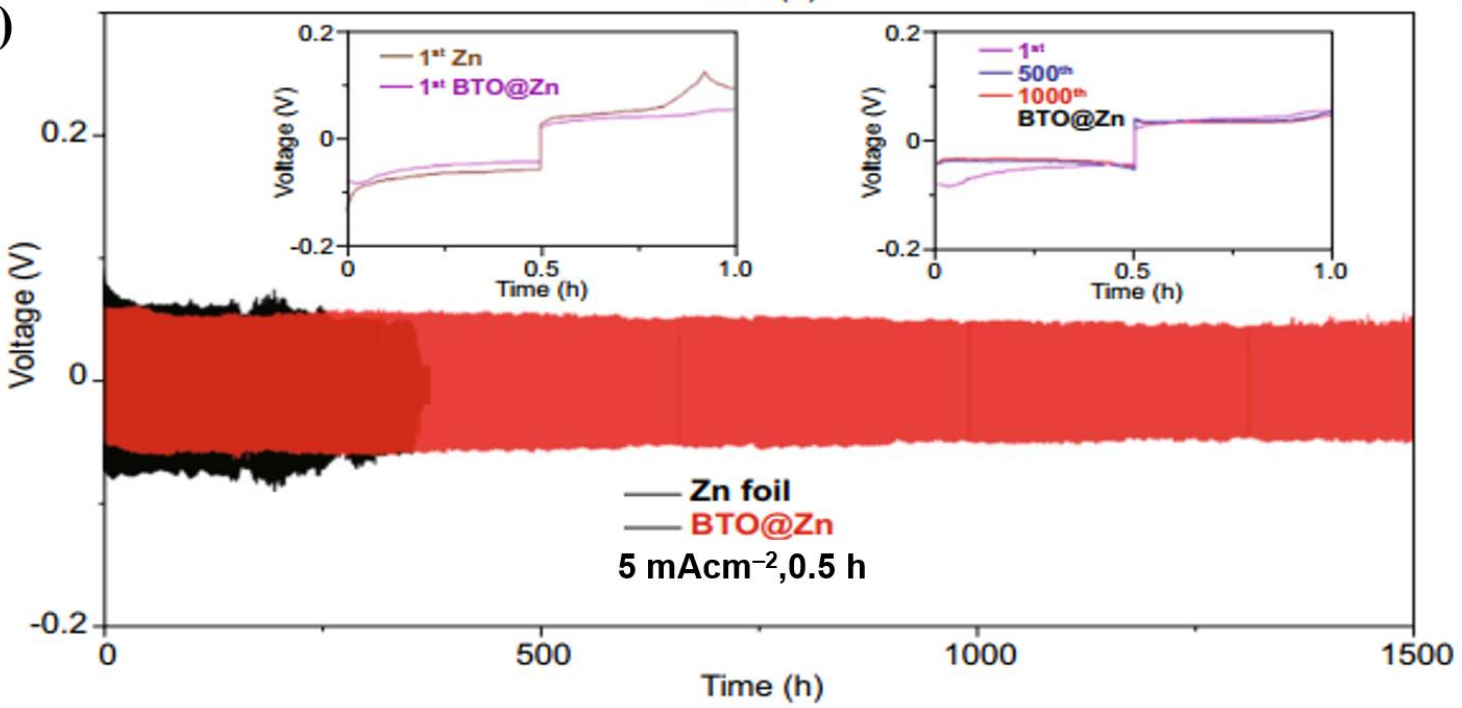

Figure 17. Schematic of Zn ion transport during Zn stripping/plating for (a) bare Zn, and (b) BTO@ Zn foil. Cyclic performances of the symmetric cells with Zn and BTO@Zn at (c) $1 \mathrm{~mA} \mathrm{~cm}^{-2}\left(1 \mathrm{mAh} \mathrm{cm}^{-2}\right)$, and (d) $5 \mathrm{~mA} \mathrm{~cm}^{-2}\left(2.5 \mathrm{mAh} \mathrm{cm}^{-2}\right)$. Reprinted with permission from [125]. 
(a)

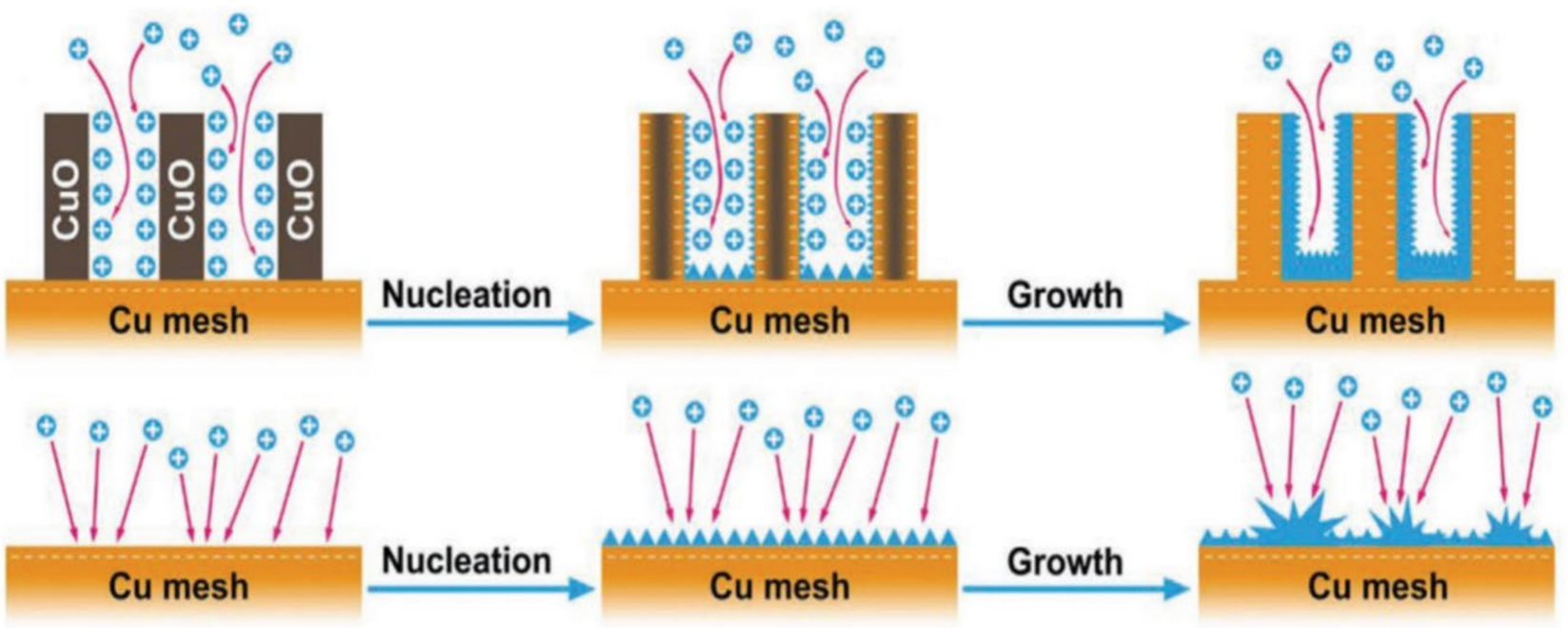

(b)
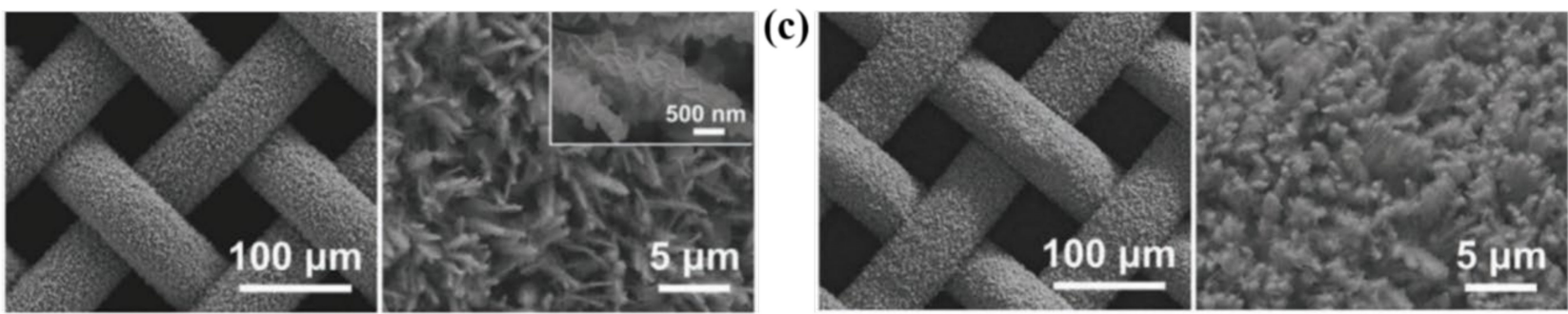

(d)
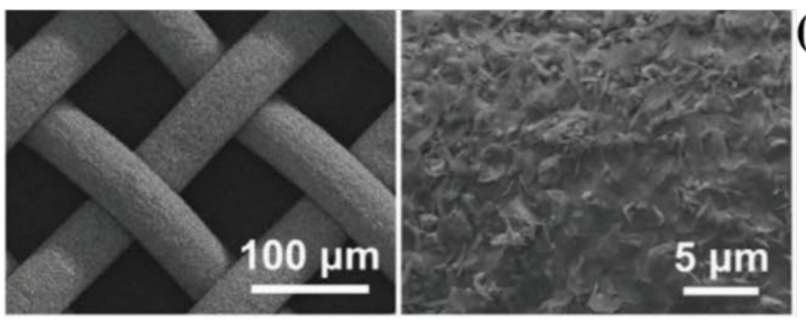

(e)
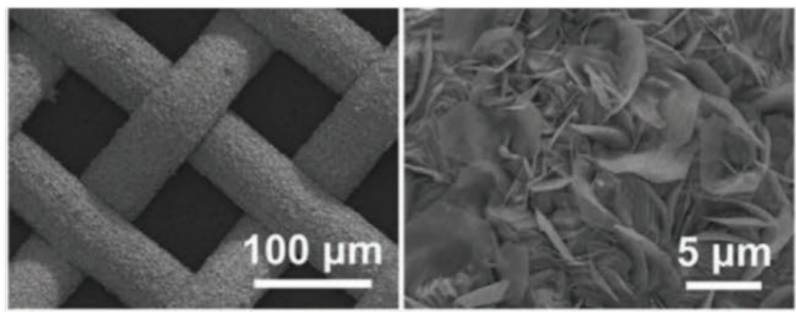

Figure 18. (a) Schematic illustration of Zn deposition on CM@CuO and CM. SEM images of CM@CuO@Zn with the capacities of (b) 1 and (c) $5 \mathrm{mAh} \mathrm{cm}^{-2}$. SEM images of CM@Zn with the capacities of (d) 1 and (e) $5 \mathrm{mAh} \mathrm{cm}^{-2}$. Reprinted with permission from [126]. Copyright 2020 Wiley-VCH GmbH.

The various modification principles used for modifying $\mathrm{Zn}$ anodes and their performances (symmetric and full cell) for AZIBs in mildly acidic electrolytes are summarized in Table 2.

According to the strategies discussed above for modifying the $\mathrm{Zn}$ metal surface, the drawbacks must be addressed concurrently to achieve a practical improvement of $\mathrm{Zn}$ metal anodes. As for the dendrites, they can be effectively suppressed by increasing the $\mathrm{Zn}$ nucleation sites, redistributing the ionic flux of $\mathrm{Zn}^{2+}$, and controlling the electric field. Corrosion and HER can be resolved by reducing the chemical activity of $\mathrm{H}_{2} \mathrm{O}$ and introducing the protective layer on the $\mathrm{Zn}$ metal anode. As can be seen from Table 2, these strategies improve the performance of the $\mathrm{Zn}$ anodes compared to the pristine state, but some of them are not still viable enough for practical applications in the perspectives of overall performance. For example, the use of carbon-based materials with a high specific surface area such as rGO can inhibit the dendrite formation, but can accelerate the corrosion, which may result in the degraded full-cell performance. Therefore, the effectiveness of modification methods should be strictly evaluated considering various performance metrics together to realize the high-performance $\mathrm{Zn}$ anode. 
Table 2. Modification mechanisms and electrochemical performances of recently reported $\mathrm{Zn}$ metal anodes in mildly acidic electrolytes for AZIBs.

\begin{tabular}{|c|c|c|c|c|c|}
\hline Anode & Mechanism & $\begin{array}{l}\text { Corrosion } \\
\text { Potential } \\
\text { (V) (vs. } \\
\text { Ag/AgCl) }\end{array}$ & $\begin{array}{c}\text { Symmetrical Cell } \\
\text { Performance:Lifespan (h), } \\
\text { Capacity, and Current Density }\end{array}$ & $\begin{array}{l}\text { Full-cell Performance:Capacity } \\
\text { (mAh g-1)/Cycle/Capacity Retention } \\
(\%) / C u r r e n t \text { Density }\left(\mathrm{mA} \mathrm{g}^{-1}\right)\end{array}$ & Ref \\
\hline $\mathrm{TiO}_{2} @ \mathrm{Zn}$ & Shielding Zn surface & -0.89 & $\begin{array}{l}150 \mathrm{~h} \\
1 \mathrm{~mA} \mathrm{~cm}^{-2}, 1 \mathrm{mAhcm}^{-2}\end{array}$ & $134 \mathrm{mAh} \mathrm{g}^{-1} / 1000$ cycles $/ 85 \% / 1 \mathrm{~A} \mathrm{~g}^{-1}$ & [116] \\
\hline $\mathrm{Al}_{2} \mathrm{O}_{3} @ \mathrm{Zn}$ & Shielding $\mathrm{Zn}$ surface & -0.88 & $1 \mathrm{~mA} \mathrm{~cm}^{-2}, 1 \mathrm{mAh} \mathrm{cm}^{-2}$ & $158 \mathrm{mAh} \mathrm{g}^{-1} / 1000$ cycles $/ 89 \% / 1 \mathrm{~A} \mathrm{~g}^{-1}$ & [117] \\
\hline $\mathrm{Cu}-\mathrm{Zn} / \mathrm{Zn}$ & Shielding Zn surface & -0.96 & $\begin{array}{l}1500 \mathrm{~h} \\
1 \mathrm{~mA} \mathrm{~cm}^{-2}, 0.5 \mathrm{mAh} \mathrm{cm}^{-2}\end{array}$ & - & [101] \\
\hline rGO@Zn & Shielding Zn surface & - & $\begin{array}{l}300 \mathrm{~h} \\
1 \mathrm{~mA} \mathrm{~cm}^{-2}, 0.5 \mathrm{mAh} \mathrm{cm}^{-2}\end{array}$ & $61 \mathrm{mAh} \mathrm{g}^{-1} / 5000$ cycles $/ 86 \% / 1 \mathrm{~A} \mathrm{~g}^{-1}$ & [119] \\
\hline NA-Zn & $\begin{array}{l}\text { Controlling } \\
\text { nucleation sites }\end{array}$ & - & $\begin{array}{l}2000 \mathrm{~h} \\
0.25 \mathrm{~mA} \mathrm{~cm}^{-2}, 0.05 \mathrm{mAh} \mathrm{cm}^{-2}\end{array}$ & $67 \mathrm{mAh} \mathrm{g}^{-1} / 2000$ cycles $/-/ 0.5 \mathrm{~A} \mathrm{~g}^{-1}$ & [120] \\
\hline $\mathrm{ZrO}_{2} @ \mathrm{Zn}$ & $\begin{array}{l}\text { Controlling } \\
\text { nucleation sites }\end{array}$ & - & $\begin{array}{l}2100 \mathrm{~h} \\
5 \mathrm{~mA} \mathrm{~cm}^{-2}, 1 \mathrm{mAh} \mathrm{cm}^{-2}\end{array}$ & $52 \mathrm{mAh} \mathrm{g}^{-1} / 3000$ cycles $/ 42 \% / 1 \mathrm{~A} \mathrm{~g}^{-1}$ & [121] \\
\hline CaCO3@Zn & $\begin{array}{l}\text { Controlling } \\
\text { nucleation sites }\end{array}$ & - & $\begin{array}{l}900 \mathrm{~h} \\
0.25 \mathrm{~mA} \mathrm{~cm}^{-2}, 0.05 \mathrm{mAh} \mathrm{cm}^{-2}\end{array}$ & $177 \mathrm{mAh} \mathrm{g}^{-1} / 1000$ cycles $/ 86 \% / 1 \mathrm{~A} \mathrm{~g}^{-1}$ & [92] \\
\hline CNT@Zn & $\begin{array}{l}\text { Controlling } \\
\text { nucleation sites }\end{array}$ & - & $200 \mathrm{~h}$ & $167 \mathrm{mAh} \mathrm{g}^{-1} / 1000$ cycles $/ 89 \% /-$ & [122] \\
\hline PA@Zn & Redistributing $\mathrm{Zn}^{2+}$ ion flux & -0.96 & $\begin{array}{l}8000 \mathrm{~h} \\
0.5 \mathrm{~mA} \mathrm{~cm}^{-2}, 0.25 \mathrm{mAh} \mathrm{cm}^{-2}\end{array}$ & $154 \mathrm{mAh} \mathrm{g}^{-1} / 1000$ cycles $/ 88 \% / 0.6 \mathrm{~A} \mathrm{~g}^{-1}$ & [94] \\
\hline PVDF@Zn & Redistributing $\mathrm{Zn}^{2+}$ ion flux & - & 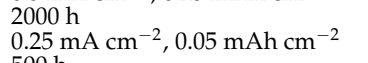 & $57 \mathrm{mAh} \mathrm{g}^{-1} / 2000$ cycles $/-/ 1 \mathrm{~A} \mathrm{~g}^{-1}$ & [123] \\
\hline MOF-PVDF@Zn & Redistributing $\mathrm{Zn}^{2+}$ ion flux & - & $\begin{array}{l}500 \mathrm{~h} \\
1 \mathrm{~mA} \mathrm{~cm}\end{array}$ & - & [124] \\
\hline BTO@Zn & Creating uniform electric field & - & $500 \mathrm{~h} \mathrm{~cm}^{-2}, 0.5 \mathrm{mAh} \mathrm{cm}^{-2}$ & $74 \mathrm{mAh} \mathrm{g}^{-1} / 300$ cycles $/ 67 \% / 2 \mathrm{~A} \mathrm{~g}^{-1}$ & [125] \\
\hline CM@CuO@Zn & Creating uniform electric field & - & $\begin{array}{l}350 \mathrm{~h} \\
1 \mathrm{~mA} \mathrm{~cm}^{-2}, 1 \mathrm{mAh} \mathrm{cm}^{-2}\end{array}$ & - & [126] \\
\hline NC@Zn & Creating uniform electric field & - & $\begin{array}{l}300 \mathrm{~h} \\
1 \mathrm{~mA} \mathrm{~cm}^{-2}, 0.5 \mathrm{mAh} \mathrm{cm}^{-2}\end{array}$ & - & [127] \\
\hline
\end{tabular}

\section{Conclusions and Outlook}

In summary, the major challenges associated with the application of $\mathrm{Zn}$ metal anodes in mild aqueous electrolytes and the modification strategies employed to overcome these challenges are discussed to provide an insight into the development of high-performance AZIBs. AZIBs are regarded as promising alternatives to LIBs (especially for large-scale energy storage systems) owing to their safety, cost-effectiveness, environmental benignity, and high energy density. The main challenges associated with the use of Zn metal anodes in neutral or mildly acidic media are dendrite growth, corrosion, and $\mathrm{H}_{2}$ evolution. The presence of uneven nucleation sites on Zn metal facilitates uncontrollable charge transfer, which accelerates the generation of an uneven electric field, causing the growth of dendrites. The corrosion of Zn metal anodes can be categorized as self-corrosion or corrosion by an electrochemical reaction. The latter refers to the irreversible $\mathrm{Zn}$ consumption due to the removal of $\mathrm{Zn}$ from the electrode as well as the side reactions between the electrode and electrolyte. $\mathrm{H}_{2}$ evolution is a complicated process that is affected by the reduction potential, overpotential, surface area, electrolyte $\mathrm{pH}$, and operating temperature. To address these issues, researchers have proposed various modification strategies, which can largely be categorized as (i) shielding the $\mathrm{Zn}$ metal from side reactions, (ii) regulating the $\mathrm{Zn}$ deposition behavior (controlling the nucleation sites and redistributing the $\mathrm{Zn}^{2+}$ ion flux), and (iii) establishing a uniform electric field.

Despite the considerable progress made in this field, there is still a long way to go to address the complex challenges discussed thus far. An efficient approach to produce a dendrite-free and highly reversible $\mathrm{Zn}$ anode is to strategically tailor the 3D structure of the electrode. The construction of 3D nanostructured $\mathrm{Zn}$ metal anodes has not been fully explored yet. Fabricating $\mathrm{Zn}$ anodes with hierarchical 3D architectures provides new opportunities for increasing the rate capability and service life of AZIBs because it allows a more uniform distribution of the electric current and provides a large number of reaction sites. The fabrication of 3D Zn architecture can be realized by the coating of Zn metal (e.g., electrodeposition) on a well-defined conductive 3D framework (e.g., metal form, porous carbon, carbon mesh, etc.) or by the selective etching of the sacrificial components in $\mathrm{Zn}$ composites. The caveat here is that while the increase in the surface area of the electrode can improve the energy density and suppress the dendrite development, it can accelerate the 
corrosion of $\mathrm{Zn}$ metal. This can be avoided by coating 3D Zn metal with corrosion inhibitors or by introducing organic/inorganic additives in the plating electrolyte. In addition, although the behavior of $\mathrm{Zn}$ electrodes in mild aqueous electrolytes differs from that in alkaline electrolytes, the knowledge of the operation of $\mathrm{Zn}$ batteries in alkaline aqueous media can provide time-saving guidance for the study of AZIBs. Furthermore, more progress can be made by investigating the previously reported strategies for modifying metal anodes (e.g., in Li/Na metal batteries).

In addition to the $\mathrm{Zn}$ metal anode, the other components (cathode and electrolyte) of the cell should also be taken into consideration to improve the performance of the anode. The type of electrolyte, electrolyte concentration, and additives are important factors that strongly influence the electrochemical reactions on the $\mathrm{Zn}$ metal anode. In particular, in mild aqueous electrolytes, $\mathrm{ZnSO}_{4}$ and $\mathrm{Zn}\left(\mathrm{CF}_{3} \mathrm{SO}_{3}\right)_{2}$ are mainly used within a certain concentration range. In most cases, $\mathrm{ZnSO}_{4}$ is preferable because of its relatively low price as compared to that of $\mathrm{Zn}\left(\mathrm{CF}_{3} \mathrm{SO}_{3}\right)_{2}$. However, $\mathrm{ZnSO}_{4}$ suffers from the formation of hydroxide sulfate by-products $\left(\mathrm{Zn}_{4}(\mathrm{OH})_{6} \mathrm{SO}_{4} \cdot \mathrm{nH}_{2} \mathrm{O}\right)$. Exploring other $\mathrm{Zn}$ salts for application under mild aqueous conditions and some appropriate $\mathrm{ZnSO}_{4}$-based additives is another potential approach. Mn-based materials are the most widely used cathode materials. As revealed by many studies on AZIBs cathodes, Mn-based oxides can be operated at high working voltages, but it is still difficult to fully understand their reaction mechanism because of the diverse phase transitions occurring during the reactions. Apart from Mn-based cathode materials, V-based materials and Prussian blue analogs can be potential candidates for application in conjunction with Zn metal anodes for AZIBs. However, in this case, the limitations of these materials (V-based oxides: low operation voltage, Prussian blue analogs: low specific capacity) should be considered.

Finally, most studies on $\mathrm{Zn}$ metal anodes have mainly focused on coin cells or pouch cells. To meet the market demands (especially in large-scale energy storage), these studies need to be expanded to larger cells (e.g., cylindrical and prismatic cells). In practical applications, unknown challenges that have not been encountered in coin cells can be encountered. The know-how of various cell configurations can narrow the gap between the lab-scale results and the commercialization of AZIBs. Finally, the development of flexible and wearable AZIBs can be an intriguing research topic because of their intrinsic safety, low cost, and facile fabrication (without the need for a glovebox). To realize this, not only should a sufficiently thin $\mathrm{Zn}$ metal electrode (beyond the commercial $\mathrm{Zn}$ foil) be developed, but appropriate components (cathode, solid electrolyte, and packing material) compatible with Zn anodes should also be carefully designed.

Author Contributions: Conceptualization, J.H., V.P.H.H., L.T.H.; validation, L.T.H.; investigation, V.P.H.H.; writing — original draft preparation, V.P.H.H. and L.T.H.; writing—review and editing, J.H.; supervision, J.H.; funding acquisition, J.H. All authors have read and agreed to the published version of the manuscript.

Funding: This work was supported by the Gachon University research fund of 2021 (GCU-202103450001) and the Korea Institute of Energy Technology Evaluation and Planning (KETEP) and the Ministry of Trade, Industry \& Energy (MOTIE) of the Korea (No. 20194030202290).

Institutional Review Board Statement: Not applicable.

Informed Consent Statement: Not applicable.

Data Availability Statement: Not applicable.

Conflicts of Interest: The authors declare no competing interests.

\section{References}

1. Jiao, Y.; Kang, L.; Berry-Gair, J.; McColl, K.; Li, J.; Dong, H.; Jiang, H.; Wang, R.; Corà, F.; Brett, D.J.L.; et al. Enabling stable $\mathrm{MnO}_{2}$ matrix for aqueous zinc-ion battery cathodes. J. Mater. Chem. A 2020, 8, 22075-22082. [CrossRef]

2. Pan, H.; Shao, Y.; Yan, P.; Cheng, Y.; Han, K.S.; Nie, Z.; Wang, C.; Yang, J.; Li, X.; Bhattacharya, P.; et al. Reversible aqueous zinc/manganese oxide energy storage from conversion reactions. Nat. Energy 2016, 1, 16039. [CrossRef] 
3. Yang, Z.; Zhang, J.; Kintner-Meyer, M.C.W.; Lu, X.; Choi, D.; Lemmon, J.P.; Liu, J. Electrochemical Energy Storage for Green Grid. Chem. Rev. 2011, 111, 3577-3613. [CrossRef] [PubMed]

4. Dong, H.; Li, J.; Zhao, S.; Zhao, F.; Xiong, S.; Brett, D.J.L.; He, G.; Parkin, I.P. An anti-aging polymer electrolyte for flexible rechargeable zinc-ion batteries. J. Mater. Chem. A 2020, 8, 22637-22644. [CrossRef]

5. $\quad$ Dong, H.; Li, J.; Zhao, S.; Jiao, Y.; Chen, J.; Tan, Y.; Brett, D.J.L.; He, G.; Parkin, I.P. Investigation of a Biomass Hydrogel Electrolyte Naturally Stabilizing Cathodes for Zinc-Ion Batteries. ACS Appl. Mater. Interfaces 2021, 13, 745-754. [CrossRef] [PubMed]

6. Qiu, C.; Zhu, X.; Xue, L.; Ni, M.; Zhao, Y.; Liu, B.; Xia, H. The function of $\mathrm{Mn}^{2+}$ additive in aqueous electrolyte for $\mathrm{Zn} / \delta-\mathrm{MnO} 2$ battery. Electrochim. Acta 2020, 351, 136445. [CrossRef]

7. Tarascon, J.M.; Armand, M. Issues and challenges facing rechargeable lithium batteries. Nature 2001, 414, 359-367. [CrossRef]

8. Fuller, T.F. Batteries: Bigger and better. Nat. Energy 2016, 1, 16003. [CrossRef]

9. Nitta, N.; Wu, F.; Lee, J.T.; Yushin, G. Li-ion battery materials: Present and future. Mater. Today 2015, 18, 252-264. [CrossRef]

10. Abdin, Z.; Khalilpour, K.R. Chapter 4-Single and Polystorage Technologies for Renewable-Based Hybrid Energy Systems. In Polygeneration with Polystorage for Chemical and Energy Hubs; Khalilpour, K.R., Ed.; Elsevier Inc.: Amsterdam, The Netherlands, 2019; pp. 77-131. [CrossRef]

11. Zhang, Z.J.; Ramadass, P.; Fang, W. 18-Safety of Lithium-Ion Batteries. In Lithium-Ion Batteries; Pistoia, G., Ed.; Elsevier B.V.: Amsterdam, The Netherlands, 2014; pp. 409-435. [CrossRef]

12. Yoshino, A. 1-Development of the Lithium-Ion Battery and Recent Technological Trends. In Lithium-Ion Batteries; Pistoia, G., Ed.; Elsevier: Amsterdam, The Netherlands, 2014; pp. 1-20. [CrossRef]

13. Mun, Y.S.; Pham, T.N.; Hoang Bui, V.K.; Tanaji, S.T.; Lee, H.U.; Lee, G.-W.; Choi, J.S.; Kim, I.T.; Lee, Y.-C. Tin oxide evolution by heat-treatment with tin-aminoclay (SnAC) under argon condition for lithium-ion battery (LIB) anode applications. J. Power Sources 2019, 437, 226946. [CrossRef]

14. Nguyen, T.L.; Park, D.; Kim, I.T. $\mathrm{Fe}_{x} \mathrm{Sn}_{y} \mathrm{O}_{z}$ Composites as Anode Materials for Lithium-Ion Storage. J. Nanosci. Nanotechnol. 2019, 19, 6636-6640. [CrossRef]

15. Nguyen, T.L.; Kim, J.H.; Kim, I.T. Electrochemical Performance of Sn/SnO/Ni 3 Sn Composite Anodes for Lithium-Ion Batteries. J. Nanosci. Nanotechnol. 2019, 19, 1001-1005. [CrossRef]

16. Pham, T.N.; Tanaji, S.T.; Choi, J.-S.; Lee, H.U.; Kim, I.T.; Lee, Y.-C. Preparation of Sn-aminoclay $\left(\mathrm{SnAC}^{-}\right.$-templated Fe ${ }_{3} \mathrm{O}_{4}$ nanoparticles as an anode material for lithium-ion batteries. RSC Adv. 2019, 9, 10536-10545. [CrossRef]

17. Nguyen, T.P.; Kim, I.T. Ag Nanoparticle-Decorated $\mathrm{MoS}_{2}$ Nanosheets for Enhancing Electrochemical Performance in Lithium Storage. Nanomaterials 2021, 11, 626. [CrossRef] [PubMed]

18. Nguyen, T.P.; Kim, I.T. Self-Assembled Few-Layered $\mathrm{MoS}_{2}$ on $\mathrm{SnO}_{2}$ Anode for Enhancing Lithium-Ion Storage. Nanomaterials 2020, 10, 2558. [CrossRef]

19. Preman, A.N.; Lee, H.; Yoo, J.; Kim, I.T.; Saito, T.; Ahn, S.-k. Progress of 3D network binders in silicon anodes for lithium ion batteries. J. Mater. Chem. A 2020, 8, 25548-25570. [CrossRef]

20. Nguyen, T.P.; Kim, I.T. W2C/WS2 Alloy Nanoflowers as Anode Materials for Lithium-Ion Storage. Nanomaterials 2020, $10,1336$. [CrossRef]

21. Kim, W.S.; Vo, T.N.; Kim, I.T. GeTe-TiC-C Composite Anodes for Li-Ion Storage. Materials 2020, 13, 4222. [CrossRef]

22. Vo, T.N.; Kim, D.S.; Mun, Y.S.; Lee, H.J.; Ahn, S.-k.; Kim, I.T. Fast charging sodium-ion batteries based on Te-P-C composites and insights to low-frequency limits of four common equivalent impedance circuits. Chem. Eng. J. 2020, 398, 125703. [CrossRef]

23. Larcher, D.; Tarascon, J.M. Towards greener and more sustainable batteries for electrical energy storage. Nat. Chem. 2015, 7, 19-29. [CrossRef] [PubMed]

24. Wang, S.; Yang, Y.; Dong, Y.; Zhang, Z.; Tang, Z. Recent progress in Ti-based nanocomposite anodes for lithium ion batteries. J. Adv. Ceram. 2019, 8, 1-18. [CrossRef]

25. Li, M.; Lu, J.; Ji, X.; Li, Y.; Shao, Y.; Chen, Z.; Zhong, C.; Amine, K. Design strategies for nonaqueous multivalent-ion and monovalent-ion battery anodes. Nat. Rev. Mater. 2020, 5, 276-294. [CrossRef]

26. Li, X.; Chen, G.; Le, Z.; Li, X.; Nie, P.; Liu, X.; Xu, P.; Wu, H.B.; Liu, Z.; Lu, Y. Well-dispersed phosphorus nanocrystals within carbon via high-energy mechanical milling for high performance lithium storage. Nano Energy 2019, 59, 464-471. [CrossRef]

27. Chao, D.; Ouyang, B.; Liang, P.; Huong, T.T.T.; Jia, G.; Huang, H.; Xia, X.; Rawat, R.S.; Fan, H.J. C-Plasma of Hierarchical Graphene Survives SnS Bundles for Ultrastable and High Volumetric Na-Ion Storage. Adv. Mater. 2018, 30, e1804833. [CrossRef] [PubMed]

28. Zhang, W.; Liu, Y.; Guo, Z. Approaching high-performance potassium-ion batteries via advanced design strategies and engineering. Sci. Adv. 2019, 5, eaav7412. [CrossRef] [PubMed]

29. Abraham, K.M. How Comparable Are Sodium-Ion Batteries to Lithium-Ion Counterparts? ACS Energy Lett. 2020, 5, 3544-3547. [CrossRef]

30. Karuppasamy, K.; Jothi, V.R.; Nichelson, A.; Vikraman, D.; Tanveer, W.H.; Kim, H.-S.; Yi, S.-C. Chapter 14-Nanostructured transition metal sulfide/selenide anodes for high-performance sodium-ion batteries. In Nanostructured, Functional, and Flexible Materials for Energy Conversion and Storage Systems; Pandikumar, A., Rameshkumar, P., Eds.; Elsevier Inc.: Amsterdam, The Netherlands, 2020; pp. 437-464. [CrossRef]

31. Jana, A.; Paul, R.; Roy, A.K. Chapter 2-Architectural design and promises of carbon materials for energy conversion and storage: In laboratory and industry. In Carbon Based Nanomaterials for Advanced Thermal and Electrochemical Energy Storage and Conversion; Paul, R., Etacheri, V., Wang, Y., Lin, C.-T., Eds.; Elsevier Inc.: Amsterdam, The Netherlands, 2019; pp. 25-61. [CrossRef] 
32. Anoopkumar, V.; John, B.; Mercy, T.D. Potassium-Ion Batteries: Key to Future Large-Scale Energy Storage? ACS Appl. Energy Mater. 2020, 3, 9478-9492. [CrossRef]

33. Min, X.; Xiao, J.; Fang, M.; Wang, W.; Zhao, Y.; Liu, Y.; Abdelkader, A.M.; Xi, K.; Kumar, R.V.; Huang, Z. Potassium-ion batteries: Outlook on present and future technologies. Energy Environ. Sci. 2021, 14, 2186-2243. [CrossRef]

34. Liu, S.; Kang, L.; Hu, J.; Jung, E.; Zhang, J.; Jun, S.C.; Yamauchi, Y. Unlocking the Potential of Oxygen-Deficient Copper-Doped $\mathrm{Co} 3 \mathrm{O} 4$ Nanocrystals Confined in Carbon as an Advanced Electrode for Flexible Solid-State Supercapacitors. ACS Energy Lett. 2021, 6, 3011-3019. [CrossRef]

35. Liu, S.; Kang, L.; Kim, J.M.; Chun, Y.T.; Zhang, J.; Jun, S.C. Recent Advances in Vanadium-Based Aqueous Rechargeable Zinc-Ion Batteries. Adv. Energy Mater. 2020, 10, 2000477. [CrossRef]

36. Kang, L.; Zhang, M.; Zhang, J.; Liu, S.; Zhang, N.; Yao, W.; Ye, Y.; Luo, C.; Gong, Z.; Wang, C.; et al. Dual-defect surface engineering of bimetallic sulfide nanotubes towards flexible asymmetric solid-state supercapacitors. J. Mater. Chem. A 2020, 8 , 24053-24064. [CrossRef]

37. Liu, S.; Kang, L.; Jun, S.C. Challenges and Strategies toward Cathode Materials for Rechargeable Potassium-Ion Batteries. Adv. Mater. 2021, 2004689. [CrossRef] [PubMed]

38. Wang, J.; Yamada, Y.; Sodeyama, K.; Watanabe, E.; Takada, K.; Tateyama, Y.; Yamada, A. Fire-extinguishing organic electrolytes for safe batteries. Nat. Energy 2018, 3, 22-29. [CrossRef]

39. Chen, L.; Cao, L.; Ji, X.; Hou, S.; Li, Q.; Chen, J.; Yang, C.; Eidson, N.; Wang, C. Enabling safe aqueous lithium ion open batteries by suppressing oxygen reduction reaction. Nat. Commun. 2020, 11, 2638. [CrossRef] [PubMed]

40. Yan, C.; Lv, C.; Wang, L.; Cui, W.; Zhang, L.; Dinh, K.N.; Tan, H.; Wu, C.; Wu, T.; Ren, Y.; et al. Architecting a Stable High-Energy Aqueous Al-Ion Battery. J. Am. Chem. Soc. 2020, 142, 15295-15304. [CrossRef]

41. Kumar, S.; Verma, V.; Arora, H.; Manalastas, W.; Srinivasan, M. Rechargeable Al-Metal Aqueous Battery Using NaMnHCF as a Cathode: Investigating the Role of Coated-Al Anode Treatments for Superior Battery Cycling Performance. ACS Appl. Energy Mater. 2020, 3, 8627-8635. [CrossRef]

42. Tian, H.; Li, Z.; Feng, G.; Yang, Z.; Fox, D.; Wang, M.; Zhou, H.; Zhai, L.; Kushima, A.; Du, Y.; et al. Stable, high-performance, dendrite-free, seawater-based aqueous batteries. Nat. Commun. 2021, 12, 237. [CrossRef]

43. Kim, H.; Hong, J.; Park, K.-Y.; Kim, H.; Kim, S.-W.; Kang, K. Aqueous Rechargeable Li and Na Ion Batteries. Chem. Rev. 2014, 114, 11788-11827. [CrossRef]

44. Chao, D.; Zhou, W.; Xie, F.; Ye, C.; Li, H.; Jaroniec, M.; Qiao, S.-Z. Roadmap for advanced aqueous batteries: From design of materials to applications. Sci. Adv. 2020, 6, eaba4098. [CrossRef]

45. Shin, J.; Lee, J.; Park, Y.; Choi, J.W. Aqueous zinc ion batteries: Focus on zinc metal anodes. Chem. Sci. 2020, 11, 2028-2044. [CrossRef]

46. Konarov, A.; Voronina, N.; Jo, J.H.; Bakenov, Z.; Sun, Y.-K.; Myung, S.-T. Present and Future Perspective on Electrode Materials for Rechargeable Zinc-Ion Batteries. ACS Energy Lett. 2018, 3, 2620-2640. [CrossRef]

47. Song, M.; Tan, H.; Chao, D.; Fan, H.J. Recent Advances in Zn-Ion Batteries. Adv. Funct. Mater. 2018, 28, 1802564. [CrossRef]

48. Lu, Y.; Zhu, T.; van den Bergh, W.; Stefik, M.; Huang, K. A High Performing Zn-Ion Battery Cathode Enabled by In Situ Transformation of $\mathrm{V}(2) \mathrm{O}(5)$ Atomic Layers. Angew. Chem. Int. Ed. 2020, 59, 17004-17011. [CrossRef] [PubMed]

49. Zhang, X.; Wang, L.; Fu, H. Recent advances in rechargeable Zn-based batteries. J. Power Sources 2021, 493, 229677. [CrossRef]

50. Li, C.; Xie, X.; Liang, S.; Zhou, J. Issues and Future Perspective on Zinc Metal Anode for Rechargeable Aqueous Zinc-ion Batteries. Energy Environ. Mater. 2020, 3, 146-159. [CrossRef]

51. Jia, H.; Wang, Z.; Tawiah, B.; Wang, Y.; Chan, C.-Y.; Fei, B.; Pan, F. Recent advances in zinc anodes for high-performance aqueous Zn-ion batteries. Nano Energy 2020, 70, 104523. [CrossRef]

52. Han, C.; Li, W.; Liu, H.K.; Dou, S.; Wang, J. Principals and strategies for constructing a highly reversible zinc metal anode in aqueous batteries. Nano Energy 2020, 74, 104880. [CrossRef]

53. Xie, C.; Li, Y.; Wang, Q.; Sun, D.; Tang, Y.; Wang, H. Issues and solutions toward zinc anode in aqueous zinc-ion batteries: A mini review. Carbon Energy 2020, 2, 540-560. [CrossRef]

54. Guo, L.; Guo, H.; Huang, H.; Tao, S.; Cheng, Y. Inhibition of Zinc Dendrites in Zinc-Based Flow Batteries. Front. Chem. 2020, 8, 557. [CrossRef]

55. Du, W.; Ang, E.H.; Yang, Y.; Zhang, Y.; Ye, M.; Li, C.C. Challenges in the material and structural design of zinc anode towards high-performance aqueous zinc-ion batteries. Energy Environ. Sci. 2020, 13, 3330-3360. [CrossRef]

56. Li, Q.; Zhao, Y.; Mo, F.; Wang, D.; Yang, Q.; Huang, Z.; Liang, G.; Chen, A.; Zhi, C. Dendrites issues and advances in Zn anode for aqueous rechargeable Zn-based batteries. EcoMat 2020, 2, e12035. [CrossRef]

57. Hao, J.; Li, X.; Zeng, X.; Li, D.; Mao, J.; Guo, Z. Deeply understanding the Zn anode behaviour and corresponding improvement strategies in different aqueous Zn-based batteries. Energy Environ. Sci. 2020, 13, 3917-3949. [CrossRef]

58. Yi, Z.; Chen, G.; Hou, F.; Wang, L.; Liang, J. Zinc-Ion Batteries: Strategies for the Stabilization of Zn Metal Anodes for Zn-Ion Batteries (Adv. Energy Mater. 1/2021). Adv. Energy Mater. 2021, 11, 2170001. [CrossRef]

59. Zhao, C.; Wang, X.; Shao, C.; Li, G.; Wang, J.; Liu, D.; Dong, X. The strategies of boosting the performance of highly reversible zinc anodes in zinc-ion batteries: Recent progress and future perspectives. Sustain. Energy Fuels 2021, 5, 332-350. [CrossRef]

60. Wang, J.; Yang, Y.; Zhang, Y.; Li, Y.; Sun, R.; Wang, Z.; Wang, H. Strategies towards the challenges of zinc metal anode in rechargeable aqueous zinc ion batteries. Energy Storage Mater. 2021, 35, 19-46. [CrossRef] 
61. Zheng, J.; Archer, L.J.S.A. Controlling electrochemical growth of metallic zinc electrodes: Toward affordable rechargeable energy storage systems. Sci. Adv. 2021, 7, eabe0219. [CrossRef] [PubMed]

62. Hu, L.; Xiao, P.; Xue, L.; Li, H.; Zhai, T. The rising zinc anodes for high-energy aqueous batteries. EnergyChem $2021,3,100052$. [CrossRef]

63. Zhao, Z.; Fan, X.; Ding, J.; Hu, W.; Zhong, C.; Lu, J. Challenges in Zinc Electrodes for Alkaline Zinc-Air Batteries: Obstacles to Commercialization. ACS Energy Lett. 2019, 4, 2259-2270. [CrossRef]

64. Wu, T.H.; Zhang, Y.; Althouse, Z.D.; Liu, N. Nanoscale design of zinc anodes for high-energy aqueous rechargeable batteries. Mater. Today Nano 2019, 6, 100032. [CrossRef]

65. Tan, P.; Chen, B.; Xu, H.; Cai, W.; He, W.; Zhang, H.; Liu, M.; Shao, Z.; Ni, M. Integration of Zn-Ag and Zn-Air Batteries: A Hybrid Battery with the Advantages of Both. ACS Appl. Mater. Interfaces 2018, 10, 36873-36881. [CrossRef]

66. Li, P.-C.; Hu, C.-C.; You, T.-H.; Chen, P.-Y. Development and characterization of bi-functional air electrodes for rechargeable zinc-air batteries: Effects of carbons. Carbon 2017, 111, 813-821. [CrossRef]

67. Zhou, W.; Zhu, D.; He, J.; Li, J.; Chen, H.; Chen, Y.; Chao, D. A scalable top-down strategy toward practical metrics of Ni-Zn aqueous batteries with total energy densities of $165 \mathrm{~W} \mathrm{~h} \mathrm{~kg}^{-1}$ and $506 \mathrm{~W} \mathrm{~h} \mathrm{~L}^{-1}$. Energy Environ. Sci. 2020, 13, $4157-4167$. [CrossRef]

68. Sun, W.; Wang, F.; Hou, S.; Yang, C.; Fan, X.; Ma, Z.; Gao, T.; Han, F.; Hu, R.; Zhu, M.; et al. Zn/ MnO 2 Battery Chemistry With H and $\mathrm{Zn}^{2+}$ Coinsertion. J. Am. Chem. Soc. 2017, 139, 9775-9778. [CrossRef] [PubMed]

69. Zhang, N.; Dong, Y.; Jia, M.; Bian, X.; Wang, Y.; Qiu, M.; Xu, J.; Liu, Y.; Jiao, L.; Cheng, F. Rechargeable Aqueous Zn-V $2 \mathrm{O}_{5}$ Battery with High Energy Density and Long Cycle Life. ACS Energy Lett. 2018, 3, 1366-1372. [CrossRef]

70. Xiaowei, C.; Yanliang, L.; Yan, Y. Electrolyte dictated materials design for beyond lithium ion batteries. In Energy Harvesting and Storage: Materials, Devices, and Applications VIII; International Society for Optics and Photonics: Bellingham, WA, USA, 2018; Volume 10663.

71. Liang, Y.; Jing, Y.; Gheytani, S.; Lee, K.-Y.; Liu, P.; Facchetti, A.; Yao, Y. Universal quinone electrodes for long cycle life aqueous rechargeable batteries. Nat. Mater. 2017, 16, 841-848. [CrossRef] [PubMed]

72. Bischoff, C.F.; Fitz, O.S.; Burns, J.; Bauer, M.; Gentischer, H.; Birke, K.P.; Henning, H.-M.; Biro, D. Revealing the Local pH Value Changes of Acidic Aqueous Zinc Ion Batteries with a Manganese Dioxide Electrode during Cycling. J. Electrochem. Soc. 2020, 167, 020545. [CrossRef]

73. Higashi, S.; Lee, S.W.; Lee, J.S.; Takechi, K.; Cui, Y. Avoiding short circuits from zinc metal dendrites in anode by backside-plating configuration. Nat. Commun. 2016, 7, 11801. [CrossRef]

74. Blanc, L.E.; Kundu, D.; Nazar, L.F. Scientific Challenges for the Implementation of Zn-Ion Batteries. Joule 2020, 4, 771-799. [CrossRef]

75. Zeng, X.; Hao, J.; Wang, Z.; Mao, J.; Guo, Z. Recent progress and perspectives on aqueous Zn-based rechargeable batteries with mild aqueous electrolytes. Energy Storage Mater. 2019, 20, 410-437. [CrossRef]

76. Wippermann, K.; Schultze, J.W.; Kessel, R.; Penninger, J. The inhibition of zinc corrosion by bisaminotriazole and other triazole derivatives. Corros. Sci. 1991, 32, 205-230. [CrossRef]

77. Hwang, B.; Oh, E.-S.; Kim, K. Observation of electrochemical reactions at Zn electrodes in Zn-air secondary batteries. Electrochim. Acta 2016, 216, 484-489. [CrossRef]

78. Toussaint, G.; Stevens, P.; Akrour, L.; Rouget, R.; Fourgeot, F. Development of a Rechargeable Zinc-Air Battery. ECS Trans. 2019, 28, 25-34. [CrossRef]

79. Zhang, W.; Zhai, X.; Zhang, Y.; Wei, H.; Ma, J.; Wang, J.; Liang, L.; Liu, Y.; Wang, G.; Ren, F.; et al. Application of Manganese-Based Materials in Aqueous Rechargeable Zinc-Ion Batteries. Front. Energy Res. 2020, 8, 195. [CrossRef]

80. Zhao, Y.; Zhu, Y.; Zhang, X. Challenges and perspectives for manganese-based oxides for advanced aqueous zinc-ion batteries. InfoMat 2020, 2, 237-260. [CrossRef]

81. Yang, H.; Chang, Z.; Qiao, Y.; Deng, H.; Mu, X.; He, P.; Zhou, H. Constructing a Super-Saturated Electrolyte Front Surface for Stable Rechargeable Aqueous Zinc Batteries. Angew. Chem. Int. Ed. 2020, 59, 9377-9381. [CrossRef]

82. Yuksel, R.; Buyukcakir, O.; Seong, W.K.; Ruoff, R.S. Metal-Organic Framework Integrated Anodes for Aqueous Zinc-Ion Batteries. Adv. Energy Mater. 2020, 10, 1904215. [CrossRef]

83. Hou, Z.; Gao, Y.; Tan, H.; Zhang, B. Realizing high-power and high-capacity zinc/sodium metal anodes through interfacial chemistry regulation. Nat. Commun. 2021, 12, 3083. [CrossRef]

84. Yu, Y.; Xie, J.; Zhang, H.; Qin, R.; Liu, X.; Lu, X. High-Voltage Rechargeable Aqueous Zinc-Based Batteries: Latest Progress and Future Perspectives. Small Sci. 2021, 1, 2000066. [CrossRef]

85. Li, G.; Liu, Z.; Huang, Q.; Gao, Y.; Regula, M.; Wang, D.; Chen, L.-Q.; Wang, D. Stable metal battery anodes enabled by polyethylenimine sponge hosts by way of electrokinetic effects. Nat. Energy 2018, 3, 1076-1083. [CrossRef]

86. Wang, Z.; Huang, J.; Guo, Z.; Dong, X.; Liu, Y.; Wang, Y.; Xia, Y. A Metal-Organic Framework Host for Highly Reversible Dendrite-free Zinc Metal Anodes. Joule 2019, 3, 1289-1300. [CrossRef]

87. Pei, A.; Zheng, G.; Shi, F.; Li, Y.; Cui, Y. Nanoscale Nucleation and Growth of Electrodeposited Lithium Metal. Nano Lett. 2017, 17, 1132-1139. [CrossRef] [PubMed] 
88. Zhang, Q.; Luan, J.; Tang, Y.; Ji, X.; Wang, S.; Wang, H. A facile annealing strategy for achieving in situ controllable $\mathrm{Cu}_{2} \mathrm{O}$ nanoparticle decorated copper foil as a current collector for stable lithium metal anodes. J. Mater. Chem. A 2018, 6, 18444-18448. [CrossRef]

89. Sagane, F.; Ikeda, K.-i.; Okita, K.; Sano, H.; Sakaebe, H.; Iriyama, Y. Effects of current densities on the lithium plating morphology at a lithium phosphorus oxynitride glass electrolyte/copper thin film interface. J. Power Sources 2013, 233, 34-42. [CrossRef]

90. Yang, Q.; Liang, G.; Guo, Y.; Liu, Z.; Yan, B.; Wang, D.; Huang, Z.; Li, X.; Fan, J.; Zhi, C. Do Zinc Dendrites Exist in Neutral Zinc Batteries: A Developed Electrohealing Strategy to In Situ Rescue In-Service Batteries. Adv. Mater. 2019, 31, 1903778. [CrossRef] [PubMed]

91. Zhang, Q.; Luan, J.; Tang, Y.; Ji, X.; Wang, H. Interfacial Design of Dendrite-Free Zinc Anodes for Aqueous Zinc-Ion Batteries. Angew. Chem. Int. Ed. 2020, 59, 13180-13191. [CrossRef]

92. Kang, L.; Cui, M.; Jiang, F.; Gao, Y.; Luo, H.; Liu, J.; Liang, W.; Zhi, C. Nanoporous $\mathrm{CaCO}_{3}$ Coatings Enabled Uniform Zn Stripping/Plating for Long-Life Zinc Rechargeable Aqueous Batteries. Adv. Energy Mater. 2018, 8, 1801090. [CrossRef]

93. Huang, S.; Zhu, J.; Tian, J.; Niu, Z. Recent Progress in the Electrolytes of Aqueous Zinc-Ion Batteries. Chem. A Eur. J. 2019, 25, 14480-14494. [CrossRef] [PubMed]

94. Zhao, Z.; Zhao, J.; Hu, Z.; Li, J.; Li, J.; Zhang, Y.; Wang, C.; Cui, G. Long-life and deeply rechargeable aqueous Zn anodes enabled by a multifunctional brightener-inspired interphase. Energy Environ. Sci. 2019, 12, 1938-1949. [CrossRef]

95. Kim, D.; Lee, C.; Jeong, S. A concentrated electrolyte for zinc hexacyanoferrate electrodes in aqueous rechargeable zinc-ion batteries. IOP Conf. Ser. Mater. Sci. Eng. 2018, 284, 012001. [CrossRef]

96. Kasiri, G.; Trócoli, R.; Bani Hashemi, A.; La Mantia, F. An electrochemical investigation of the aging of copper hexacyanoferrate during the operation in zinc-ion batteries. Electrochim. Acta 2016, 222, 74-83. [CrossRef]

97. Zeng, Y.; Zhang, X.; Meng, Y.; Yu, M.; Yi, J.; Wu, Y.; Lu, X.; Tong, Y. Achieving Ultrahigh Energy Density and Long Durability in a Flexible Rechargeable Quasi-Solid-State $\mathrm{Zn}-\mathrm{MnO}_{2}$ Battery. Adv. Mater. 2017, 29, 1700274. [CrossRef]

98. Lee, B.; Seo, H.R.; Lee, H.R.; Yoon, C.S.; Kim, J.H.; Chung, K.Y.; Cho, B.W.; Oh, S.H. Critical Role of pH Evolution of Electrolyte in the Reaction Mechanism for Rechargeable Zinc Batteries. ChemSusChem 2016, 9, 2948-2956. [CrossRef]

99. Jiang, B.; Xu, C.; Wu, C.; Dong, L.; Li, J.; Kang, F. Manganese Sesquioxide as Cathode Material for Multivalent Zinc Ion Battery with High Capacity and Long Cycle Life. Electrochim. Acta 2017, 229, 422-428. [CrossRef]

100. Zhao, S.; Han, B.; Zhang, D.; Huang, Q.; Xiao, L.; Chen, L.; Ivey, D.G.; Deng, Y.; Wei, W. Unravelling the reaction chemistry and degradation mechanism in aqueous $\mathrm{Zn} / \mathrm{MnO}_{2}$ rechargeable batteries. J. Mater. Chem. A 2018, 6, 5733-5739. [CrossRef]

101. Cai, Z.; Ou, Y.; Wang, J.; Xiao, R.; Fu, L.; Yuan, Z.; Zhan, R.; Sun, Y. Chemically resistant Cu-Zn/Zn composite anode for long cycling aqueous batteries. Energy Storage Mater. 2020, 27, 205-211. [CrossRef]

102. Chao, D.; Zhou, W.; Ye, C.; Zhang, Q.; Chen, Y.; Gu, L.; Davey, K.; Qiao, S.-Z. An Electrolytic Zn-MnO 2 Battery for High-Voltage and Scalable Energy Storage. Angew. Chem. Int. Ed. 2019, 58, 7823-7828. [CrossRef] [PubMed]

103. Zhang, T.; Tang, Y.; Guo, S.; Cao, X.; Pan, A.; Fang, G.; Zhou, J.; Liang, S. Fundamentals and perspectives in developing zinc-ion battery electrolytes: A comprehensive review. Energy Environ. Sci. 2020, 13, 4625-4665. [CrossRef]

104. Lu, J.; Xiong, T.; Zhou, W.; Yang, L.; Tang, Z.; Chen, S. Metal Nickel Foam as an Efficient and Stable Electrode for Hydrogen Evolution Reaction in Acidic Electrolyte under Reasonable Overpotentials. ACS Appl. Mater. Interfaces 2016, 8, 5065-5069. [CrossRef] [PubMed]

105. Barton, G.W.; Scott, A.C. Industrial applications of a mathematical model for the zinc electrowinning process. J. Appl. Electrochem. 1994, 24, 377-383. [CrossRef]

106. Selvakumaran, D.; Pan, A.; Liang, S.; Cao, G. A review on recent developments and challenges of cathode materials for rechargeable aqueous Zn-ion batteries. J. Mater. Chem. A 2019, 7, 18209-18236. [CrossRef]

107. Ibrahim, M.A.M. Improving the throwing power of acidic zinc sulfate electroplating baths. J. Chem. Technol. Biotechnol. 2000, 75, 745-755. [CrossRef]

108. Kühne, H.M.; Schefold, J. Tafel Plots from Illuminated Photoelectrodes: A New Insight Into Charge Transfer Mechanism. J. Electrochem. Soc. 1990, 137, 568-575. [CrossRef]

109. Beverskog, B.; Puigdomenech, I. Revised pourbaix diagrams for zinc at 25-300 ${ }^{\circ}$ C. Corros. Sci. 1997, 39, 107-114. [CrossRef]

110. Dong, H.; Lei, T.; He, Y.; Xu, N.; Huang, B.; Liu, C.T. Electrochemical performance of porous $\mathrm{Ni}_{3} \mathrm{Al}$ electrodes for hydrogen evolution reaction. Int. J. Hydrog. Energy 2011, 36, 12112-12120. [CrossRef]

111. Miles, M.H.; Kissel, G.; Lu, P.W.T.; Srinivasan, S. Effect of Temperature on Electrode Kinetic Parameters for Hydrogen and Oxygen Evolution Reactions on Nickel Electrodes in Alkaline Solutions. J. Electrochem. Soc. 1976, 123, 332-336. [CrossRef]

112. Zhang, Q.B.; Hua, Y.X.; Dong, T.G.; Zhou, D.G. Effects of temperature and current density on zinc electrodeposition from acidic sulfate electrolyte with [BMIM]HSO4 as additive. J. Appl. Electrochem. 2009, 39, 1207. [CrossRef]

113. Pan, D.; Ma, L.; Xie, Y.; Jen, T.C.; Yuan, C. On the physical and chemical details of alumina atomic layer deposition: A combined experimental and numerical approach. J. Vac. Sci. Technol. A 2015, 33, 021511. [CrossRef]

114. Johnson, R.W.; Hultqvist, A.; Bent, S.F. A brief review of atomic layer deposition: From fundamentals to applications. Mater. Today 2014, 17, 236-246. [CrossRef]

115. Kim, H.; Lee, H.-B.-R.; Maeng, W.J. Applications of atomic layer deposition to nanofabrication and emerging nanodevices. Thin Solid Film. 2009, 517, 2563-2580. [CrossRef] 
116. Zhao, K.; Wang, C.; Yu, Y.; Yan, M.; Wei, Q.; He, P.; Dong, Y.; Zhang, Z.; Wang, X.; Mai, L. Ultrathin Surface Coating Enables Stabilized Zinc Metal Anode. Adv. Mater. Interfaces 2018, 5, 1800848. [CrossRef]

117. He, H.; Tong, H.; Song, X.; Song, X.; Liu, J. Highly stable $\mathrm{Zn}$ metal anodes enabled by atomic layer deposited $\mathrm{Al}_{2} \mathrm{O}_{3}$ coating for aqueous zinc-ion batteries. J. Mater. Chem. A 2020, 8, 7836-7846. [CrossRef]

118. Xie, X.; Liang, S.; Gao, J.; Guo, S.; Guo, J.; Wang, C.; Xu, G.; Wu, X.; Chen, G.; Zhou, J. Manipulating the ion-transfer kinetics and interface stability for high-performance zinc metal anodes. Energy Environ. Sci. 2020, 13, 503-510. [CrossRef]

119. Xia, A.; Pu, X.; Tao, Y.; Liu, H.; Wang, Y. Graphene oxide spontaneous reduction and self-assembly on the zinc metal surface enabling a dendrite-free anode for long-life zinc rechargeable aqueous batteries. Appl. Surf. Sci. 2019, 481, 852-859. [CrossRef]

120. Cui, M.; Xiao, Y.; Kang, L.; Du, W.; Gao, Y.; Sun, X.; Zhou, Y.; Li, X.; Li, H.; Jiang, F.; et al. Quasi-Isolated Au Particles as Heterogeneous Seeds To Guide Uniform Zn Deposition for Aqueous Zinc-Ion Batteries. ACS Appl. Energy Mater. 2019, 2, 6490-6496. [CrossRef]

121. Liang, P.; Yi, J.; Liu, X.; Wu, K.; Wang, Z.; Cui, J.; Liu, Y.; Wang, Y.; Xia, Y.; Zhang, J. Highly Reversible Zn Anode Enabled by Controllable Formation of Nucleation Sites for Zn-Based Batteries. Adv. Funct. Mater. 2020, 30, 1908528. [CrossRef]

122. Zeng, Y.; Zhang, X.; Qin, R.; Liu, X.; Fang, P.; Zheng, D.; Tong, Y.; Lu, X. Dendrite-Free Zinc Deposition Induced by Multifunctional CNT Frameworks for Stable Flexible Zn-Ion Batteries. Adv. Mater. 2019, 31, 1903675. [CrossRef]

123. Hieu, L.T.; So, S.; Kim, I.T.; Hur, J. Zn anode with flexible $\beta$-PVDF coating for aqueous Zn-ion batteries with long cycle life. Chem. Eng. J. 2021, 411, 128584. [CrossRef]

124. Liu, M.; Yang, L.; Liu, H.; Amine, A.; Zhao, Q.; Song, Y.; Yang, J.; Wang, K.; Pan, F. Artificial Solid-Electrolyte Interface Facilitating Dendrite-Free Zinc Metal Anodes via Nanowetting Effect. ACS Appl. Mater. Interfaces 2019, 11, 32046-32051. [CrossRef]

125. Wu, K.; Yi, J.; Liu, X.; Sun, Y.; Cui, J.; Xie, Y.; Liu, Y.; Xia, Y.; Zhang, J. Regulating Zn Deposition via an Artificial Solid-Electrolyte Interface with Aligned Dipoles for Long Life Zn Anode. Nano-Micro Lett. 2021, 13, 79. [CrossRef]

126. Zhang, Q.; Luan, J.; Huang, X.; Zhu, L.; Tang, Y.; Ji, X.; Wang, H. Simultaneously Regulating the Ion Distribution and Electric Field to Achieve Dendrite-Free Zn Anode. Small 2020, 16, 2000929. [CrossRef]

127. He, M.; Shu, C.; Zheng, R.; Xiang, W.; Hu, A.; Yan, Y.; Ran, Z.; Li, M.; Wen, X.; Zeng, T.; et al. Manipulating the ion-transference and deposition kinetics by regulating the surface chemistry of zinc metal anodes for rechargeable zinc-air batteries. Green Energy Environ. 2021. [CrossRef] 